\title{
Functional Analysis of Mars (CG17064) in Drosophila development
}

\author{
Dissertation \\ for the award of the degree \\ "Doctor of Philosophy" (PhD) \\ Division of Mathematics and Natural Sciences \\ of the Georg-August-University Goettingen \\ Submitted by \\ Gang Zhang \\ From Shandong, China
}

Goettingen, 2009 
Member of thesis committee:

Wodarz, Andreas, Prof. Dr. - Stem Cell Biology (Uni-Med)

Wimmer, Ernst, Prof. Dr. - Developmental Biology (Uni-Bio)

Grosshans, Joerg, Prof. Dr. - Developmental Biochemistry (Uni-Med)

Date of the oral examination:

$25^{\text {th }}$, Jan, 2010 
Chapter 1. Introduction

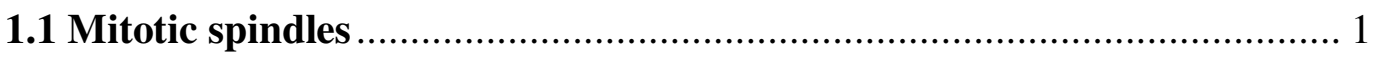

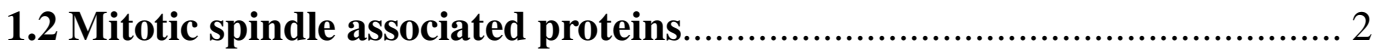

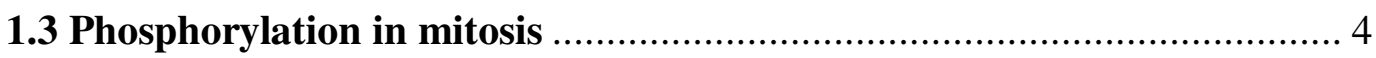

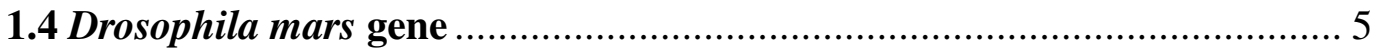

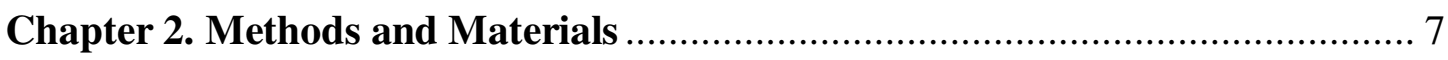

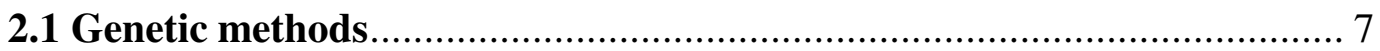

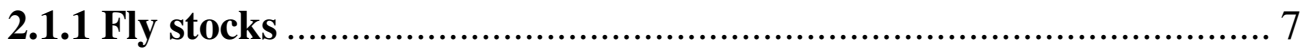

2.1.2 Generation of transgenic flies ................................................. 7

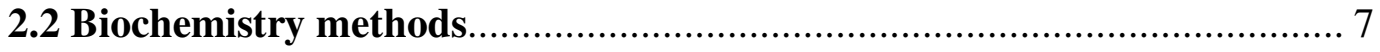

2.2.1 Antibodies and Western blotting............................................. 7

2.2.2 In vivo microtubule disassembly assay .................................... 8

2.2.3 Microtubule cosedimentation assay ....................................... 8

2.2.4 GST fusion protein purification.............................................. 9

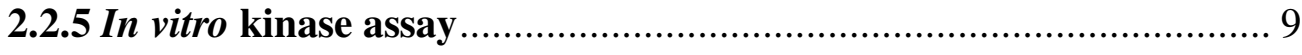

2.2.6 Antibody coupling to sepharose beads...................................... 10

2.2.7 Immunoprecipitation with antibody-coupled beads .................. 10

2.2.8 GFP-Mars purification by GFP-Trap beads ........................... 10

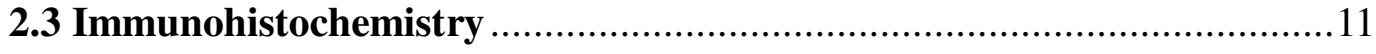

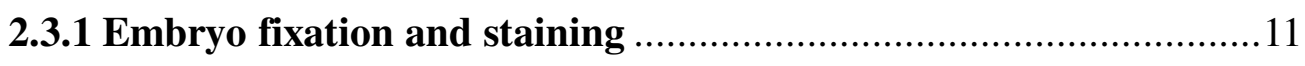

2.3.2 Cell fixation and staining ....................................................... 12

2.3.3 Microscopy and image acquisition........................................ 12

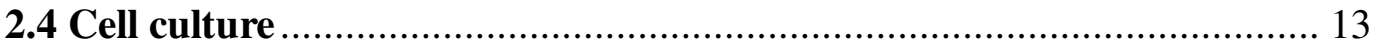

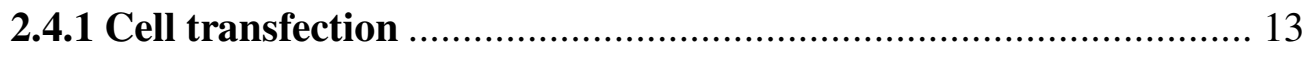

2.4.2 RNA interference in S2r cells ................................................ 13

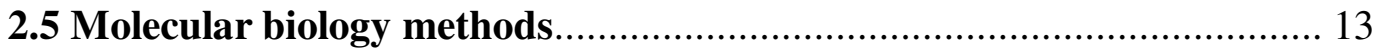

2.5.1 Generation of mars expression constructs ................................. 14

2.5.2 Multisite mutagenesis............................................................. 14

2.5.3 Extraction of genomic DNA from flies...................................... 17

2.5.4 Long-template PCR ............................................................ 17 
3.1 Localization of Mars

3.1.1 Mars shuttles between the nucleus and the mitotic spindle and is enriched at kinetochore fibers during anaphase

3.1.2 Mitotic spindle localization of Mars is not disrupted in cytoplasmic dynein, polo and aurora $A$ hypomorphic mutants.

3.1.3 Spindle localization of Mars is dependent on microtubules

3.1.4 The N-terminal region of Mars is necessary and sufficient for spindle localization

3.2 Phenotype analysis of mars mutant

3.2.1 Generation and molecular analysis of mars mutant alleles.

3.2.2 mars mutant embryos show mitotic defects during cleavage divisions

3.3 Overexpression of truncated Mars causes mitotic spindle defects in embryos

3.3.1 Localization of GFP-N Mars in embryos 43

3.3.2 Defects caused by overexpression of GFP-N Mars. 45

3.3.3 Localization of GFP-C Mars. 48

3.3.4 Defects caused by overexpression of GFP-C Mars. 48

3.3.5 Endogenous Mars in the presence of overexpressed GFP-N and C Mars 50

3.4 Regulation of Mars translocation and function ..... 52

3.4.1 Phosphorylation study of Mars. 52

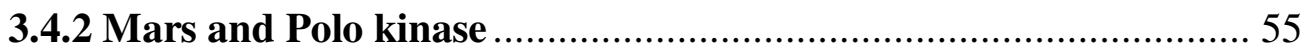

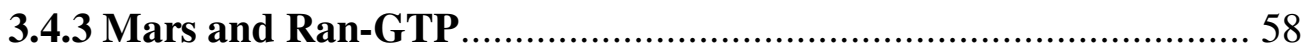

3.5 Identification of potential interaction partners of Mars 59

Chapter 4. Discussion

4.1 Mars is required for the attachment of centrosomes to the nuclear envelope and to the mitotic spindle

4.2 Is Mars generally required for proper spindle formation in Drosophila? 
4.3 Is Mars a functional homolog of HURP? 66

4.4 Mars may be functionally related to vertebrate TPX2 and NuMa ........ 67

4.5 Molecular mechanism of the function of Mars ..................................... 69

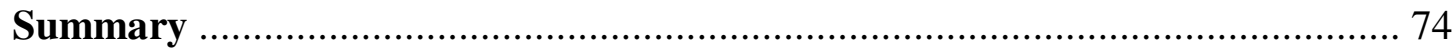

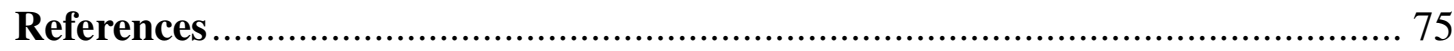

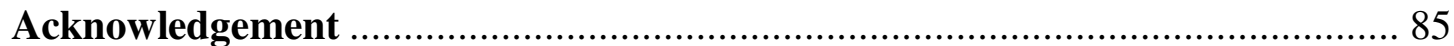




\section{Chapter 1. Introduction}

\subsection{Mitotic spindles}

The successful establishment and maintenance of the bipolar mitotic spindle are critical for the proper segregation of genetic material into the daughter cells. Any defect in this process can result in aneuploidy, which is often associated with tumorigenesis (Nasmyth, 2002; Weaver and Cleveland, 2005). The mitotic spindles consist primarily of polarized microtubule filaments composed of $\alpha / \beta$-tubulin heterodimers (Fig. 1, Walczak and Heald, 2008). The minus ends of microtubules (MTs) focus into two poles while the plus ends interact with chromosomes at the mitotic plate to generate the typical fusiform shape of the mitotic spindle (McIntosh and Euteneuer, 1984). Currently, two main mechanisms have been proposed for the formation of the bipolar mitotic spindles in eukaryotic cells. The stochastic "search and capture" model proposes that the centrosomes nucleate microtubules which capture the kinetochores of chromosomes from both ends to establish the bipolar spindle (Hill, 1985; Kirschner and Mitchison, 1986; Holy and Leibler, 1994). The second model proposes microtubule nucleation and growth in the vicinity of condensed chromatin in which Ran-GTP is required as a crucial regulator (Wilde and Zheng, 1999; Khodjakov et al., 2000; Clarke and Zhang, 2008). Those two mechanisms may operate in parallel to different extents in different types of cells (Gruss and Vernos, 2004; O'Connell and Khodjakov, 2007). Recently, a third mechanism to generate mitotic spindle microtubules was proposed by two independent studies (Zhu et al., 2008; Goshima et al., 2008). In a human cell culture system, a protein called FAM29A was found to target NEDD1, an accessory subunit of $\gamma$-TuRC ( $\gamma$-Tubulin Ring Complex) and $\gamma$-tubulin to the spindle. Depletion of FAM29A destabilizes the k-fibers, weakens the microtubule-kinetochore attachment and activates the spindle assembly checkpoint. Zhu and colleagues proposed a MT-dependent MT polymerization which is critical for the assembly of the mitotic spindle. 


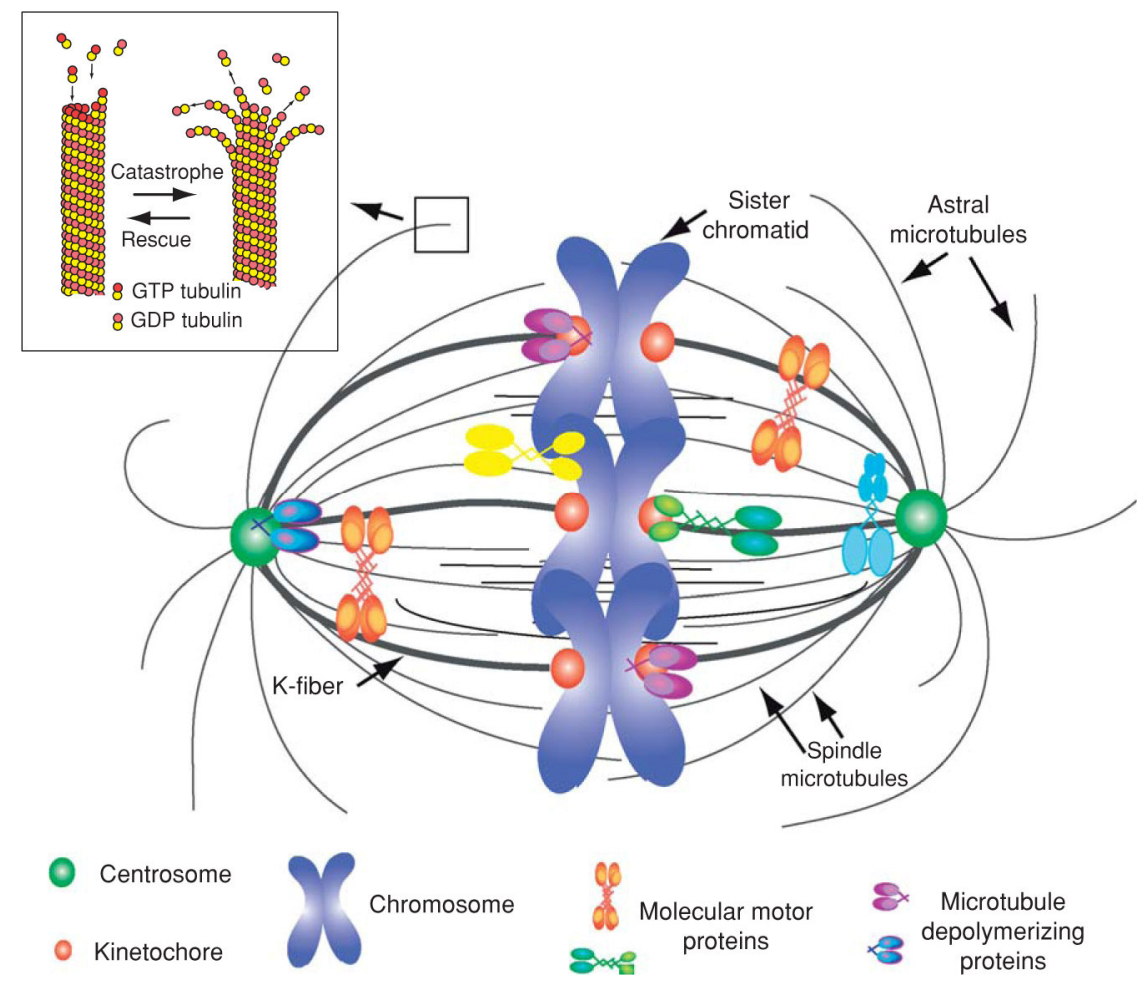

Fig. 1 Key components of the mitotic spindle. Microtubules (grey) compose antiparallel spindle microtubules, kinetochore fibers and astral microtubules extending out from the centrosomes. The inset shows the configuration of the $\alpha / \beta$-tubulin heterodimers and the transitions between growth and shrinkage. Many microtubule associated proteins are also illustrated in the figure such as motor proteins and microtubules depolymerizing proteins (Walczak and Heald, 2008).

In Drosophila cell culture system, Augmin, a protein complex containing Dgt proteins (dim gamma-tubulin 2-6) was proposed to nucleate MT growth from existing MTs produced by centrosomes and chromosomes together with $\gamma$-TuRC. Dgt6 was also found to be the homologue of FAM29A from human cells which links those two discoveries (Goshima et al., 2008).

\subsection{Mitotic spindle associated proteins}

MTs are highly dynamic polymers that transit between the state of growth and shrinkage which is known as dynamic instability (Mitchison and Kirschner, 1984). To accomplish the essential roles in mitosis, the highly dynamic MTs must be properly regulated. In vivo, microtubule associated proteins (MAPs) are responsible for the regulation of the dynamics of microtubules (Maiato et al., 2004). Currently, many 
MAPs have been well studied. According to these studies, MAPs can be classified into four groups: (1) MAPs that promote and stabilize microtubule polymerization, (2) MAPs that induce depolymerization or severing of microtubules, (3) MAPs that link various microtubule structures, and (4) motor proteins responsible for motility-related functions (Maiato et al., 2004). Some MAPs may have multiple functions during mitosis. For example, the nuclear mitotic apparatus protein (NuMA), accumulating at spindle poles at mitosis, focuses microtubule minus ends and tethers centrosomes to the body of the spindle together with cytoplasmic dynein and dynactin (Merdes et al., 1996; Merdes et al., 2000). TPX2, the targeting protein for Xenopus kinesin-like protein 2, is required to target Xklp2 to microtubule minus ends during mitosis and the kinase Aurora A to the spindle (Kufer et al., 2002). TPX2 is also involved in spindle pole organization and centrosome integrity (Wittmann et al., 2000; Garrett et al., 2002). HURP (hepatoma upregulated protein), localizes to kinetochore microtubules proximal to the chromosomes, stabilizes kinetochore fibers and helps to capture the chromosome (Koffa et al., 2006; Sillje et al., 2006; Wong and Fang, 2006). The activities of NuMa, TPX2 and HURP are all regulated by high Ran-GTP concentration around chromosomes, which liberates these factors from inhibition by binding to members of the importin $\beta$ superfamily (Gruss et al., 2001; Wiese et al., 2001; Koffa et al., 2006; Sillje et al., 2006; Wong and Fang, 2006; Clarke and Zhang, 2008).

In Drosophila, cytoplasmic dynein, the minus end directed microtubule motor is required for spindle pole organization and centrosome attachment to both the nuclear envelope and the mitotic spindle, similar as in vertebrate cells (Robinson et al., 1999; Morales-Mulia and Scholey, 2005). However, in Drosophila, there are no obvious structural homologs of NuMa and TPX2. The Mushroom body defect (Mud) protein shows limited sequence similarity to NuMa. It was shown to bind Pins, which is the fly homolog of the NuMa binding partner Lgn (Bowman et al., 2006; Izumi et al., 2006; Siller et al., 2006). Mud is required for correct spindle orientation in neuroblasts (Bowman et al., 2006; Izumi et al., 2006; Siller et al., 2006) and for meiosis II in 
female flies (Yu et al., 2006), but a function in spindle pole organization has not been demonstrated so far. The protein Asp (abnormal spindle) localizes to the mitotic spindle poles and is required for spindle pole focusing (Saunders et al., 1997; do Carmo Avides and Glover, 1999; Wakefield et al., 2001; Morales-Mulia and Scholey, 2005). Based on these properties, Asp has been discussed as a functional Drosophila homolog of vertebrate NuMa and TPX2 (Manning and Compton, 2008).

\subsection{Phosphorylation in mitosis}

One of the most important post-translational modifications (PTM) is reversible protein phosphorylation. It is estimated that more than $50 \%$ of all human proteins are phosphorylated during their life time (Reinders and Sickmann, 2005). Protein phosphorylation is involved in many intracellular processes, such as transcriptional and translational regulation, cell cycle progression, cell differentiation and apoptosis (Thingholm et al., 2009). In the cell cycle, it is well studied that the phosphorylation of multiple targets by Cdk1/cyclin B initiates the entry into mitosis. On mitotic spindles, MAPs that regulate the dynamics of microtubules are often found phosphorylated at different sites by different mitotic kinases and those phosphorylation events play important roles for the activity regulation of MAPs and also for the dynamic regulation of mitotic spindles. For instance, to correct the attachment errors between MTs and kinetochores, Aurora B kinase phosphorylates the basic $\mathrm{N}$-terminal tail of $\mathrm{Ndc} 80$ to lower its affinity towards microtubules by neutralizing the positive charge (Cheeseman et al., 2006; Ciferri et al., 2008). Aurora $\mathrm{B}$ also regulates the stability of kinetochore microtubules by phosphorylation of two motor proteins MCAK and Kif2a (Knowlton et al., 2007, 2009; Zhang et al., 2007). At the spindle poles, the motor protein Klp10A, which regulates spindle assembly and poleward flux during mitosis (Rogers et al., 2004), is phosphorylated at S573 by casein kinase $1 \alpha$ during mitosis (Mennella et al., 2009). This phosphorylation controls the microtubule depolymerase activity of Klp10A. Tumor associated microtubule associated protein (TMAP) primarily localizes on the mitotic spindles during mitosis. T622 is specifically phosphorylated by Cdk1/cyclin B1 during mitosis and this 
phosphorylation is important for the regulation of microtubule dynamics and establishment of bipolar spindles (Hong et al., 2009).

\subsection{Drosophila mars gene}

In order to achieve a better understanding of the microtubule-associated factors required for the proper execution of mitosis in Drosophila, we focused on Mars, the closest relative of vertebrate HURP (Bennett and Alphey, 2004). Mars was first identified from a yeast-two-hybrid screening against PP1c, the catalytic subunit of Protein Phosphatase 1 (Bennett and Alphey, 2002). The protein was named because it is one of only two proteins containing a Guanylate Kinase Associated Protein (GKAP) domain in Drosophila while the other protein is called Vulcan (in Roman legends, Mars and Vulcan are brothers, Bennett and Alphey, 2004). By RNA in situ hybridization, Mars transcripts were found already in syncytial embryos, suggesting it is maternally supplied. In later stages, Mars transcripts were mainly found in the central nervous system and brain (Bennett and Alphey, 2004). The first functional study of Mars was published shortly after its identification (Yang et al., 2005). In this study, Yang and colleagues showed that Mars is highly enriched in mitotic cells and that overexpression of Mars in the eye imaginal disc caused mitotic defects. However, the precise subcellular localization and actual function of Mars were unknown so far. Here I show that Mars is a microtubule-associated protein that translocates from the nucleus at interphase to the mitotic spindle at metaphase. During anaphase it is mainly detected on kinetochore fibers. Mars mutants flies are homozygous viable and fertile. However, more than $90 \%$ of embryos laid by mars homozygous mutant females do not develop properly with severe mitotic defects during early blastoderm stages. Based on our results, we propose that Mars is required for centrosome attachment to the mitotic spindle, to the nuclear envelope and for the maintenance of the mitotic spindle integrity.

Nearly at the same time as we achieved our results, another two research papers on Mars were published (Tan et al., 2008, Yang and Fan, 2008). Tan and colleagues 
confirmed the interaction of Mars with PP1 by immunoprecipitation. By the same method, they also found that Mars interacts with two MAPs, Msps (mini-spindles) and D-TACC (Drosophila transforming acidic coiled-coil). Genetic assays and immunohistology assays indicate that Mars is involved in promoting the dephosphorylation of D-TACC by interaction with PP1. The dephosphorylation of D-TACC at Ser 863 is required to stabilize the minus ends of centrosome-associated MTs (Barros et al., 2005). In the other report, Yang and Fan explored the function of Mars in Drosophila S2 cells. Mars was found mainly on the kinetochore microtubules during mitosis. RNA interference against Mars in S2 cells affected the assembly of kinetochore microtubules, misalignment of condensed chromosomes and mitotic spindle localization of $\gamma$-tubulin (Yang and Fan, 2008). The results from the two reports are largely consistent with our results though there are still some disagreements. For example, the molecular weight of Mars was reported to be $100 \mathrm{kD}$ in Tan's paper while Yang found it to be over $130 \mathrm{kD}$ which is more consistent to our finding around $145 \mathrm{kD}$. Our result is also confirmed by overexpression of Mars protein without any tag in cells besides the analysis in RNAi treated cells and mars mutant embryos. The other disagreements will be discussed in the chapter 4 . 


\section{Chapter 2. Methods and Materials}

\subsection{Genetic methods}

\subsubsection{Fly stocks}

The P-element insertion $P[E P 2477]$ was used for generating deletion mutants of mars by imprecise excision as described below. $D f(2 R) C X 1$ extends from 49C1 - 50D1 and removes the whole mars coding region. To obtain embryos with cytoplasmic dynein maternal effect phenotypes in syncytial blastoderm embryos as described (Robinson et al., 1999), $D h c 64 C^{6-6}$ and $D h c 64 C^{6-8}$ were used to generate transheterozygous females. aurA mutant embryos were obtained by crossing homozygous mutant $\operatorname{aurA}^{287}$ females to their male siblings (Glover et al., 1995; Giet et al., 2002). polo mutant embryos were obtained by crossing homzygous mutant polo ${ }^{1}$ females to their male siblings (Sunkel and Glover, 1988). $a s p^{1}$ and $a s p^{L 1}$ (Gonzalez et al., 1990) were used to test for genetic interaction with mars. pUASP-GFP-Mars (this work), ubi- $\alpha$-tubulin-GFP (gift from C. Gonzalez) and ubi-histone 3B-RFP (gift from Y. Bellaïche) transgenics were used for live imaging of spindle dynamics in embryos.

\subsubsection{Generation of transgenic flies}

$20 \mu \mathrm{g}$ of pUASP-GFP-Mars plasmid was mixed with $5 \mu \mathrm{g}$ of transposase DNA in 50 $\mu \mathrm{l}$ injection buffer containing $5 \mathrm{mM} \mathrm{KCl}, 0.1 \mathrm{mM}$ sodium phosphate, $\mathrm{pH}$ 6.8. Dechorionated white wild type embryos were aligned on cover slips and immersed in 10S Voltalef oil (Prolabo, Paris, France). The plasmid mixture was injected to the posterior ends of the embryos by micromanipulator (InjectMan NI2, Eppendorf, Hamburg, Germany). After injection, embryos were kept in $10 \mathrm{~S}$ Voltalef oil at $18^{\circ} \mathrm{C}$ for $48 \mathrm{hr}$ before the hatched larvae were collected. Flies were single-crossed to flies with $w^{-}$; Gla/CyO for the transgenic fly selection and insertion site analysis.

\subsection{Biochemistry methods}

\subsubsection{Antibodies and Western blotting}


To generate peptide antibodies against Mars, the peptides QRHKELYKEQSLVLS (aa 2 - 16, at N-terminus) and TLRNRRVNLRPSSEFM (aa 906 - 921, at C-terminus) were used to inject into rabbits (Eurogentec, Seraing, Belgium). The affinity purified final bleed against the C-terminal peptide was used for all experiments described in this study except it is specially mentioned in figures.

Primary antibodies were used for Western blotting according to standard procedures (Wodarz, 2008) as follows: rabbit anti Mars (1:1000), rabbit anti EB1 (1:200; (Rogers et al., 2002), mouse anti $\alpha$-tubulin 12G10 (1:5000; DSHB). For the Western blot in Fig. 11, the homozygous mutant mars $^{91}$ embryos were obtained from homozygous mutant parents, whereas the homozygous mutant mars $^{102}$ embryos were sorted at late embryonic stages for absence of GFP fluorescence from the $\mathrm{CyO}\{$ twi::GFP $\}$ balancer chromosome.

\subsubsection{In vivo microtubule disassembly assay}

The treatment of embryos described previously ( $\mathrm{Lu}$ et al., 1999) was modified as follows: Embryos were dechorionated in 50\% bleach and rinsed with embryo washing buffer $(0.7 \% \mathrm{NaCl}, 0.03 \%$ Triton $\mathrm{X}-100)$. Embryos were then transferred into Schneider's medium containing demecolcine ( $5 \mu \mathrm{g} / \mathrm{ml}$; Sigma D7385). After addition of an equal volume of n-heptane, the mixture was incubated at room temperature for 20 min. Drug-treated embryos were subsequently fixed in $4 \%$ formaldehyde and processed for immunostaining as described below.

\subsubsection{Microtubule cosedimentation assay}

This assay was based on described procedures (Sisson et al., 1997; Lantz and Miller, 1998) which were modified as follows: 0-4 hr old embryos were collected and dechorionated in 50\% bleach. Around $3 \mathrm{ml}$ of embryos were homogenized in $6 \mathrm{ml}$ of ice-cold lysis buffer (0.1 M Pipes, pH 6.6, 5 mM EGTA, $1 \mathrm{mM} \mathrm{MgSO}_{4}, 0.9 \mathrm{M}$ glycerol, $1 \mathrm{mM}$ DTT with protease inhibitors) with a Dounce homogenizer. The embryo extract was incubated on ice for 15 min to depolymerize microtubules. After depolymerization, the extract was centrifuged at $16,000 \mathrm{~g}$ for $30 \mathrm{~min}$ at $4^{\circ} \mathrm{C}$. Again, 
the supernatant was centrifuged at $50,000 \mathrm{~g}$ for $30 \mathrm{~min}$ at $4{ }^{\circ} \mathrm{C}$. The supernatant was incubated at room temperature for $30 \mathrm{~min}$ to re-polymerize microtubules after addition of GTP to a final concentration of $1 \mathrm{mM}$ and Taxol to $20 \mu \mathrm{M}$. One half of the supernatant not treated with GTP and Taxol was kept as control. $2.5 \mathrm{ml}$ aliquots of treated and untreated extract were layered on top of $2.5 \mathrm{ml}$ of $15 \%$ sucrose cushions prepared in lysis buffer supplemented with Taxol and GTP separately. After centrifugation at $54,000 \mathrm{~g}$ for $30 \mathrm{~min}$ at $20^{\circ} \mathrm{C}$, supernatants were saved and pellets were resuspended in lysis buffer. Samples were separated by SDS-PAGE and subsequently analyzed by Western blot.

\subsubsection{GST fusion protein purification}

$100 \mathrm{ml}$ of LB medium was inoculated with $5 \mathrm{ml}$ overnight culture of bacterial transformed with target plasmid and incubated at $20-37{ }^{\circ} \mathrm{C}$ till the culture reached the mid log phase $\left(\mathrm{OD}_{550}=0.5-1.0\right)$. IPTG was added to a final concentration of $0.5 \mathrm{mM}$ to induce the expression of GST-Mars for $4 \mathrm{hr}$. Bacterial were harvested by centrifugation at $5,000 \mathrm{~g}$ for $15 \mathrm{~min}$ at $4^{\circ} \mathrm{C}$. The pellet was resuspended in $0.75 \mathrm{ml}$ $1 \times \mathrm{PBS}$ with protease inhibitors and sonicated by $10 \mathrm{sec}$ bursts alternated with $10 \mathrm{sec}$ of incubation on ice. $20 \%$ Triton-X100 was added to the lysate to a final of $1 \%$. The mixture was gently rotated for $30 \mathrm{~min}$ and centrifuged at $12,000 \mathrm{~g}$ for $10 \mathrm{~min}$ at $4^{\circ} \mathrm{C} .50 \mu \mathrm{l}$ of 50:50 slurry of glutathione-Sepharose beads (GE Healthcare) was added to the supernatant and rotated for $30 \mathrm{~min}$ at $4{ }^{\circ} \mathrm{C}$. The beads were sedimented and washed three times. The bound protein was eluted from the beads by elution buffer containing $20 \mathrm{mM}$ reduced glutathione in $50 \mathrm{mM}$ Tris. $\mathrm{HCl}$, pH8.0. Eluted protein was snap frozen and stored at $-70{ }^{\circ} \mathrm{C}$ for later use.

\subsubsection{In vitro kinase assay}

0.5-1 $\mu \mathrm{g}$ of GST-Mars protein was incubated with $0.2 \mu \mathrm{g}$ of Polo kinase (Cell Signaling, Danvers, MA) at $30^{\circ} \mathrm{C}$ for $1 \mathrm{hr}$ in reaction buffer containing $25 \mathrm{mM}$ Tris. $\mathrm{HCl}$, pH7.5, $10 \mathrm{mM} \mathrm{MgCl}, 1 \mathrm{mM}$ DTT, $0.1 \mathrm{mM}$ ATP, $3 \mu \mathrm{Ci}\left[\gamma_{-}{ }^{32} \mathrm{P}\right] \mathrm{ATP}$, and a cocktail of protease and phosphatase inhibitors. The reactions were terminated by adding SDS sample buffer and boiled at $100^{\circ} \mathrm{C}$ for $5 \mathrm{~min}$ before loading onto 
SDS-PAGE gel. The gel was dried overnight and the phosphorylation extent was detected by x-ray sensitive films.

\subsubsection{Antibody coupling to sepharose beads}

$500 \mu \mathrm{l}$ of NHS-activated sepharose 4 fast flow beads (GE Healthcare) were washed with $5 \mathrm{ml}$ of ice-cold $1 \mathrm{mM} \mathrm{HCl}$, then resuspended in $1 \mathrm{ml}$ of coupling buffer containing $0.2 \mathrm{M} \mathrm{NaHCO}_{3}, 0.5 \mathrm{M} \mathrm{NaCl}, \mathrm{pH}$ 8.3. 100-500 $\mu \mathrm{g}$ of affinity purified Mars antibody was diluted in $0.5 \mathrm{ml}$ of coupling buffer. Antibody solution was mixed with beads suspension as $0.5: 1$ by volume. The mixture was rotated slowly at room temperature for $3 \mathrm{hr}$. The beads were spun down at 2,000 rpm for $1 \mathrm{~min}$ and the supernatant was aspirated. $0.5 \mathrm{M}$ of ethanolamine in $0.5 \mathrm{M} \mathrm{NaCl}, \mathrm{pH} 8.3$ was used to block the beads at room temperature for $1 \mathrm{hr}$. After blocking, the beads were washed six times with $1.5 \mathrm{ml}$ of alternating buffers of high $\mathrm{pH}(0.1 \mathrm{M}$ Tris. $\mathrm{HCl}, \mathrm{pH} 8-9)$ and low $\mathrm{pH}(0.1 \mathrm{M}$ acetate buffer, $0.1 \mathrm{M} \mathrm{NaCl}, \mathrm{pH} 4-5)$. The antibody coupled beads were stored in $20 \%$ ethanol at $4^{\circ} \mathrm{C}$.

\subsubsection{Immunoprecipitation with antibody-coupled beads}

0-4 hr old embryos were collected and dechorionated by $50 \%$ bleach. The embryos were homogenized in lysis buffer containing $50 \mathrm{mM}$ Tris. $\mathrm{HCl}, \mathrm{pH} 8.0,150 \mathrm{mM} \mathrm{NaCl}$, $0.5 \%$ Triton $\mathrm{X}-100$ and a cocktail of protease inhibitors. The lysate $(10 \mathrm{mg})$ was centrifuged at $13,000 \mathrm{rpm}$ for $10 \mathrm{~min}$ at $4^{\circ} \mathrm{C}$ and the supernatant was pre-incubated for $1 \mathrm{hr}$ at $4^{\circ} \mathrm{C}$ with $50 \mu \mathrm{l}$ of blocked sepharose beads. The pre-cleaned lysate was mixed with $50 \mu 1$ of antibody-coupled sepharose beads and rotated gently at $4{ }^{\circ} \mathrm{C}$ for 1-2 hr. The beads were washed three times before the bound proteins were eluted with $50 \mu 1$ of $2 \times \mathrm{SDS}$ sample buffer by boiling at $100^{\circ} \mathrm{C}$ for $10 \mathrm{~min}$.

\subsubsection{GFP-Mars purification by GFP-Trap beads}

The process of purification of GFP-Mars from transgenic embryos was modified according to the standard protocol (Chromotek, Planegg-Martinsried, Germany). Basically, dechorionated embryos were homogenized in the lysis buffer containing 10 $\mathrm{mM}$ Tris $\cdot \mathrm{HCl}, \mathrm{pH}$ 7.5, $150 \mathrm{mM} \mathrm{NaCl}, 0.5 \mathrm{mM}$ EDTA, 0.5\% NP40, $25 \mathrm{mM} \mathrm{NaF}, 1$ 
$\mathrm{mM} \mathrm{Na} \mathrm{VO}_{4}$ and protease inhibitors at a volume ratio of 1:4. The lysate was incubated on ice for $10 \mathrm{~min}$ with occasional mixing. Afterwards, the mixture was centrifuged twice at $20,000 \mathrm{~g}$ for $15 \mathrm{~min}$. During the incubation time, $25 \mu \mathrm{l}$ of GFP-Trap beads were washed three times with lysis buffer without detergent. The beads were added into the embryo lysate and rotated for $1 \mathrm{hr}$ at $4{ }^{\circ} \mathrm{C}$. After incubation, the beads were sedimented at 2,000 $\mathrm{g}$ for $2 \mathrm{~min}$ and washed three times with lysis buffer before being boiled in $100 \mu \mathrm{l}$ of $2 \times$ SDS sample buffer for $10 \mathrm{~min}$.

\subsection{Immunohistochemistry}

\subsubsection{Embryo fixation and staining}

Strong fixation and methanol fixation were used in this study as described before (McCartney et al., 1999; Giet et al., 2002). In general, for strong fixation, 0-4 hr old embryos were dechorionated in a mixture of $50 \%$ bleach, $0.1 \%$ Triton $\mathrm{X}-100$ and $0.7 \% \mathrm{NaCl}$ and rinsed with $0.1 \%$ Triton $\mathrm{X}-100,0.7 \% \mathrm{NaCl}$ afterwards. The embryos were transferred into $3 \mathrm{ml}$ of heptane and shaken vigorously for $30 \mathrm{~s}$. An equal volume of $33 \%$ formaldehyde, $50 \mathrm{mM}$ EGTA, $\mathrm{pH} 8,0$ was added to the heptane and the mixture was incubated with gentle shaking for $5 \mathrm{~min}$ at room temperature. The aqueous phase was removed and another $3 \mathrm{ml}$ of methanol was added. After $30 \mathrm{~s}$ of vigorous shaking, the embryos that sank to the bottom were collected and washed three times with methanol. After rehydration in 50:50 of methanol:PBS for $5 \mathrm{~min}$, embryos were transferred into PBT containing $0.1 \%$ Tween-20 in $1 \times$ PBS. For methanol fixation, $0-4 \mathrm{hr}$ old embryos were collected and dechorionated by $50 \%$ bleach. Embryos were incubated in a mixture of 50\% heptane and 50\% methanol for $10 \mathrm{~min}$ at room temperature. After vigorous shaking for $30 \mathrm{~s}$, the embryos that sank to the bottom were collected and washed three times in methanol. Then the fixed embryos were rehydrated by successive rinsing in 70, 50 and $30 \%$ methanol in PBS for $5 \mathrm{~min}$ each followed by another $5 \mathrm{~min}$ incubation in PBS.

Incubation of fixed embryos with primary and secondary antibodies was done according to standard procedures (Müller, 2008). The antibodies for 
immunofluorescence were used as follows: rabbit anti Mars (1:200), mouse anti $\beta$-tubulin E7 (1:50; DSHB), rabbit anti centrosomin (1:1000; (Vaizel-Ohayon and Schejter, 1999), rabbit anti D-TACC (1:1000; (Gergely et al., 2000), mouse anti $\gamma$-tubulin GTU-88 (1:1000; Sigma), rat anti HA 12CA5 (1:1000; Roche).

\subsubsection{Cell fixation and staining}

Drosophila S2r cells growing on poly-lysine coated cover slips were washed three times by $1 \times \mathrm{PBS}$ in wells of a 6 -well plate. Fixation solution containing $3.7 \%$ formaldehyde in PBS was added into the well to fix cells at room temperature for 10 min. Fixed cells were washed three times with PBT and permeabilized cells were blocked in blocking solution (PBT containing 5\% normal horse serum) for $10 \mathrm{~min}$. Cells were incubated with primary antibody in blocking solution overnight at $4{ }^{\circ} \mathrm{C}$. Before incubation with secondary antibody for $2 \mathrm{hr}$ at room temperature, cells were washed three times with PBT. Afterwards, the stained cells were washed again three times with PBT with DAPI in the second washing for DNA staining. The cover slip was then mounted onto a glass slide with mounting medium for microscopy examination.

\subsubsection{Microscopy and image acquisition}

Samples were examined using a $63 \times 1,4$ NA Zeiss Plan-Apochromat oil immersion objective on a confocal laser-scanning microscope (Carl Zeiss LSM 510 Meta). Pinholes were normally set to 1 airy unit for image acquisition. Images were captured by $1024 \times 1024$ or $512 \times 512$ pixels at approximately 4-fold zoom using 2-line mean averaging. Live imaging of Drosophila embryos was performed as described (Cavey and Lecuit, 2008). Generally, 0-2 hr old embryos were dechorionated by 50\% bleach. The embryos were then transferred into a well by plastic tapes on glass slide filled with Halocarbon oil 27 (Sigma) and covered by cover slips. Series images were taken with low laser intensity and the fastest scanning speed. Frames were captured every 10 seconds and avi files were generated with a frame rate of 12 frames per second. Movies were further processed using ImageJ (NIH) software. 


\subsection{Cell culture}

\subsubsection{Cell transfection}

FuGene HD Transfection Reagent (Roche, Indianapolis, IN) was used for cell transfection according to the instructions. $2 \times 10^{6} \mathrm{~S} 2 \mathrm{r}$ cells were resuspended in $2 \mathrm{ml}$ of fresh Drosophila S2 medium supplemented with serum and antibiotics (Invitrogen, Carlsbad, CA). Resuspended cells were planted in one well of a 6-well plate. $2 \mathrm{mg}$ of target plasmid was diluted in $100 \mu \mathrm{l}$ of sterile water. $4 \mu \mathrm{l}$ of FuGene transfection reagent was added into the plasmid solution and vortexed for $10 \mathrm{sec}$. The mixture was incubated at room temperature for $15 \mathrm{~min}$ before pipetting into the cell culture. Normally, cells were harvested after 2-4 days if not indicated otherwise.

\subsubsection{RNA interference in S2r cells}

RNA interference in S2r cells was done as described previously (Giet et al., 2002). The following primers carrying the minimal T7 promoter sequence (5'-TAATACGACTCACTATAGGGAGA-3') at the 5' end were used to amplify a fragment of Mars: 5'-T7-GCAGCAGCTCCTCCGTCATCCAATAC-3' (forward) and 5'-T7-GGTGTCGCCAAACGCCTCCAAAAGA-3' (reverse). Genomic DNA from wild type embryos was used as template for PCR. High Pure PCR Product Purification Kit (Roche) was used to purify the PCR product after amplification. The purified template was used to produce dsRNA corresponding to the target gene using the MEGASCRIPT T7 transcription kit (Ambion). The procedures were carried out according to the instructions. 15-50 $\mu \mathrm{g}$ of dsRNA was added into $1 \times 10^{6}$ freshly seeded Drosophila S2r cells in $1 \mathrm{ml}$ of S2 medium without serum and antibiotics. The cell culture was mixed by hand for $10 \mathrm{sec}$ and incubated at room temperature for $1 \mathrm{hr}$ before the addition of $2 \mathrm{ml}$ of S2 medium. 2-6 days were allowed for the turnover of the targeted protein.

\subsection{Molecular biology methods}




\subsubsection{Generation of mars expression constructs}

To express full length and partially deleted versions of Mars in S2r cells and transgenic flies, the corresponding regions of the mars coding region were amplified with the following primers:

Marsfor: 5'-CACCATGCAGCGCCACAAGGAAC-3';

Marsrev: 5'-CTACATAAACTCGGAGGAGG-3';

Mars-Nrev: 5'-GCTGCTATTGTTCGACTTGC-3';

Mars-Mfor: 5'-CACCGGTCATCTTTTGGAGGCG-3';

Mars-Mrev: 5'-TGTGCGGGCGGGCGAAAAG-3';

Mars-Cfor: 5'-CACCGTACTCCGCATGTCCACC-3'

The PCR products were cloned into pENTR/D-TOPO vector (Invitrogen). The inserts of the corresponding pENTR constructs were recombined into pAW, pAHW and pPGW destination vectors (the Drosophila Gateway Vector Collection, Carnegie Institution of Washington, Baltimore, MD) with the actin 5C promoter and no epitope tag (pAW), the actin 5C promoter and the $\mathrm{N}$-terminal hemagglutinin (HA) epitope tag (pAHW) or the UASp promoter and an N-terminal EGFP tag (pPGW). FuGene was used for transfecting the plasmids into S2r cells according to the manufacturer's instructions.

\subsubsection{Multisite mutagenesis}

Plasmid pENTR-Mars ${ }^{\mathrm{wt}}$ was used as a template for generation of alanine or glutamate mutations at the targeted Ser/Thr sites by a PCR-based multisite-directed mutagenesis. The primers used for mutagenesis are listed in the following. $50 \mathrm{ng}$ of each primer was used for 4-5 sites mutation simultaneously. After the reaction, $1 \mu$ l of DpnI (Fermentas) was added to the reaction mixture and the whole mixture was incubated at $37^{\circ} \mathrm{C}$ for $3-4 \mathrm{hr}$ to digest the original plasmid. $10 \mu \mathrm{l}$ of the mixture was used for transforming competent cells. 10 colonies were selected for plasmid preparation and sequencing verification. 
S16A: 5'-TCGCTGGTGCTGGCTCCGCGCAATCAC-3'

S49AT51A: 5'-ATCATCAGCGTGGCCCCGGCGCCCGTCAAAATAAAG-3'

S76A: 5'-CCCAAACTGGAGGCTCCGGAGCGGCTG-3'

S170A: 5'-CAAGCGGTGTGCTCTCTACATGATTGCC-3'

T275A: 5'-ATACCCAGACCCGCCCCAGCGACAGTC-3'

T280A: 5'-CCAGCGACAGTCGCGAAAGCGAAAACG-3'

S426A: 5'-ACGCAGTGCAAGGCGAACAATAGCAGC-3'

S444A: 5'-ACCATCTTGTTGGCCCCGGTGGCACCG-3'

T519A: 5'-GAGGGTACAAAGGCACCGCCACGTCGC-3'

S525A: 5'-CCACGTCGCGAAGCCAATGGAATGCCC-3'

S554A: 5'-GGAGAAACGCAATGCCTTCTACCTGTCC-3'

S785A: 5'-GTACTCCGCATGGCCACCGGCGAGGGC-3'

S792A: 5'-GAGGGCCGTCAGGCGATTGCGCCAAATG-3'

T814A: 5'-AACGCTGCCAAGGCGCCGCCGCCTAAG-3'

T826A: 5'-TCCATCCTCAAGGCGCCCGGCACCACG-3'

T829A: 5'-AAGACGCCCGGCGCCACGAAACGCCAG-3'

S840A: 5'-GGCGTGCTCTTCGCCGCCAAGAAGAGC-3'

S16E: 5'-CGCTGGTGCTGGAGCCGCGCAATCACTGC-3'

S49ET51E: 5'-CCGCATCATCAGCGTGGAGCCGGAGCCCGTCAAAATAAAG-3'

S76E: 5'-CCCAAACTGGAGGAGCCGGAGCGGCTGG-3'

S170E: 5'-CCTCCCAAGCGGTGTGAGCTCTACATGATTGCC-3'

T275E: 5'-CCATACCCAGACCCGAGCCAGCGACAGTC-3'

T280E: 5'-CCCAGCGACAGTCGAGAAAGCGAAAACGC-3'

S426E: 5'-CGCAGTGCAAGGAGAACAATAGCAGCGG-3' 
S444E: 5'-CACCATCTTGTTGGAGCCGGTGGCACCGG-3'

T519E: 5'-GAGGGTACAAAGGAACCGCCACGTCGC-3'

S525E: 5'-CCGCCACGTCGCGAAGAGAATGGAATGCCC-3'

S554E: 5'-GTGAGAAGGAGAAACGCAATGAGTTCTACCTGTCC-3'

S785E: 5'-GTACTCCGCATGGAGACCGGCGAGGGCC-3'

S792E: 5'-GAGGGCCGTCAGGAGATTGCGCCAAATG-3'

T814E: 5'-AACGCTGCCAAGGAGCCGCCGCCTAAG-3'

T826E: 5'-TCCATCCTCAAGGAGCCCGGCACCACG-3'

T829E: 5'-TCAAGACGCCCGGCGAGACGAAACGCCAG-3'

S840E: 5'-CGTGGCGTGCTCTTCGAGGCCAAGAAGAGCG-3'

Polymerase, ligase reaction mix:

\begin{tabular}{|l|l|}
\hline \multicolumn{1}{|c|}{ Component } & Volume $(\mu \mathrm{l})$ \\
\hline Phosphorylated primer & $\mathrm{x}$ \\
\hline $10 \times$ Pfu polymerase buffer $\left(\mathrm{MgSO}_{4}\right)$ & 1.25 \\
\hline $10 \times$ Taq ligase buffer & 1.25 \\
\hline dNTPs (10 mM) & 1 \\
\hline Pfu DNA polymerase & 0.5 \\
\hline Taq DNA ligase & 0.5 \\
\hline ddH ${ }_{2} \mathrm{O}$ & $18.5-\mathrm{x}$ \\
\hline Template DNA & $2(100 \mathrm{ng})$ \\
\hline Total volume & 25 \\
\hline
\end{tabular}


Reaction conditions:

$65{ }^{\circ} \mathrm{C} 5 \mathrm{~min}$

$95^{\circ} \mathrm{C} 2 \mathrm{~min}$

$95^{\circ} \mathrm{C} 30 \mathrm{sec}$

$55^{\circ} \mathrm{C} 30 \mathrm{sec}$

$65^{\circ} \mathrm{C} \times \min (2 \mathrm{~min} / \mathrm{kb})$

\}

18 cycles

$75^{\circ} \mathrm{C} 7 \mathrm{~min}$

$4^{\circ} \mathrm{C}$

\subsubsection{Extraction of genomic DNA from flies}

30 male flies were collected in one eppendorf tube and snap frozen in liquid nitrogen. $400 \mu \mathrm{l}$ of lysis buffer containing $100 \mathrm{mM}$ Tris.HCl, $\mathrm{pH}$ 7.5, $100 \mathrm{mM}$ EDTA, $\mathrm{pH}$ 8.0, $100 \mathrm{mM} \mathrm{NaCl}$ and $0.5 \% \mathrm{SDS}$ was added into the tube. Frozen flies were homogenized by a biovortexer. The lysate was incubated at $65^{\circ} \mathrm{C}$ for $15-30 \mathrm{~min}$. Afterwards, $228.4 \mu \mathrm{l}$ of $5 \mathrm{M} \mathrm{KAc}$ and $571.6 \mu \mathrm{l}$ of $6 \mathrm{M} \mathrm{LiCl}$ were added into the lysate and incubated on ice for $15 \mathrm{~min}$ before being centrifuged at 13,000 rpm for $15 \mathrm{~min} .1$ $\mathrm{ml}$ of supernatant was transferred into a new tube. $600 \mu \mathrm{l}$ of isopropanol was added and the mixture was centrifuged again at $13,000 \mathrm{rpm}$ for $15 \mathrm{~min}$. DNA pellet was washed with $70 \%$ ethanol and dissolved in $150 \mu 1$ of sterile water.

\subsubsection{Long-template PCR}

Expand Long Template PCR System (Roche) was used for the characterization of gene deletion in mars mutant alleles. Components of PCR reaction and thermal cycles were set up according to the instructions. 
Polymerase chain reaction mix:

\begin{tabular}{|l|l|}
\hline \multicolumn{1}{|c|}{ Components } & Volume $(\mu \mathrm{l})$ \\
\hline $\mathrm{ddH}_{2} \mathrm{O}$ & 37.75 \\
\hline $\mathrm{dNTPs}(10 \mathrm{mM})$ & 2.5 \\
\hline Primers $(10 \mathrm{mM})$ & $1.5+1.5$ \\
\hline $10 \times$ PCR buffer $\left(\mathrm{MgCl}_{2}\right)$ & 5 \\
\hline Template DNA & $1(\leq 500 \mathrm{ng})$ \\
\hline Long template enzyme mix & 0.75 \\
\hline Total & 50 \\
\hline
\end{tabular}

PCR conditions:

$94^{\circ} \mathrm{C} 2 \mathrm{~min}$

$94^{\circ} \mathrm{C} 10 \mathrm{sec}$

$55^{\circ} \mathrm{C} 30 \mathrm{sec}$

$68^{\circ} \mathrm{C} 10 \mathrm{~min}$

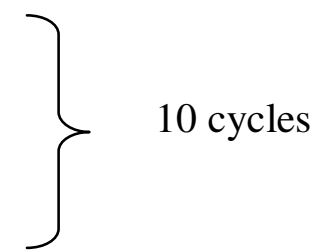

$94^{\circ} \mathrm{C} 15 \mathrm{sec}$

$55^{\circ} \mathrm{C} 30 \mathrm{sec}$

$68^{\circ} \mathrm{C} 10 \mathrm{~min}+20 \mathrm{sec}$

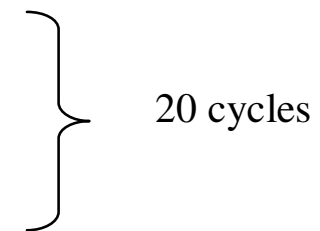

$68^{\circ} \mathrm{C} 7 \mathrm{~min}$

$4^{\circ} \mathrm{C}$ 


\section{Chapter 3. Results}

\subsection{Localization of Mars}

\subsubsection{Mars shuttles between the nucleus and the mitotic spindle and is enriched at kinetochore fibers during anaphase}

Mars is a rather basic $(\mathrm{pI}=10.0)$ cytoplasmic protein of 921 aa with a predicted molecular weight of $102 \mathrm{kD}$. It contains a guanylate kinase associated protein (GKAP) domain that shows significant homology to the GKAP domain of vertebrate HURP (Tsou et al., 2003; Bennett and Alphey, 2004). In order to determine the expression pattern and subcellular localization of Mars, we performed whole mount immunofluorescence stainings of embryos using affinity purified peptide antibody raised against the C-terminus of Mars. Mars was found to be maternally contributed and ubiquitously expressed during early embryonic development (data not shown) which is in agreement with RNA in situ data available at the Berkeley Drosophila genome project embryo database (http://www.fruitfly.org/cgi-bin/ex/insitu.pl). From gastrulation onwards, when the pattern of mitoses became asynchronous, the staining was much more intense in mitotic cells compared to interphase cells (Fig. 2). At the subcellular level, Mars showed punctate staining in interphase nuclei at the syncytial blastoderm stage, but was not associated with interphase microtubules (Fig. 3A). At prometaphase, Mars translocated from the nucleus to the microtubule asters organized by centrosomes, but only to the region facing the nucleus (Fig. 3B). At metaphase, Mars staining was restricted to spindle microtubules but not asters and was more intense towards the spindle poles (Fig. 3C). At anaphase, Mars was mainly detected on kinetochore fibers under anaphase shortening (Fig. 3D). At telophase, Mars was recruited to the newly formed nuclei and was absent from the central spindle (Fig.3E). 

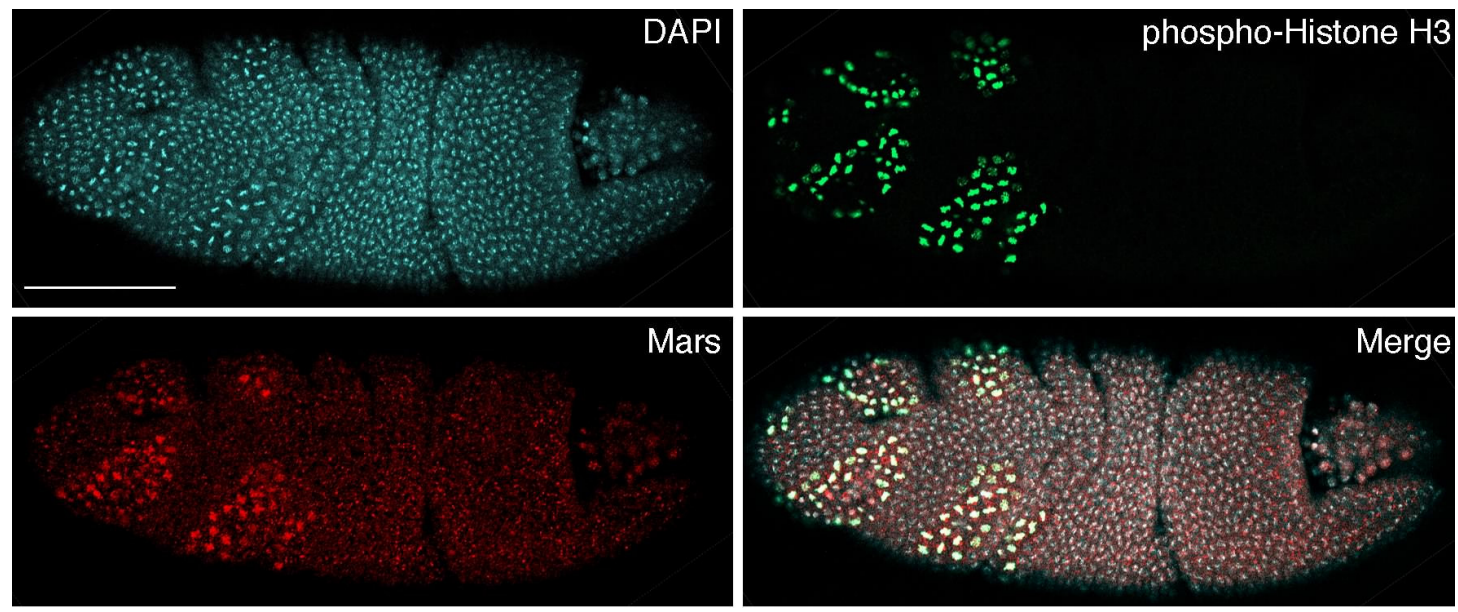

Fig. 2 Mars protein levels are controlled by the cell cycle. A wild type embryo at gastrulation (stage 7) was stained for DAPI (turquoise), phospho-histone H3 (green) and Mars (red). Mars protein levels are strongly elevated in cells undergoing mitosis, which are labelled by phospho-histone H3. Anterior is to the left. Scale bar $=100 \mu \mathrm{m}$.
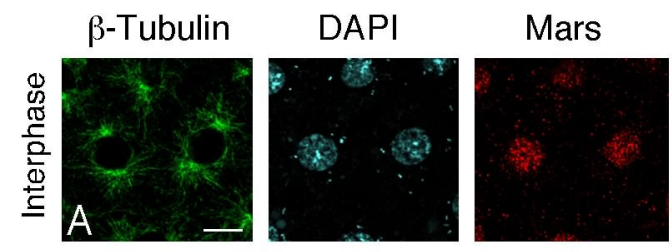

Merge
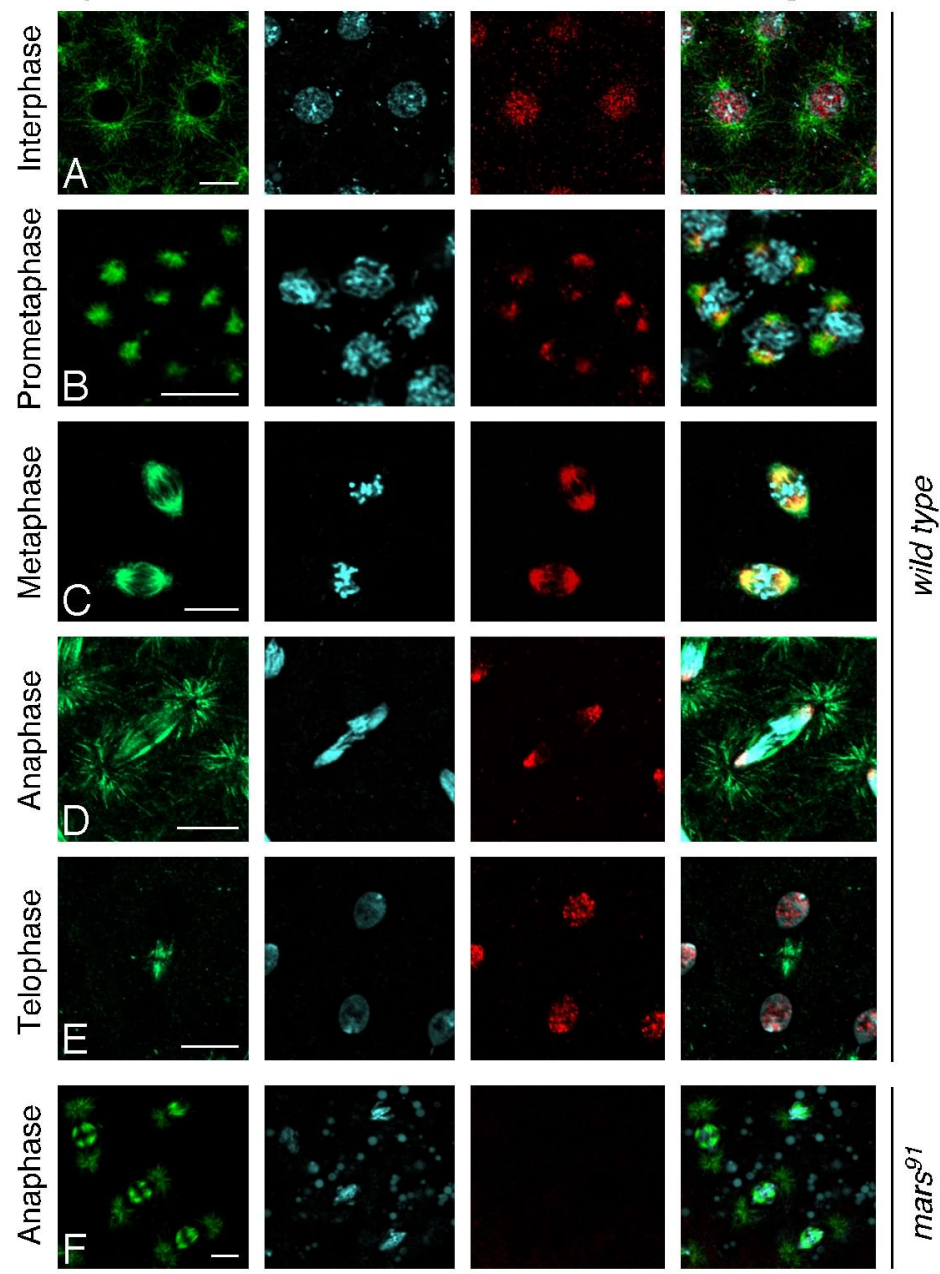
Fig. 3 Subcellular localization of Mars in embryos. Mars shuttles between the nucleus and the mitotic spindle and is mainly detected on kinetochore-fibers during anaphase. The subcellular localization of Mars was analyzed in fixed wild type embryos at the syncytial blastoderm stage. (A) At interphase, Mars (red) localizes to the nucleus and does not colocalize with $\beta$-tubulin (green). DNA was stained with DAPI (turquoise). (B) At prometaphase after nuclear envelope breakdown, Mars colocalizes with $\beta$-tubulin at microtubule asters in the vicinity to the chromatin. (C) At metaphase, Mars is present on the mitotic spindle. (D) At anaphase, Mars is enriched on kinetochore-fibers and is absent from the central spindle and aster microtubules nucleated at the centrosomes. (E) At telophase, Mars enters the newly formed nuclei and is absent from the central spindle. (F) In mars $^{91}$ homozygous mutant embryos, Mars is not detectable with the antibody raised against the C-terminus of Mars. Scale bars $=10 \mu \mathrm{m}$.

Similar results were obtained in S2r cells (Fig. 4). At interphase, Mars was only faintly detected in the nucleus (Fig. 4A) which may be caused by degradation after mitosis. However, the redistribution into the nucleus was more obvious at telophase when the new nuclei formed (Fig. 4E).

To confirm the staining results, we generated GFP-Mars transgenic flies. By live imaging, we recorded the dynamics of GFP-Mars in embryos at syncytial blastoderm stage. The movie shows a localization pattern very similar to that of endogenous Mars in fixed embryos (Fig. 5B). The kinetochore fiber localization is very obvious during anaphase as GFP-Mars signals (green) always end at the segregated chromosomes (red). The central spindle visualized by GFP-Tub that formed between the segregated chromosomes (Fig. 5A, $190 \mathrm{sec}$ ) was not decorated by GFP-Mars (Fig. 5B, $130 \mathrm{sec}$ ). 


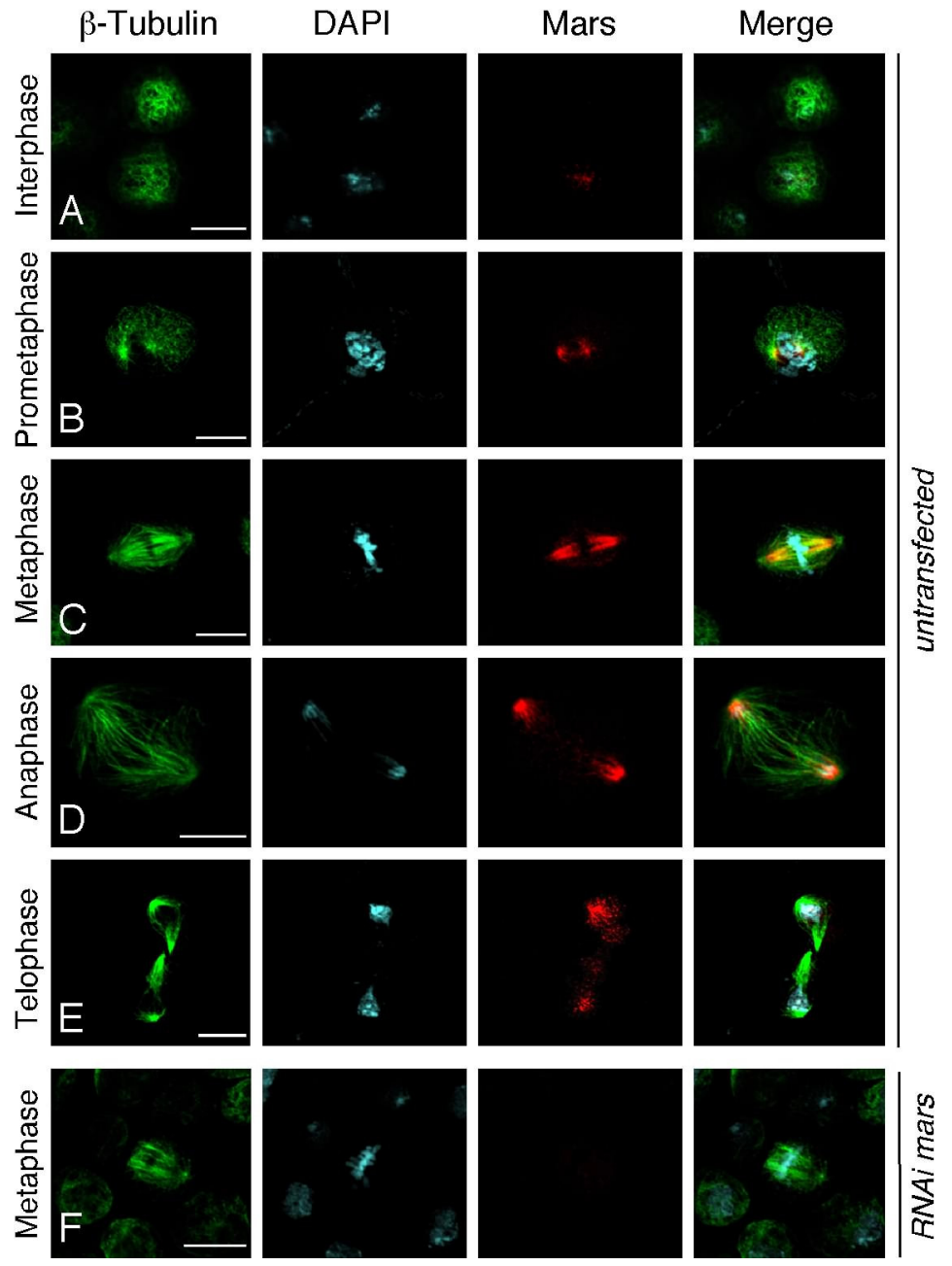

Fig. 4 Subcellular localization of Mars in S2r cells. (A - E) Untransfected S2r cells were stained with antibodies against $\beta$-tubulin (green) and Mars (red). DNA was stained with DAPI (turquoise). (A) At interphase, weak Mars staining is detectable in the nucleus. (B) At prometaphase, Mars colocalizes with $\beta$-tubulin at microtubule asters, but only at the region facing the chromatin and does not colocalize with cytoplasmic microtubules. (C) At metaphase and (D) anaphase, Mars localizes to the mitotic spindle and kinetochore fibers undergoing anaphase shortening. (E) At telophase, Mars relocalizes to the newly formed nuclei and is absent from the central spindle. (F) In S2r cells treated with double stranded RNA corresponding to the mars mRNA (RNAi mars), Mars protein is not detectable. Scale bars $=10 \mu \mathrm{m}$. 

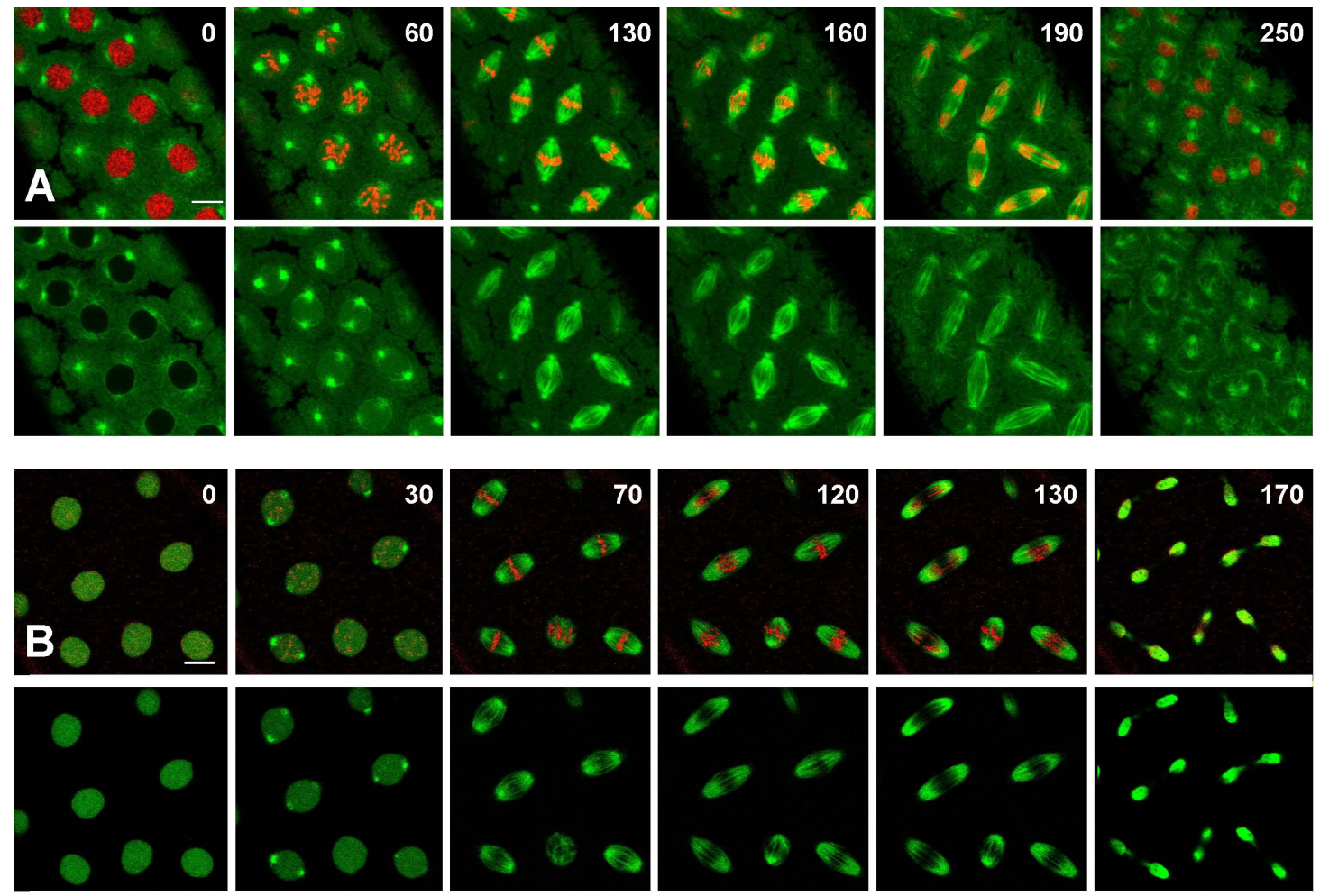

Fig. 5 Subcellular localization of GFP-Mars in embryos by live imaging. Subcellular localization of $\alpha$-Tub-GFP, histone-3B-RFP (A) and GFP-Mars, histone-3B-RFP (B) were recorded by living imaging from transgenic embryos at syncytial blastoderm stage. (A) Synchronous nuclear divisions in an embryo at the $10^{\text {th }}$ nuclear division cycle were recorded by the dynamics of $\alpha$-tubulin-GFP (green) and histone-3B-RFP (red). The elapsed time (in seconds) after the beginning of the time-lapse recording is given in the upper right corner of each image. In this embryo, nuclei are evenly distributed and divide synchronously. Central spindle was obvious at the mid region of anaphase spindles at $190 \mathrm{sec}$ picture. (B) The subcellular localization of GFP-Mars (green) and histone-3B-RFP (red) were recorded in a living embryo at nuclear division cycle 10. pUASP-GFP-Mars was driven by the maternal daughterless-GAL4 driver. The dynamics of GFP-Mars localization during mitosis reflects the subcellular localization of endogenous Mars as described in Fig. 3 and 4. Consistently, GFP-Mars was not observed at the mid region of the spindles at anaphase (Fig. 5B, $130 \mathrm{sec}$ ).

To check whether Mars is present on centrosomes, we performed stainings of embryos with antibodies against Mars and the centrosome marker $\gamma$-tubulin. Our data show that Mars is absent from centrosomes, both at interphase (Fig. 6A) and at metaphase (Fig. 6B). 

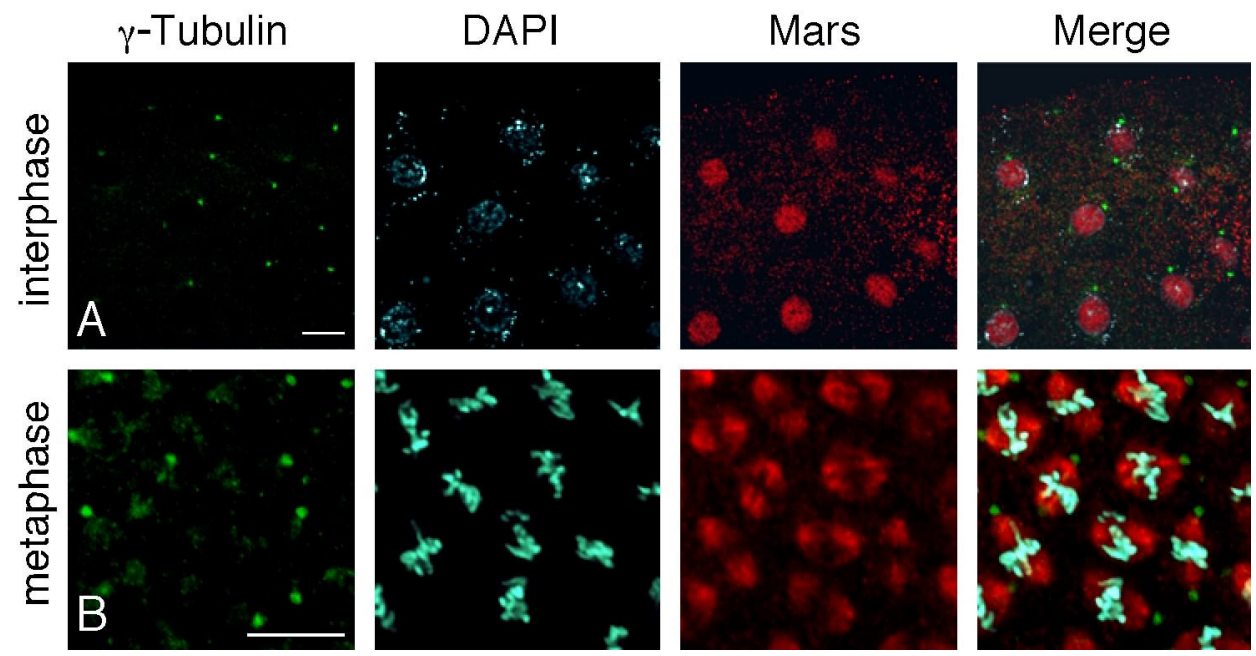

Fig. 6 Mars is not present on centrosomes. Wild type embryos at the syncytial blastoderm stage were simultaneously labelled for the centrosome marker $\gamma$-tubulin (green) and Mars (red). DNA was stained with DAPI (turquoise). $\gamma$-tubulin and Mars did neither colocalize at interphase (A) nor at metaphase (B). Scale bars $=10 \mu \mathrm{m}$.

\subsubsection{Mitotic spindle localization of Mars is not disrupted in cytoplasmic dynein, polo and aurora $A$ hypomorphic mutants}

The Dynein/Dynactin complex is required for the transport of microtubule-associated proteins such as NuMA and TPX2 to the minus ends of microtubules (Merdes et al., 2000; Wittmann et al., 2000). By staining and live imaging analysis, Mars also showed enrichment at spindle poles at metaphase and anaphase (Fig. 3, 4, 5). To test whether the spindle pole enrichment of Mars was dependent on the Dynein/Dynactin complex, we analyzed the localization of Mars in embryos mutant for Dhc64C, the gene encoding the dynein heavy chain. As reported previously, mitotic spindles showed loosely attached centrosomes and unfocused spindle poles upon mutation of Dhc64C (Fig. 7A) (Robinson et al., 1999; Morales-Mulia and Scholey, 2005). However, Mars was still enriched at the minus end region of spindle microtubules in Dhc64C mutant embryos (Fig. 7A).

The proper localization of the microtubule associated protein D-TACC to spindle poles depends on phosphorylation by the mitotic kinase Aurora A, and the localization of $\gamma$-tubulin and CP190 to the spindle poles depends on Polo kinase (Donaldson et al., 
2001; Giet et al., 2002; Barros et al., 2005). In embryos mutant for hypomorphic alleles of aurora $A$ or polo, Mars was enriched at the minus end region of spindle microtubules (Fig. 7B, C) suggesting that either these two kinases are not required for proper spindle localization of Mars or that the low levels of residual kinase activity still present in the homozygous mutant embryos are sufficient for proper localization of Mars.
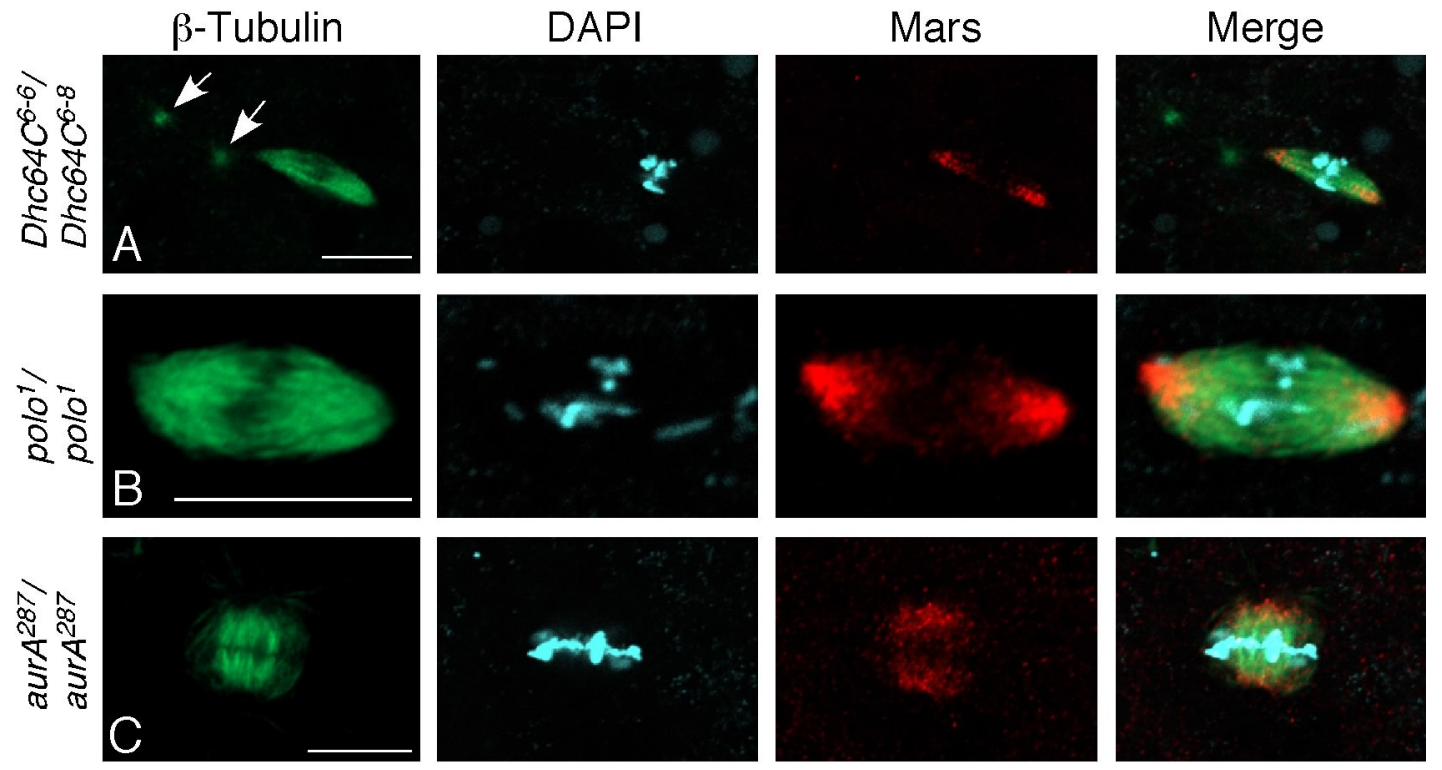

Fig. 7 Mars spindle localization is independent of dynein, polo and aurora A. Subcellular localization of Mars in embryos mutant for cytoplasmic dynein heavy chain, polo and aurora A. (A) Transheterozygous $D h c 64 C^{6-6} / D h c 64 C^{6-8}$ mutant embryos frequently show detachment of the centrosomes from the mitotic spindle (arrows). Mars was still enriched at the minus ends of spindle microtubules. (B) In polo $^{l}$ homozygous mutant embryos, Mars was enriched at spindle poles. (C) In homozygous aur ${ }^{287}$ mutant embryos, Mars was enriched at the minus ends of spindle microtubules similar to wild type. Note the abnormal shape of the spindle typical for aurA mutants. Scale bars $=10 \mu \mathrm{m}$.

\subsubsection{Spindle localization of Mars is dependent on microtubules}

To investigate whether the spindle localization of Mars depends on microtubules, demecolcine was used to depolymerize microtubules in wild type embryos. This treatment resulted in the complete disappearance of tubulin staining at mitotic figures in embryos at the syncytial blastoderm stage (Fig. 8A). Concomitantly, Mars staining 
also vanished, demonstrating that the spindle localization of Mars is dependent on microtubules. Moreover, after depolymerization of microtubules, Mars did not associate with any other cellular structure, e. g. the centrosome or the chromosomes, showing that its localization strictly depends on microtubules. To test whether Mars is physically associated with microtubules, we performed microtubule cosedimentation assays using Drosophila embryo extracts. In the absence of taxol and GTP, Mars, $\alpha$-tubulin and the microtubule associated protein EB1 (Rogers et al., 2002) were in the supernatant (Fig. 8B). In the presence of taxol and GTP, a significant amount of Mars was detected in the pellet together with $\alpha$-tubulin and EB1 (Fig. 8B). Thus, Mars is a microtubule-associated protein.
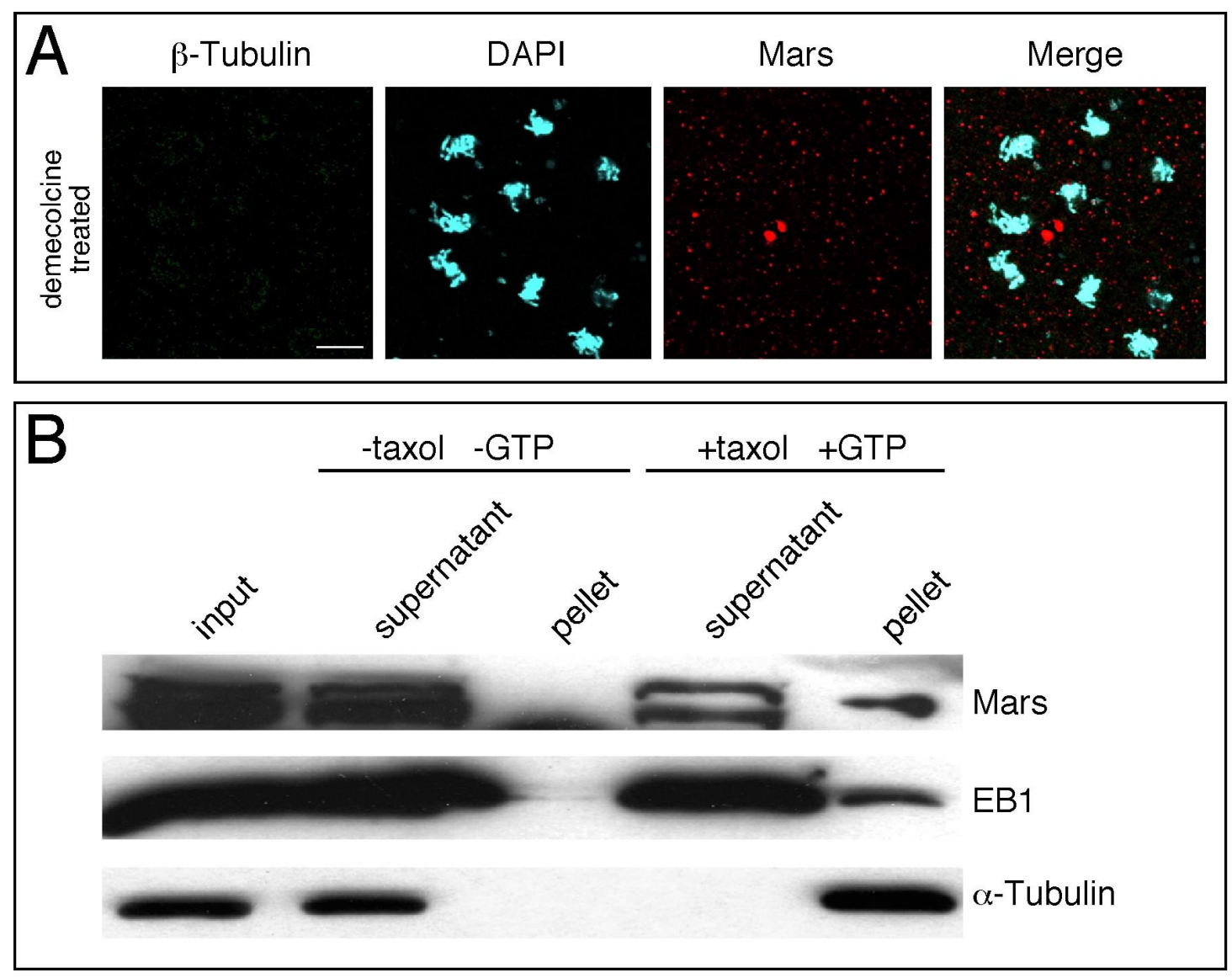

Fig. 8 Spindle localization of Mars depends on microtubules. (A) In embryos treated with demecolcine to disrupt microtubules, neither $\beta$-tubulin (green) nor Mars (red) showed any spindle-shaped localization. DNA was stained with DAPI (turquoise). (B) In a microtubule spin-down assay, Mars, the microtubule-associated protein EB1 and $\alpha$-tubulin remained in the 
supernatant in the absence of taxol and GTP. After addition of taxol and GTP, all three proteins sedimented in the microtubule pellet. Scale bar in $(\mathrm{A})=10 \mu \mathrm{m}$.

\subsubsection{The N-terminal region of Mars is necessary and sufficient for spindle localization}

With the exception of the guanylate kinase associated protein (GKAP) domain, Mars does not contain any protein domains that are recognized by the SMART (http://smart.embl-heidelberg.de/) search algorithm. In order to find out which portions of Mars are responsible for the spindle localization and for the nuclear localization, we generated a series of hemagglutinin (HA) tagged deletion constructs of Mars (Fig. 9A) and expressed them in S2r tissue culture cells. HA tagged full length Mars (HA-Mars-full) localized into the nucleus at interphase (Fig. 9B) and onto the mitotic spindle at metaphase (Fig. 9C), which are consistent with the localization of endogenous Mars and transgenic GFP-Mars (Fig. 3, 4, 5). HA-Mars-N, containing amino acids 1 - 430 of Mars, showed very similar subcellular localization as HA-Mars-full, both at interphase (Fig. 9D) and at metaphase (Fig. 9E). The middle portion of Mars containing the GKAP domain (HA-Mars-M, aa 431 - 780) was nuclear at interphase (Fig. 9F) but did not localize to the mitotic spindle at metaphase (Fig. 9G). The C-terminal region of Mars (HA-Mars-C, aa 781 - 921) was cytoplasmic at both interphase and metaphase and showed neither nuclear nor spindle localization (Fig. 9H, I). Thus, the N-terminal region of Mars appears to be sufficient for proper localization of Mars in interphase and in mitosis and there appears to be a second nuclear localization signal in the middle portion of the protein. 

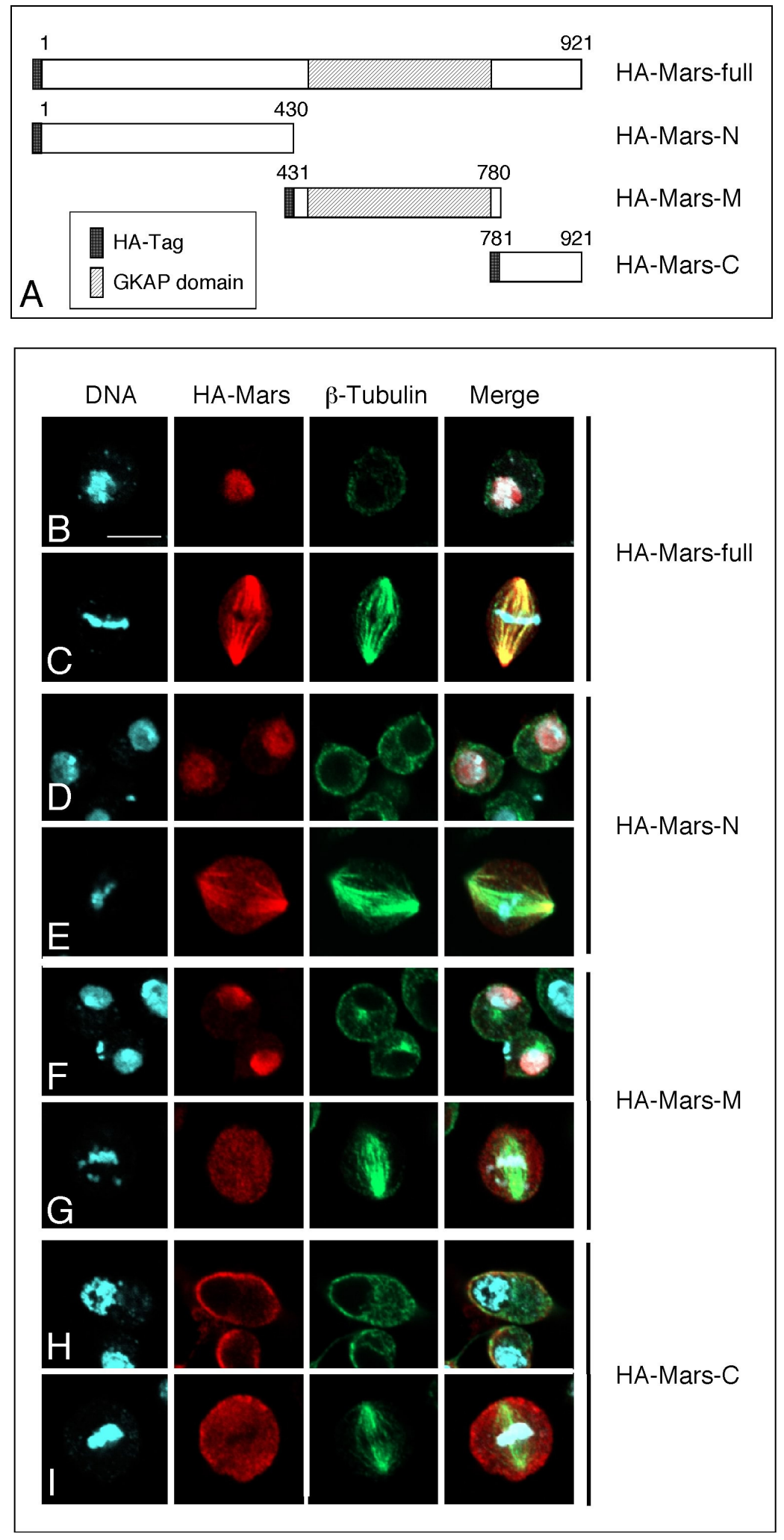

Fig. 9 N-Mars is sufficient for spindle localization. (A) A series of HA-tagged full length and deletion versions of Mars was generated for expression in S2r cells. (B - I) The subcellular localization of the four different versions of Mars in S2r cells was determined by staining with an antibody against the HA tag (red). Microtubules were stained with an antibody against $\beta$-tubulin 
(green) and DNA with DAPI (turquoise). At interphase (B, D, F, H), HA-Mars-full, HA-Mars-N and HA-Mars-M were localized into the nucleus, whereas HA-Mars-C was localized in the cytoplasm and was excluded from the nucleus. At metaphase (C, E, G, I), both HA-Mars-full and HA-Mars-N localized to the spindle, whereas HA-Mars-M and HA-Mars-C localized throughout the cytoplasm. Scale bar $=10 \mu \mathrm{m}$.

It has been proposed that the interaction between MAPs and microtubules is mediated by electrostatic force (Cravchik et al., 1994). The MAP-binding positions on tubulins are acidic while the MT-binding regions of MAPs are basic. By the software program Protean from DNASTAR software package (DNASTAR Inc, Madison, WI), we mapped the average charge of the Mars protein (Fig. 10A). Three continuous positively charged regions within N-Mars (aa 1-430) were found including aa 1-60, 90-190, 210-390. To further narrow down the region required for the mitotic spindle localization, we generated a series of truncated Mars constructs and expressed them in S2r cells. The localization pattern was analyzed and summarized in Fig. 10B. Very strong mitotic spindle localization was detected for the truncated protein 1-210, but not for the 211-430 fragment indicating that the first two positively charged regions are necessary for mitotic spindle localization. The protein encoded by construct 80-210 only showed weak staining on the mitotic spindle which indicates that the first positively charged region may have the highest affinity to MTs (Fig. 10B). For nuclear localization, we first analyzed the protein sequence using the online prediction program PSORTII (http://psort.ims.u-tokyo.ac.jp/form2.html) which indicated a par7 type NLS (PVAKKKF) around 472 site. To confirm this, we transfected S2r cells with the construct containing amino acids 481-780. As expected, the truncated protein did not show nuclear localization in contrast to M-Mars (aa 430-780), suggesting that the NLS found by PSORTII is necessary for nuclear localization of M-Mars. By the same way, we found that the NLS of N-Mars was within the region aa 211-430. Further analysis may narrow it down to a shorter region (Fig. 10B). 

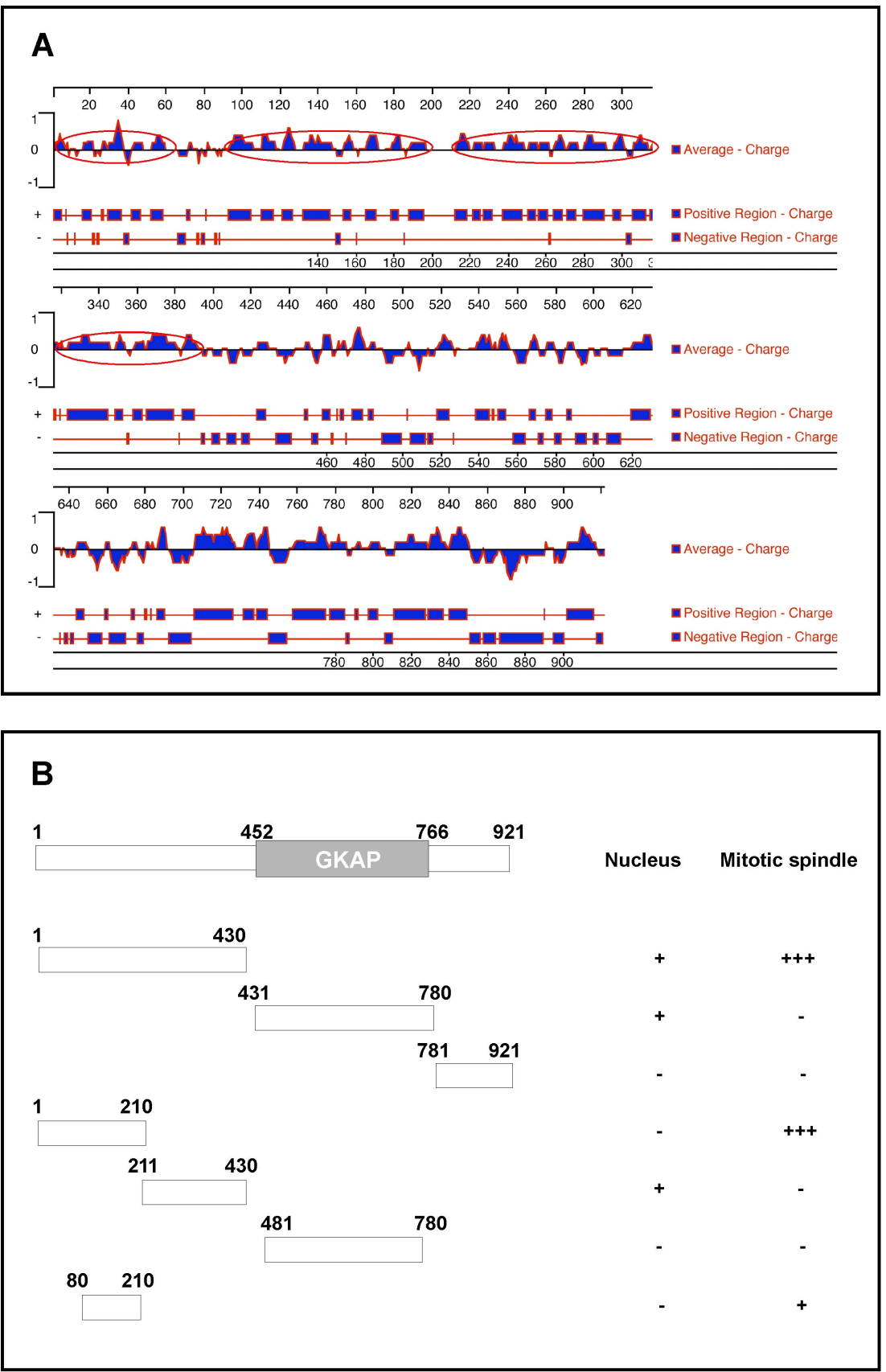

Fig. 10 Average charge and localization analysis of Mars. (A) The average charge of Mars was analyzed by Protean (DNASTAR Software). In the N-terminal region (aa 1-430), there are three continuous positively charged regions (red circles). (B) The regions for nuclear and mitotic spindle localization were analyzed by a series of truncated Mars proteins expressed in S2r cells. The region for mitotic spindle localization could be narrowed down to the first 210 amino acids. There is one NLS within the region aa 211-430 and another one within aa 431-480. 


\subsection{Phenotype analysis of mars mutant}

\subsubsection{Generation and molecular analysis of mars mutant alleles}

To investigate the function of mars, mars mutant alleles were generated by imprecise excision of the $P\{E P\} 2477 \mathrm{P}$-element insertion. In this line, the P-element is inserted in the 5' UTR of mars, 20 bp upstream of the predicted translation start site (Fig. 11A). The P-element was mobilized by crossing to the $\Delta 2-3$ transposase source (Robertson et al., 1988) and excision events were scored by the loss of the white ${ }^{+}$marker. Five excision chromosomes carried deletions of chromosomal DNA that extended into the coding region of mars to different degrees. In the homozygous viable mars $^{91}$ allele, $531 \mathrm{bp}$ of the first exon including the start codon are deleted (Fig. 11A). The homozygous lethal excision chromosome mars $^{102}$ carries a larger deletion of $6502 \mathrm{bp}$ that completely removes the coding region of mars and extends into the coding region of the adjacent mip120 and EfTuM loci (Fig. 11A), which is the most likely explanation for the lethality of this allele. mip120 mutants are viable but female sterile (Beall et al., 2007), whereas EfTuM is an essential gene (Spradling et al., 1999).

To check whether the homozygous mutant $\operatorname{mars}^{91}$ and mars $^{102}$ embryos still expressed the Mars protein, we performed Western blot analysis. In wild type embryonic extracts the antiserum affinity-purified against the C-terminal Mars peptide specifically recognized one band of $145 \mathrm{kD}$ that was absent in homozygous mutant mars $^{91}$ and mars $^{102}$ embryos (Fig. 11B). The $145 \mathrm{kD}$ band was also detectable in extracts of S2r cells and disappeared after RNA interference (RNAi) directed against mars (Fig. 11C). Conversely, overexpression of Mars in S2r cells resulted in a significant increase of the $145 \mathrm{kD}$ band (Fig. 11D). Indirect immunofluorescence microscopy was performed to check for the presence of Mars immunoreactivity in embryos and S2r cells. Consistent with the results of the Western blots, no specific staining was detected in homozygous mutant mars $^{91}$ embryos (Figs. 3F, 12B) and in S2r cells, in which mars had been knocked down by RNAi (Fig. 4F). 

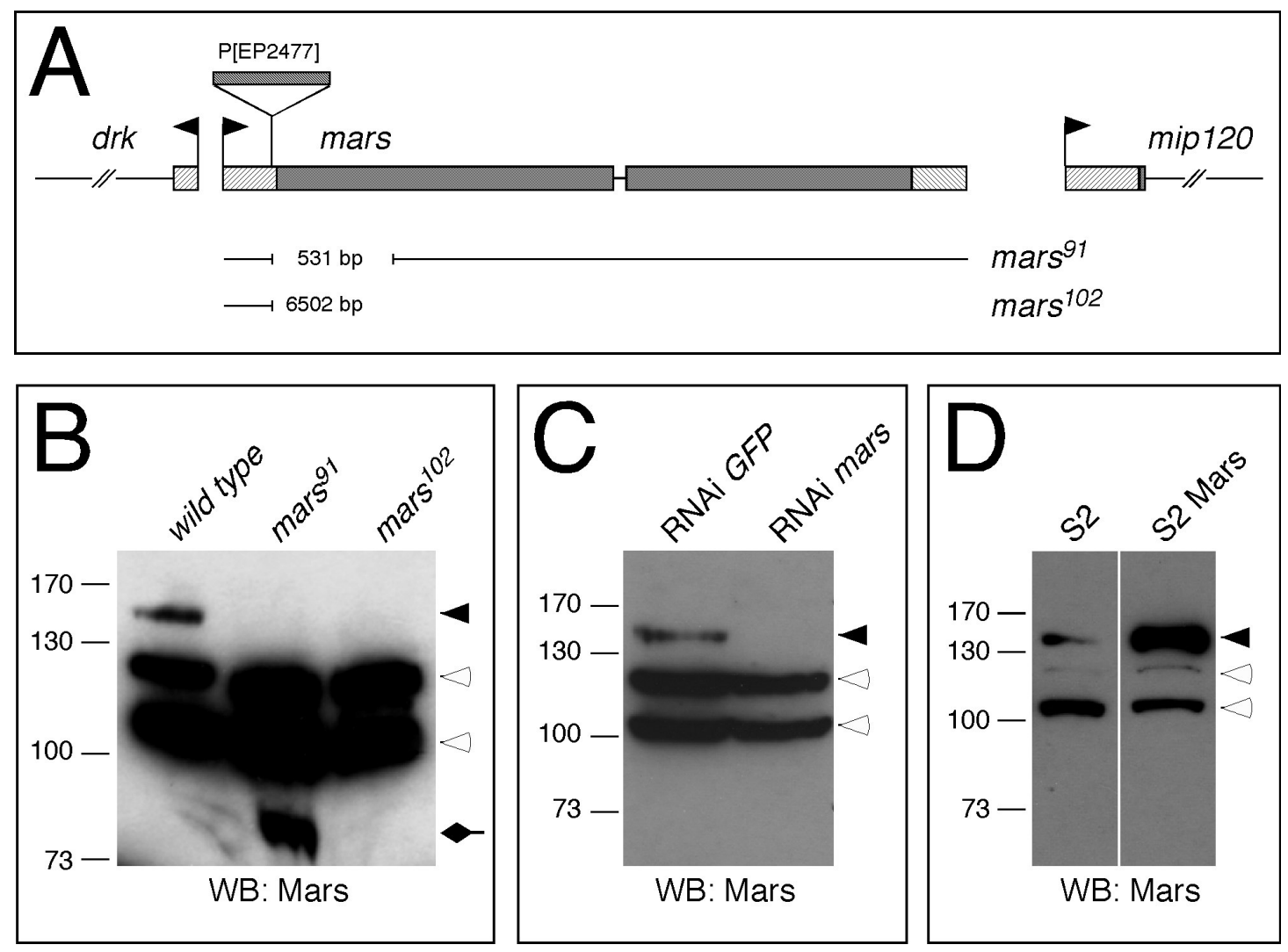

Fig. 11 Molecular characterization of mars mutant alleles. (A) Mutant alleles of mars were generated by imprecise excision of the P[EP2477] P-element, which is inserted in the 5' UTR of mars, 20 bp upstream of the translation start site. The transcription start sites of mars and of the adjacent genes $d r k$ and mip120 are indicated by flags. Untranslated regions are hatched, and ORFs are in dark gray. The position and the extent of the deletions generated by imprecise excision of P[EP2477] are shown below the genomic map. (B) A peptide antibody raised against the C-terminus of Mars specifically recognizes the Mars protein. Embryonic extracts of wild type embryos, mars $^{91}$ and mars $^{102}$ embryos were analyzed by Western blot. In wild type, a band of 145 $\mathrm{kD}$ corresponding to full length Mars was detectable (filled arrowhead) that was absent in embryos homozygous for any one of the two mars mutant alleles. In homozygous mars $^{91}$ mutant embryos, a shorter band of $78 \mathrm{kD}$ was detectable (filled arrow), that most likely represents an $\mathrm{N}$-terminally truncated form of Mars that is generated by the use of an alternative start codon in the mars coding region downstream of the right breakpoint of the mars $^{91}$ deletion. This blot was overexposed to demonstrate the complete absence of the $145 \mathrm{kD}$ band in embryos homozygous for the two mars mutant alleles. Both in embryos and in S2r cells, the anti Mars antibody detected two additional bands of 105 and $125 \mathrm{kD}$ (open arrowheads) that apparently are unrelated to Mars and 
that served as an internal loading control in our experiments. (C) The $145 \mathrm{kD}$ band representing full length Mars disappeared in S2r cells treated with double stranded RNA corresponding to mars (RNAi mars), but not in cells treated with double stranded RNA corresponding to GFP (RNAi $G F P$ ) as control. (D) Overexpression of mars in cells transfected with a mars expression construct (S2 Mars) resulted in strong increase of the $145 \mathrm{kD}$ band corresponding to full length Mars.

\subsection{2 mars mutant embryos show mitotic defects during cleavage divisions}

mars $^{91}$ homozygous mutant females and males are fertile, but $90.8 \%$ of embryos produced by homozygous mutant parents died during embryogenesis. $9.2 \%$ of embryos hatched as larvae but only $5.5 \%$ of embryos survived to adulthood. Of the embryos that died, the majority $(92.2 \%)$ failed to cellularize properly. Heterozygous $\operatorname{mars}^{91} / D f(2 R) C X 1$ animals were also viable and produced offspring with the same percentage of embryonic defects, arguing that $\operatorname{mars}^{91}$ is a strong hypomorphic or amorphic allele of mars. This interpretation is supported by the molecular analysis of $\operatorname{mars}^{91}$, which shows that the translation start site is deleted in this allele, and by the fact that in homozygous mars $^{91}$ mutant embryos no staining over background levels is detectable with the anti Mars antibody.

To analyze the function of Mars during early embryogenesis, we stained 0-4 hr old embryos from homozygous mutant mars $^{91}$ parents with antibodies against $\beta$-tubulin, Mars and DAPI. Unlike in wild type embryos at the syncytial blastoderm stage (Fig. 12A), nuclei and mitotic figures at the cortex of mars $^{91}$ mutant embryos were unevenly distributed and the synchrony of nuclear divisions was partially lost (Fig. 12B). Several types of mitotic defects were commonly found in fixed mars $^{91}$ mutant embryos. From the first mitotic division onward, centrosomes were only loosely attached to the mitotic spindle and spindle poles were poorly focused (Fig. 12D). This phenotype occurred with very high penetrance at early stages of syncytial development (Table 1) and frequently led to complete separation of centrosomes from the spindle. Most likely as a consequence of this primary defect, additional mitotic abnormalities accumulated in the course of the cleavage divisions. Anastral spindles (Fig. 12E) and monopolar spindles with circular chromosomes (Fig. 12F) were the 
most common phenotype in embryos at later stages of syncytial development (Table 1). Those monopolar spindles always had one, sometimes two centrosomin positive dots in their center (data not shown), demonstrating that the monopolar spindles were associated with a centrosome. Monastral monopolar spindles (Fig. 12G) and multipolar spindles (Fig. 12H) were also frequently found (Table 1). Like in wild type, in these abnormal spindles every microtubule aster contained a centrosome at the center. Besides those defects, many microtubule asters that were neither attached to the nuclear envelope nor to a mitotic spindle were present at the embryo cortex (Fig. 12I). Those microtubule asters were nucleated by free centrosomes. Like normal centrosomes in wild type embryos, these free centrosomes showed staining for the centrosome markers $\gamma$-tubulin, Cnn (Centrosomin), D-TACC and Aurora A (Fig. 13).
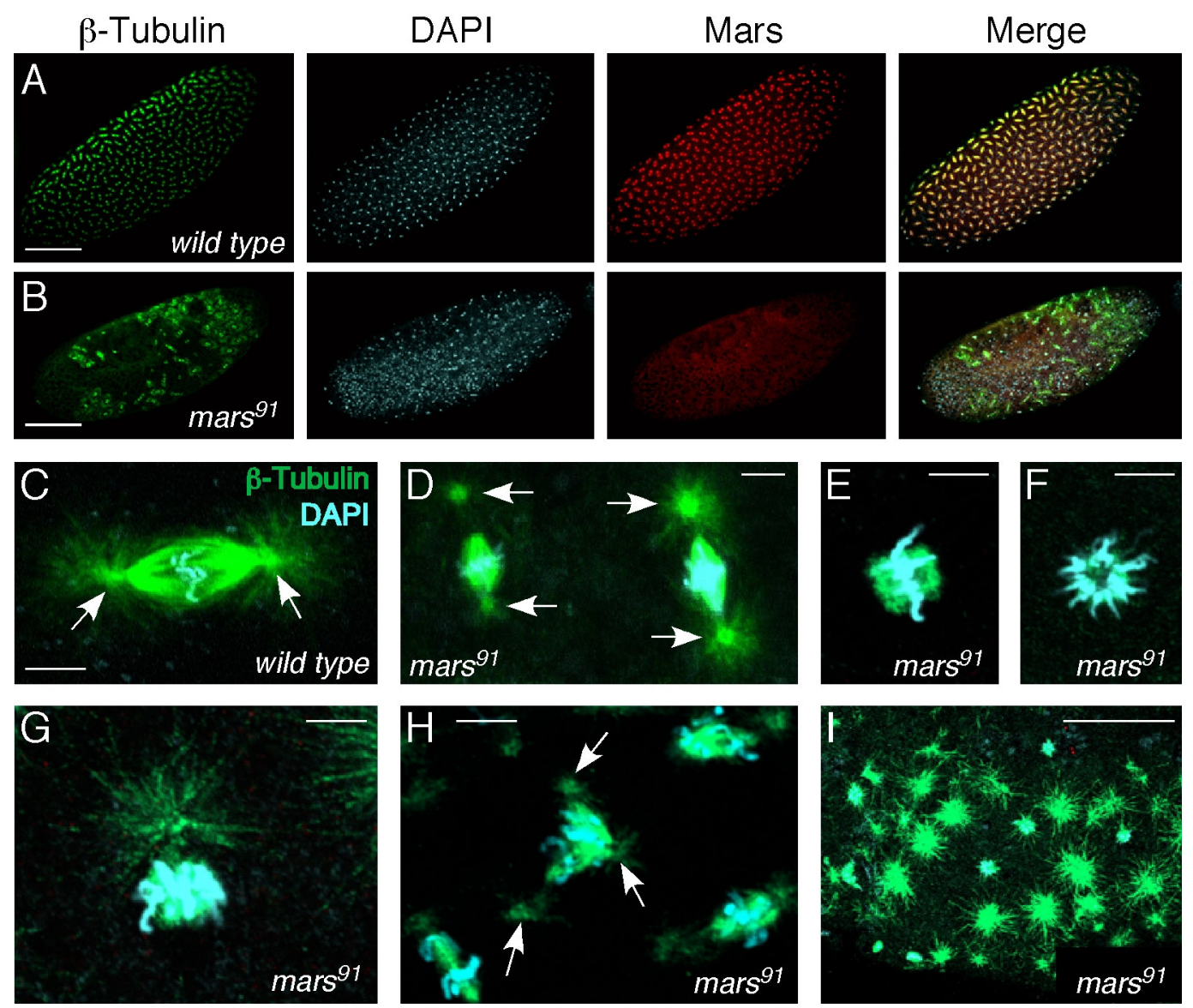

Fig. 12 Spindle defects in mars mutant embryos. mars mutant embryos show severe mitotic defects during cleavage divisions at the syncytial blastoderm stage. (A) In a wild type embryo at nuclear cycle 11, the division of the cortical nuclei occurs nearly simultaneously and nuclei are 
evenly spaced. Microtubules were stained with an antibody against $\beta$-tubulin (green), Mars is shown in red and DNA was stained with DAPI (turquoise). (B) In a arrs $^{91}$ homozygous mutant embryo of about the same age, nuclei do not divide synchronously and are dispersed randomly throughout the embryo. Note that staining for Mars is reduced to background levels. (C) A wild type mitotic spindle at metaphase during nuclear cycle 2 . Note the tight association of the centrosomes (arrows) with the spindle. (D - I) Common mitotic defects observed in homozygous mars $^{91}$ mutant embryos. (D) Bipolar spindles at nuclear cycle 2 with detached centrosomes. (E) Anastral spindle. (F) Circular monopolar mitotic figure. (G) Monastral monopolar spindle. (H) Multipolar fused spindle (arrows mark spindle poles). (I) Free centrosomes. Scale bars in (A) and (B) $=100 \mu \mathrm{m}$. Scale bars in $(\mathrm{C}-\mathrm{H})=5 \mu \mathrm{m}$. Scale bar in $\mathrm{I}=50 \mu \mathrm{m}$.

\begin{tabular}{|c|c|c|}
\hline Spindle Phenotype & $\begin{array}{l}\text { Before nuclear } \\
\text { migration } \\
(n=141)\end{array}$ & $\begin{array}{l}\text { After nuclear } \\
\text { migration } \\
(n=188)\end{array}$ \\
\hline bipolar spindle with detached centrosomes & $40(28,4 \%)$ & $9 \quad(4,8 \%)$ \\
\hline monastral monopolar spindle & $30(21,3 \%)$ & $29(15,4 \%)$ \\
\hline anastral spindle & $25(17,7 \%)$ & $47(25,0 \%)$ \\
\hline circular monopolar mitotic figure & $8 \quad(5,7 \%)$ & $66(35,1 \%)$ \\
\hline multipolar fused spindle & $0 \quad(0,0 \%)$ & $3(1,6 \%)$ \\
\hline normal bipolar spindle & $38(27,0 \%)$ & $34(18,1 \%)$ \\
\hline
\end{tabular}

Table 1. Quantification of spindle phenotypes in mars $^{91}$ homozygous mutant embryos.

Mitotic defects were scored at early stages of syncytial development before nuclei had migrated to the cortex and at later stages of syncytial development after migration of nuclei to the cortex. $\mathrm{n}=$ number of nuclei scored for each time point. Representative fields containing 10-20 nuclei of at least ten embryos were scored for each time point. 


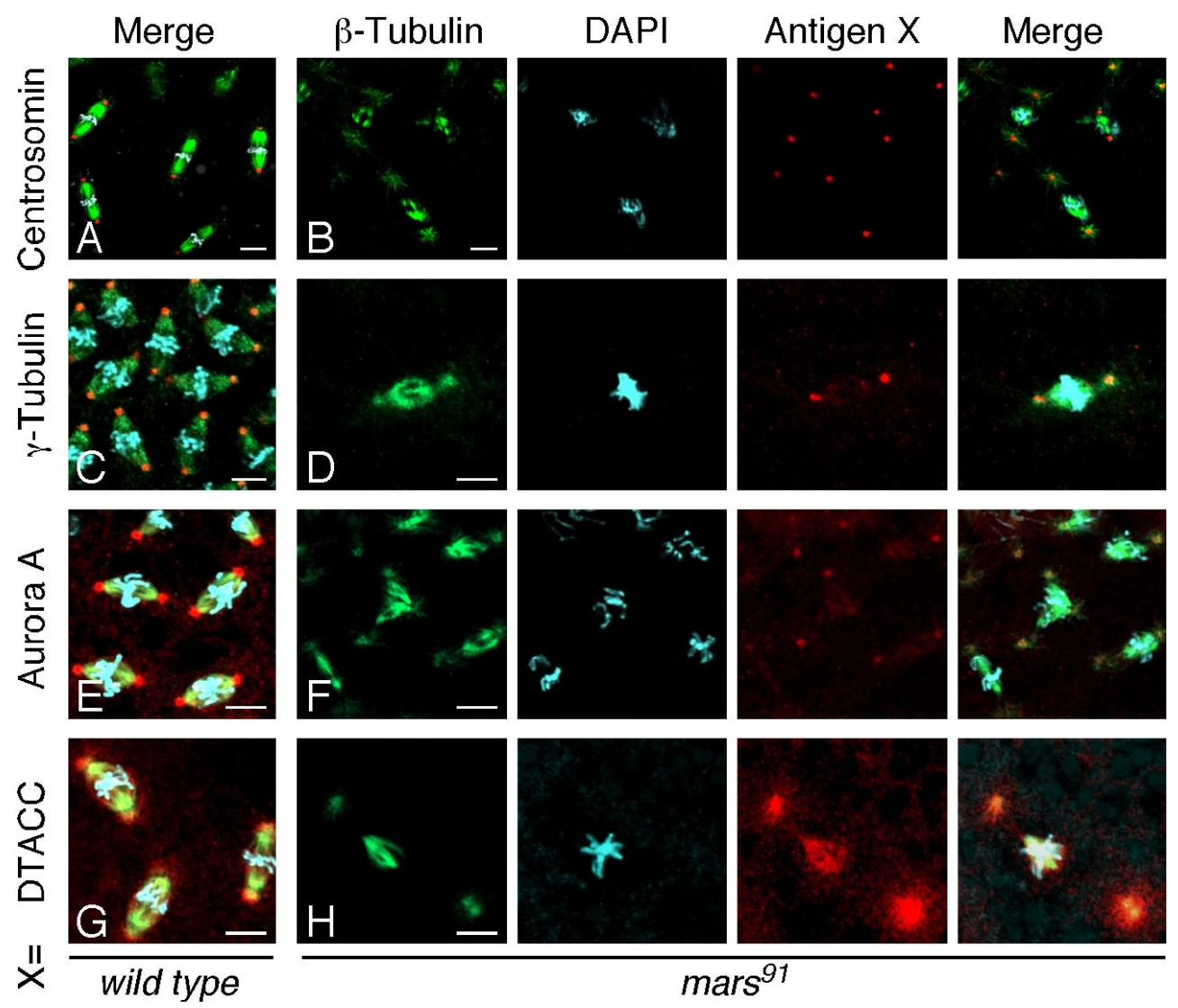

Fig. 13 mars loss-of function does not affect localization of centrosomal proteins. (A) Wild type and (B) mars $^{91}$ homozygous mutant embryos showed centrosomal localization of centrosomin (red). (C) Wild type and (D) $\operatorname{mars}^{91}$ homozygous mutant embryos showed centrosomal localization of $\gamma$-Tubulin (red). (E) Wild type and (F) $\operatorname{mars}^{91}$ homozygous mutant embryos showed centrosomal localization of Aurora A (red). (G) Wild type and (H) mars $^{91}$ homozygous mutant embryos showed centrosomal localization of D-TACC (red). Scale bars $=5$ $\mu \mathrm{m}$.

To confirm that these phenotypes were indeed caused by the loss of function of Mars, the GFP-Mars transgene was crossed into the mutant background together with the maternal driver daughterless-Gal4 for the rescue experiment. In the presence of GFP-Mars, the embryo hatching ratio was brought up to $96 \%$, which means that GFP-Mars is fully functional and can rescue the mutant phenotype caused by the loss of Mars (Fig. 14). 


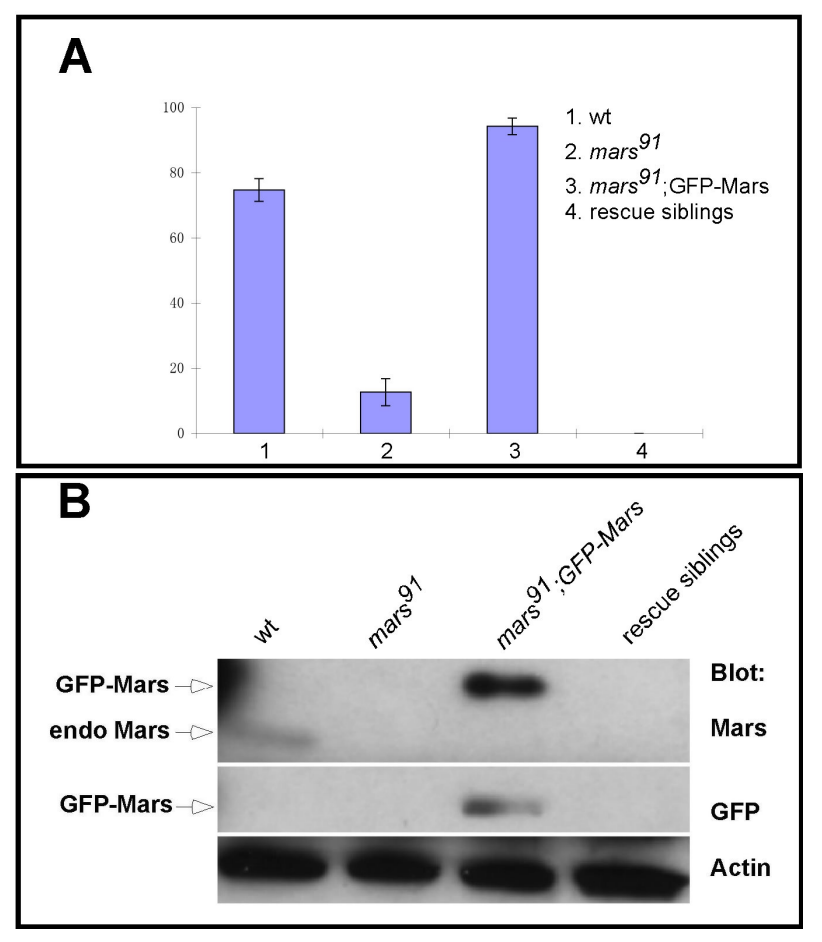

Fig. 14 mars $^{91}$ mutant embryos can be rescued by GFP-Mars. (A) GFP-Mars was driven by the maternal daughterless-GAL4 driver in mars $^{91}$ mutant embryos. 100 embryos were collected and recorded for the hatching ratios. The counting was repeated three times. The hatching ratio was restored to normal level in $\operatorname{mars}^{91}$;GFP-Mars embryos (column 3) as compared with wild type (column 1) and mars $^{91}$ mutant embryos (column 2). (B) The protein levels were determined by Western blot. In wild type embryos, endogenous Mars was detected as a faint band at the normal size $\left(145 \mathrm{kD}\right.$, arrow in middle). In the other three genotypes with mars $^{91}$ mutant background, this band was not detected. The third lane shows one band around $175 \mathrm{kD}$ which was confirmed as GFP-Mars by both Mars antibody (arrow on top) and GFP antibody (arrow at bottom). Actin was used as loading control.

GFP-Mars can rescue the mars $^{91}$ mutant embryos but the flies with double GFP-Mars transgenes in wild type background were infertile. The embryos died at very early stages after fertilization (Fig. 15A). Sometimes, we observed giant mitotic spindle-like figures with poorly organized structure (Fig. 15B). The spindle was split in the middle and had very robust MT structures at the poles. The staining with the centrosome marker centrosomin showed several dots within these MT structures (Fig. 15C, D) which indicates either the separation of centrosomes was impaired or several 
mitotic spindles fused into one when GFP-Mars was overexpressed.

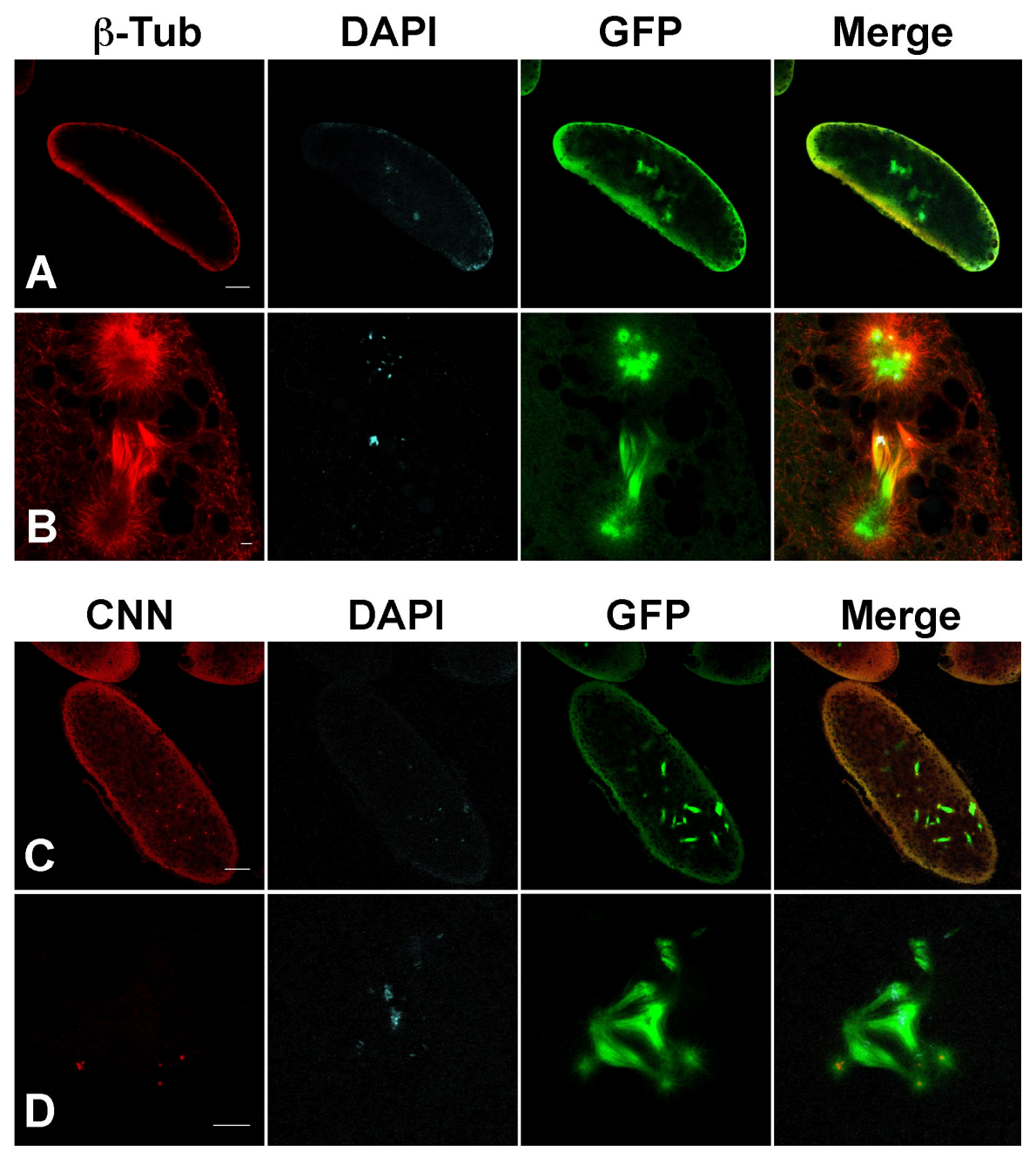

Fig. 15 Mitotic spindle defects caused by overexpression of GFP-Mars. Embryos laid by female flies with double copies of GFP-Mars in wild type background died at very early stages. Fixed embryos were stained with an antibody against $\beta$-tubulin (red in A and B), an antibody against centrosomin (red in C and D), an antibody against GFP (green) and DAPI for DNA (turquoise). (A) Overview picture shows very early arrest of embryo development around the $3^{\text {rd }}$ division after fertilization. (B) Overexpression of GFP-Mars caused enlargement of mitotic spindle poles and of the spindle itself. GFP-Mars was also detected in the region where centrosomes normally reside as several round dots. It also caused the splitting of the mitotic spindle. (C) Fixed embryos were stained with centrosomin to reflect the status of centrosomes. More than one dot was detected at the end of some mitotic spindles. (D) In this multipolar spindle, several centrosomin dots were detected at the lower left pole. Scale bars $=50 \mu \mathrm{m}$ at (A) and (C), 10 $\mu \mathrm{m}$ at (B) and (D). 
To better understand the mitotic defects in the $\operatorname{mars}^{91}$ mutant embryos, we performed live imaging of microtubule and chromosome behavior by confocal microscopy. Transgenes encoding ubiquitin-promoter driven $\alpha$-tubulin-GFP and histone-3B-RFP were crossed into the $\operatorname{mars}^{91}$ mutant background, which allowed dual color live recording of microtubules and chromatin. These analyses revealed five ways of how free centrosomes were generated in mars $^{91}$ mutant embryos. 1) At prophase of mitosis, centrosomes lost contact to the nuclear envelope and moved away from the nucleus (Fig. 16A). 2) Centrosomes detached from the mitotic spindle at metaphase or anaphase (Fig. 16B). 3) Free centrosomes duplicated and separated, which increased the number of free centrosomes (Fig. 16B). 4) One centrosome moved away from the mitotic spindle after duplication without attaching to a newly formed nucleus (Fig. 17). 5) Defective nuclei from aberrant mitotic figures dropped from the cortex into the yolk and the centrosomes originating from such nuclei remained in the cortical layer (Fig. 13I and data not shown). One characteristic feature of these free centrosomes was the excessive nucleation of very long astral microtubules (Fig. 12I).

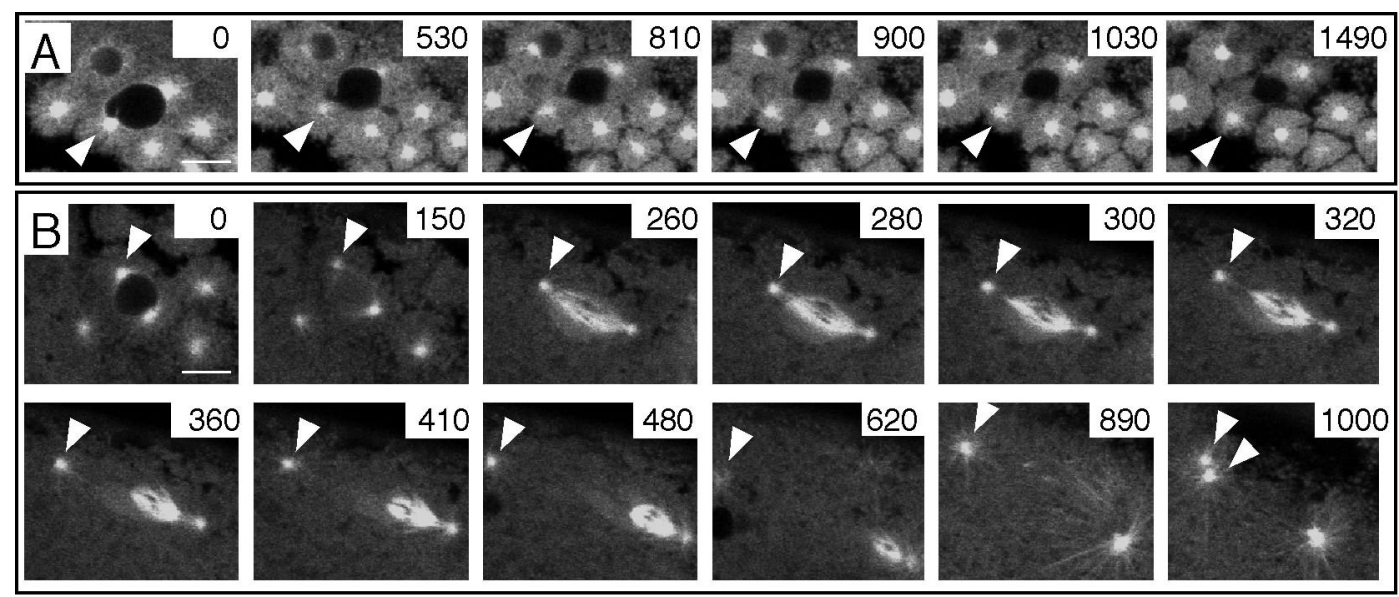

Fig. 16 Live imaging showing centrosome detachment in mars $^{91}$ homozygous mutant embryos. An $\alpha$-tubulin-GFP fusion protein was expressed in $\operatorname{mars}^{91}$ homozygous mutant embryos under control of the ubiquitin promoter. (A) Detachment of centrosomes from the nuclear envelope. This sequence shows the detachment of both centrosomes from the nuclear envelope in

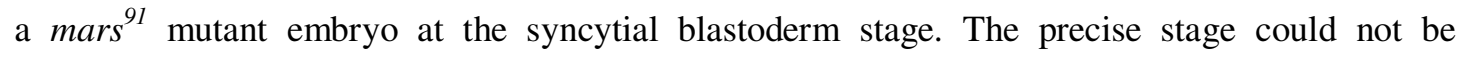
determined due to highly aberrant arrangement of nuclei in the cortex (cf. Fig. 12B). One centrosome is marked with an arrowhead. (B) During mitosis, one centrosome (arrowhead) 
detaches from the mitotic spindle, leading to the formation of a free centrosome and a monastral spindle. At the end of the sequence $(t=890 \mathrm{~s})$ both centrosomes duplicate, resulting in the formation of an additional free centrosome. The monastral spindle finally collapsed into a monopolar spindle ( $\mathrm{t}=890 \mathrm{~s}$ ). The time (in seconds) after beginning of the movie sequence is given in the upper right corner of each image. Scale bars $=10 \mu \mathrm{m}$.

In order to study the behaviors of the chromatids during mitosis in living mars mutant embryos, we simultaneously imaged histone-3B-RFP and $\alpha$-tubulin-GFP. Whereas mitoses occurred almost simultaneously and with even spacing between nuclei in wild type embryos at the syncytial blastoderm stage (Fig. 5B), many irregular mitoses resulting in nuclei of abnormal size and shape were observed in mars mutant embryos. Very often, we observed complete segregation of chromosomes even when the centrosomes detached from the spindles (Fig. 17). In those cases, the centrosomes did not completely lose contact with the mitotic spindles. It looked as if there were still some microtubule fibers in between the detached centrosomes and the spindle poles (Fig. 17, $390 \mathrm{sec}$ ).
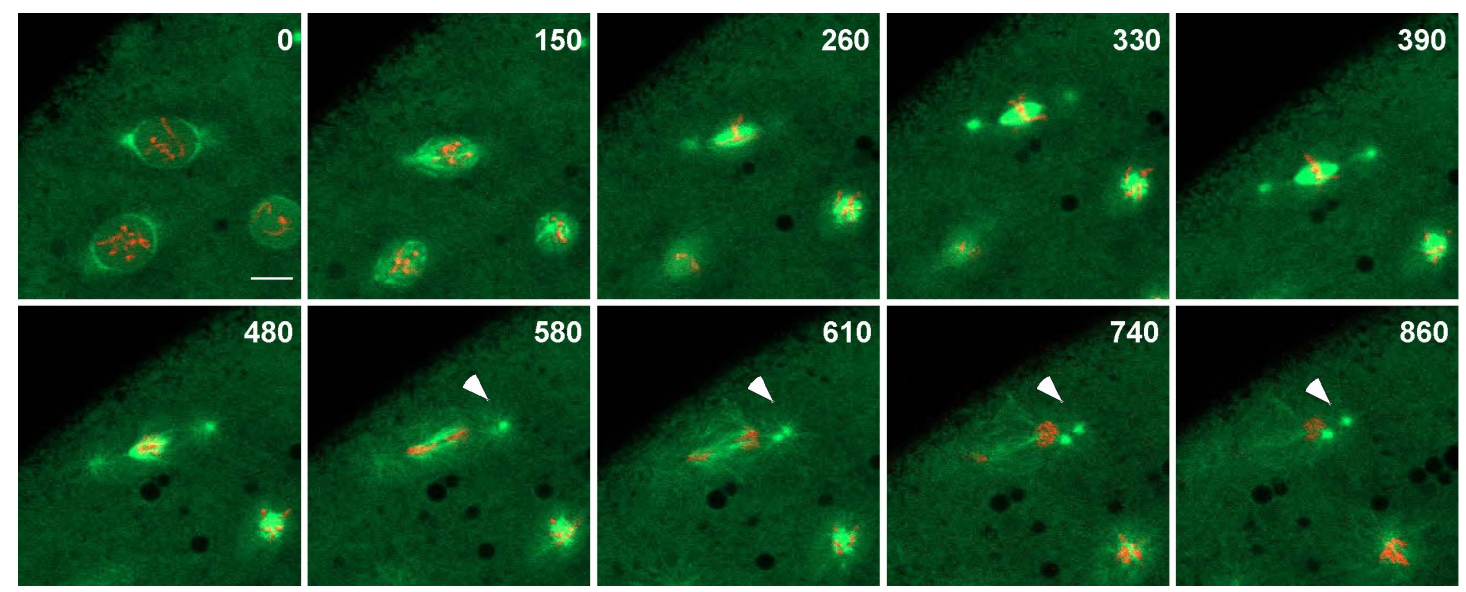

Fig. 17 chromosome segregation and premature centrosome separation in mars $^{91}$ mutant embryos. Chromosomes segregated in a spindle with detached centrosomes and the spindle-associated centrosome split without reattachment to the newly formed nucleus in a mars $^{91}$ mutant embryo. Microtubules were labeled with $\alpha$-tubulin-GFP (green), chromatin was labeled with histone-3B-RFP (red). The centrosome on the right duplicated before the completion of mitosis and one daughter centrosome moved away from the spindle (arrow head in 580, 610, 740, 
$860 \mathrm{sec})$. Scale bar=10 $\mu \mathrm{m}$.

In other cases, chromosomes failed to segregate and were still captured by the remaining monastral bipolar spindle which finally collapsed into a monopolar spindle (Fig. 18).
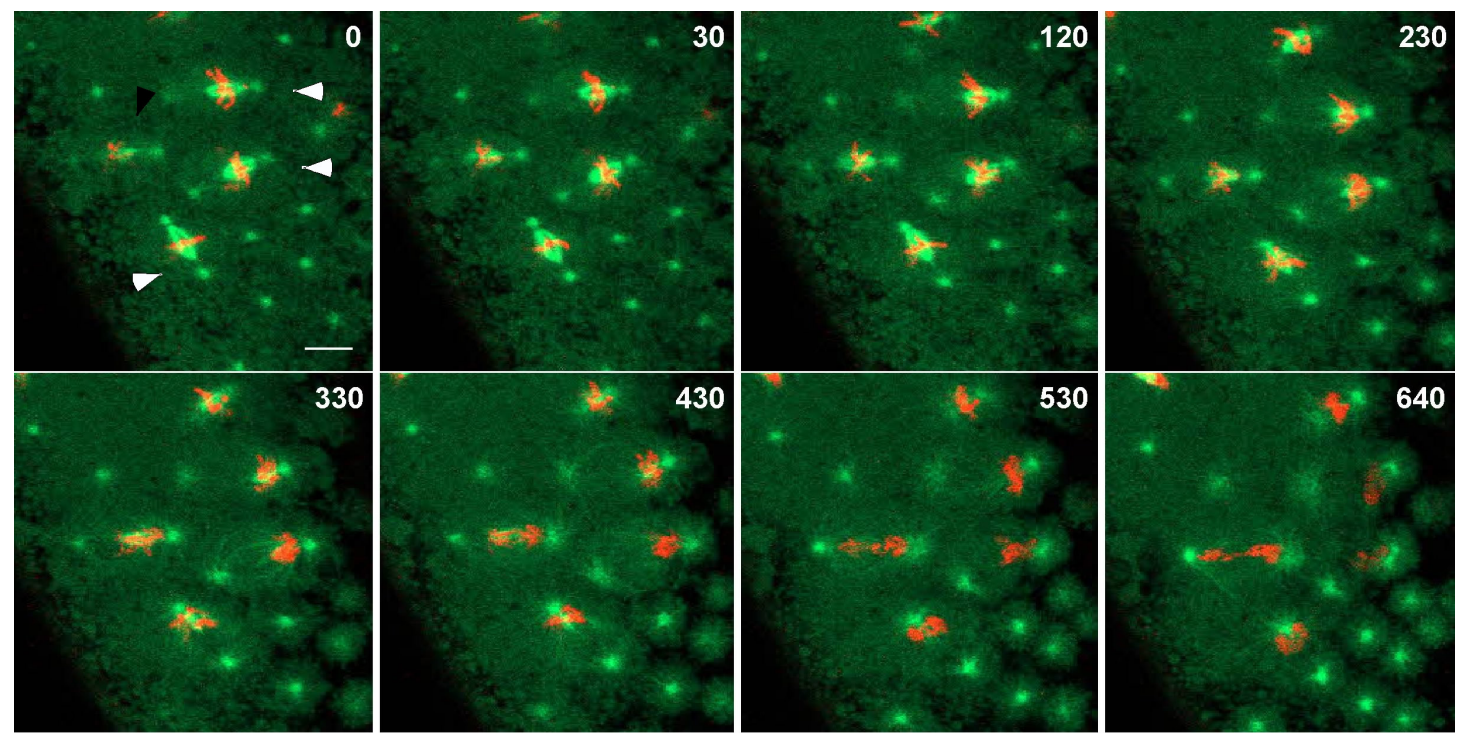

Fig. 18 Chromosome segregation failed in mars $^{91}$ mutant embryos. Chromosomes were not segregated when the mitotic spindles lost centrosomes in a $\operatorname{mars}^{91}$ mutant embryo. Microtubules were labeled with $\alpha$-tubulin-GFP (green), chromatin was labeled with histone-3B-RFP (red). The three spindles with detached centrosomes (arrow heads) could not segregate duplicated chromosomes properly and finally collapsed into monopolar spindles. However, the spindle on the left showed partial chromosome segregation. Scale bar=10 $\mu \mathrm{m}$.

More surprisingly, we also observed the formation of two mitotic spindles sharing one spindle pole as shown in figure 19. During interphase, the newly separated centrosomes started to lose contact with the nuclear envelope (white arrow head, Fig. 19, $210 \mathrm{sec}$ ). The lost centrosome was captured by a neighboring nucleus (Fig. 19, $310 \mathrm{sec}$ ). The original nucleus re-captured the same centrosome which resulted in two nuclei linked by one centrosome (Fig. 19, $710 \mathrm{sec}$ ). Both nuclei entered mitosis by forming mitotic spindles sharing one centrosome (arrow heads, Fig. 19, $1210 \mathrm{sec}$ ). However, the lower spindle did not form properly. The upper one and the pair of spindles beside which also had one pole shared were apparently normal. As a result of 
defective spindle structure, one chromosome with duplicated chromatids was found around the spindle pole and did not move to the metaphase plate (black arrow head, Fig. 19, 1310, 1350, $1370 \mathrm{sec})$. Finally the chromosome went together with the segregated chromatids at anaphase, which resulted in aneuploidy. The upper spindle segregated the chromosomes normally. Together, all the defects uncovered by live imaging of mars mutant embryos were highly consistent with the phenotypic analysis based on stainings of fixed embryos.
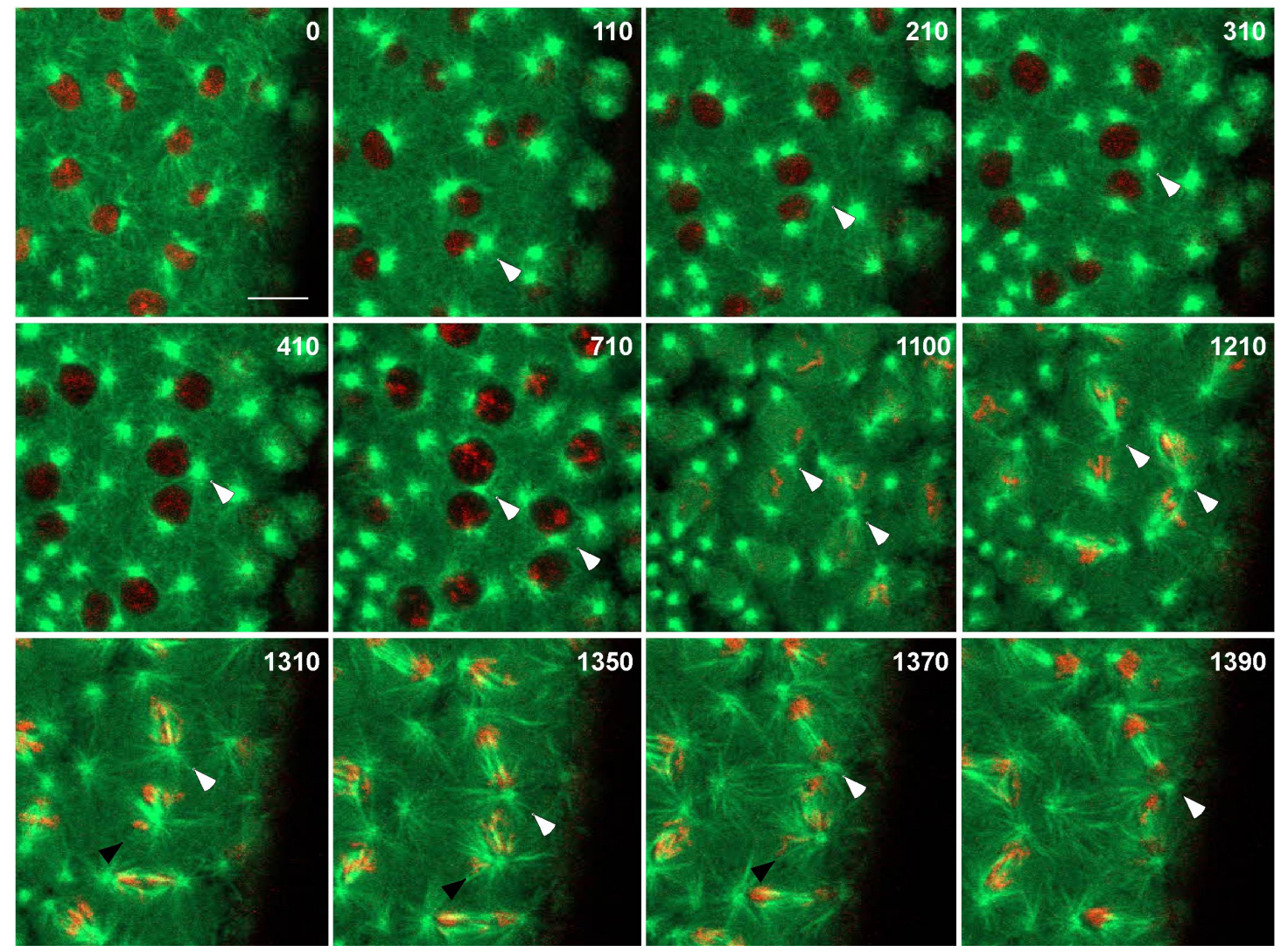

Fig. 19 Mitotic spindles sharing centrosomes in mars $^{91}$ mutant embryos. Microtubules were labeled with $\alpha$-tubulin-GFP (green), chromatin was labeled with histone-3B-RFP (red). As indicated by arrowhead, one centrosome detached from the nuclear envelope $(310 \mathrm{sec})$. The lost centrosome was captured by a neighboring nucleus $(410 \mathrm{sec})$ and the two nuclei were linked by it (710 sec). Mitotic spindles started to form in two pairs of nuclei with shared centrosomes (arrowheads, 1100, $1200 \mathrm{sec}$ ). Chromosomes were segregated in the pair of spindles with one centrosome $(1310,1350 \mathrm{sec})$. The lower spindle had chromosomes around the pole which were not aligned at the metaphase plate and did not segregate (black arrowheads, 1310, 1350, $1370 \mathrm{sec}$ ). Scale bar $=10 \mu \mathrm{m}$. 
The vast majority of $\operatorname{mars}^{91}$ mutant embryos did not develop beyond cellularization. In those mutant embryos that looked healthy at later stages of embryonic development, we did not detect major abnormalities in spindle morphology, indicating that Mars is not strictly required for proper spindle formation once the rapid cleavage divisions have been completed. Because the phenotypes of mars mutant embryos were quite similar to those reported for asp mutants, we tested whether these two genes interact genetically. Flies homozygous for $\operatorname{mars}^{91}$ and heterozygous for either $a s p^{l}$ or $a s p^{L l}$ were viable, showing that one intact copy of asp is sufficient to allow normal development in the complete absence of Mars. Flies transheterozygous for $a s p^{l}$ and $a s p^{L 1}$ that were heterozygous for $\operatorname{mars}^{91}$ were also viable, but we neverobtained any doubly mutant flies with the genotype $\operatorname{mars}^{91} / \operatorname{mars}^{91} ; \operatorname{asp}^{1} / \operatorname{asp}^{L 1}$ (n=263), suggesting that the two genes indeed function redundantly.

\subsection{Overexpression of truncated Mars causes mitotic spindle defects}

\section{in embryos}

\subsubsection{Localization of GFP-N Mars in embryos}

To better understand the roles that different portions of Mars play in mitosis, we generated transgenic fly lines with UASP-GFP-N Mars containing the first 430 amino acids and UASP-GFP-C-Mars with the last 491 amino acids. Overexpression of both truncated proteins by the maternal driver mat67-GAL4 caused severe embryonic lethality as less than $10 \%$ of embryos hatched. We first looked at the localization of GFP-N Mars by indirect immunofluorescence microscopy (Fig. 20). From previous studies in Drosophila S2 cells, a microtubule-binding domain and at least one NLS were found within this region. The staining result from embryos was quite consistent with the previous study. GFP-N Mars was recruited into the nucleus during interphase and became detectable on the microtubule asters organized by centrosomes when the nuclear envelop broke down at prometaphase (Fig. 20 A, B). At metaphase, GFP-N Mars localized to the mitotic spindle and moved back into the nucleus when the nuclear envelope reformed at telophase (Fig. 20 C, E). In contrast to full length Mars 
which localized mainly to the kinetochore fibers at anaphase, GFP-N Mars showed strong staining on the central spindle and faint staining on the kinetochore fibers (Fig. 20D). At telophase, the central spindle localized GFP-N Mars was still visible (Fig. 20E). By live imaging, we achieved similar results showing quite a large amount of GFP-N Mars on the central spindles (data not shown). This suggests that the $\mathrm{C}$ region of Mars is required to restrict Mars protein to the kinetochore fibers during anaphase. The mechanism is unknown at the moment.

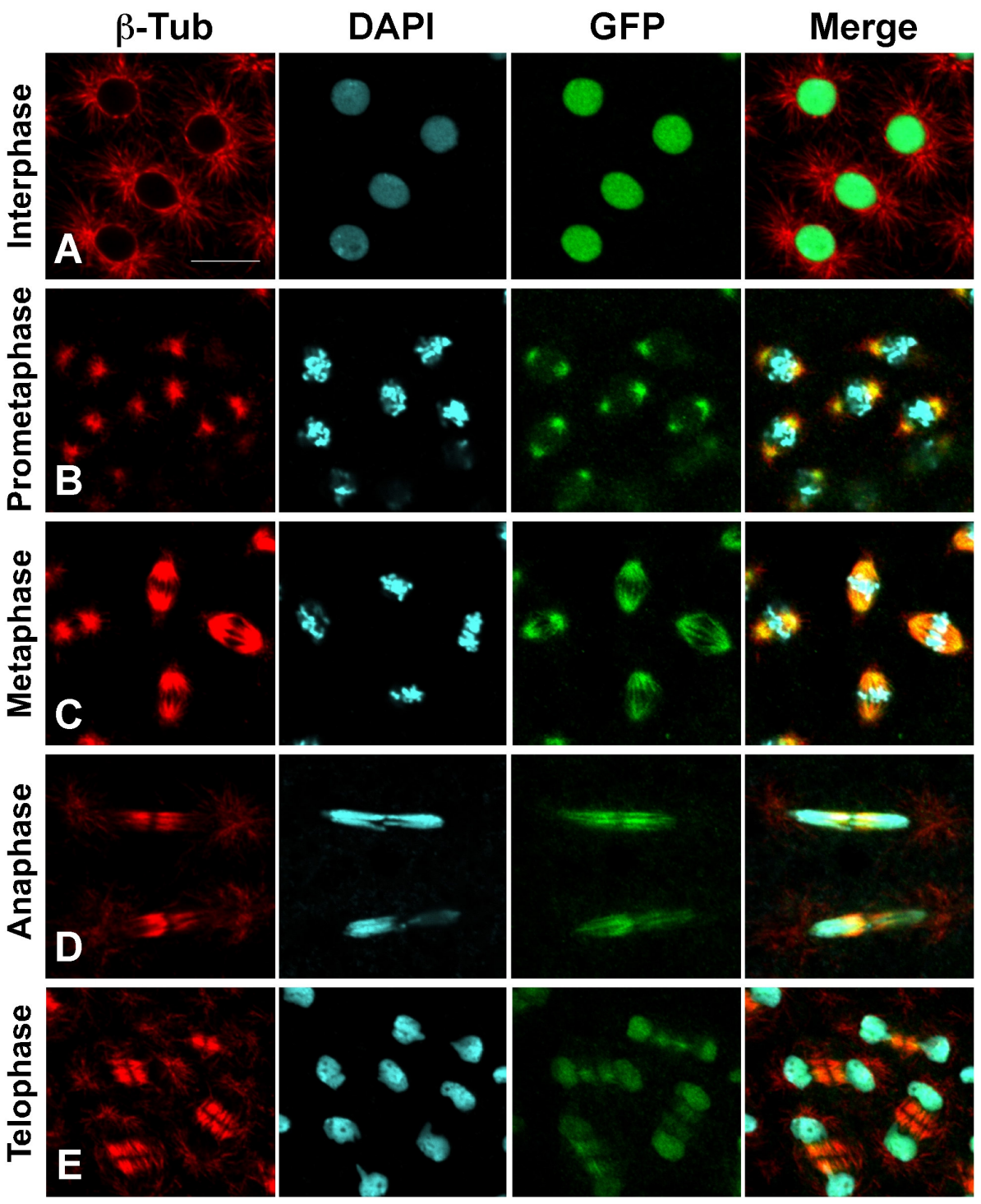

Fig. 20 Localization of GFP-N Mars in embryos. GFP-N Mars shuttles between the nucleus and the mitotic spindle in a similar way as full length Mars. GFP-N Mars was driven by the maternal driver mat67-GAL4. The subcellular localization of GFP-N Mars was analyzed in fixed embryos at the syncytial blastoderm stage. (A) At interphase, GFP-N Mars (green) localizes to the nucleus 
and does not colocalize with $\beta$-tubulin (red). DNA was stained with DAPI (turquoise). (B) At prometaphase after nuclear envelope breakdown, GFP-N Mars colocalizes with $\beta$-tubulin at microtubule asters in the vicinity to the chromatin. (C) At metaphase, GFP-N Mars is present on the mitotic spindle. (D) At anaphase, GFP-N Mars is primarily detected at the central spindle and is faintly detected at the kinetochore fibers. GFP-N Mars is absent on the astral microtubules. (E) At telophase, GFP-N Mars enters the newly formed nuclei and there is still some staining left on the central spindle. Scale bars $=10 \mu \mathrm{m}$.

\subsubsection{Defects caused by overexpression of GFP-N Mars}

Since more than $90 \%$ of embryos with overexpressed GFP-N Mars died, we further investigated these embryos. Within these embryos, the synchrony of spindle formation was lost and the spindles also showed serious defects (Fig. 21A). Similar to the phenotype of the $\operatorname{mars}^{91}$ mutant, overexpression of GFP-N Mars caused the detachment of centrosomes from the mitotic spindle (Fig. 21B). But the remaining spindles without centrosomes did not collapse into monopolar spindles like in the mars $^{91}$ mutant. The poles of the spindles were still well focused (Fig. 21B, C). Those spindles tended to stack together and sometimes even fused into a big mitotic spindle (Fig. 21D). Time lapse analysis shows how two mitotic spindles got close to each other and fused eventually (Fig. 22). Very often, we observed chromosomes around the spindle poles while others were aligned at the metaphase plate. These findings strongly indicate that the MT-kinetochore attachment is affected due to the overexpression of GFP-N Mars. As a result, chromosomes could not be segregated properly as shown by the chromosome bridges at anaphase (Fig. 22E). Compared with mars $^{91}$ mutant embryos, there were more bipolar mitotic spindles including the ones losing centrosomes upon overexpression of GFP-N Mars (Fig. 23). mars $^{91}$ mutant embryos had more than $30 \%$ of monopolar spindles at the cortex while this phenotype was very rare in the embryos with overexpressed GFP-N Mars (Fig. 23). Though the overexpression of GFP-N Mars caused detachment of centrosomes from mitotic spindles by reasons unknown yet, it can apparently stabilize the spindles without centrosomes and prevent the spindle from collapsing. 


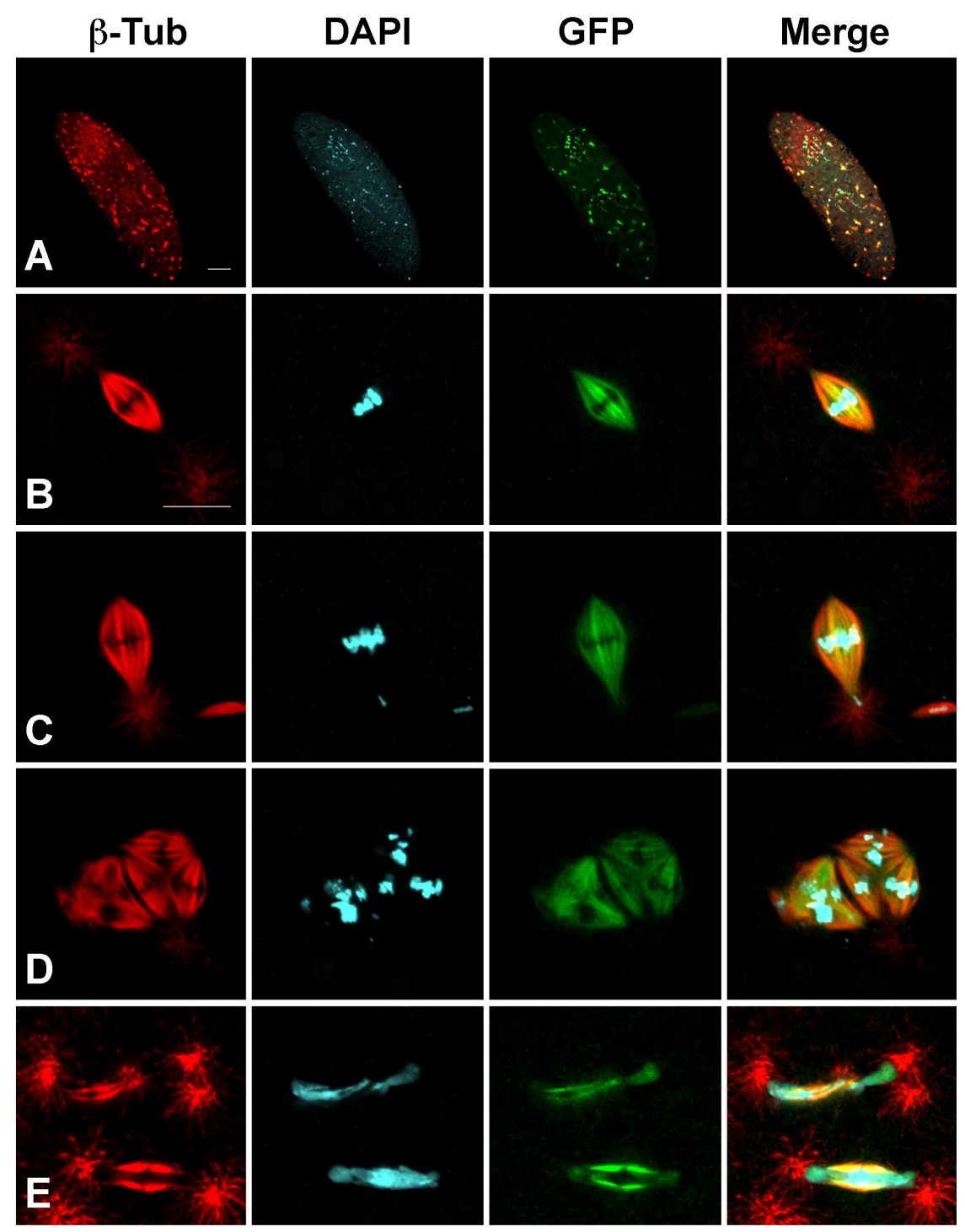

Fig. 21 Defects caused by overexpression of GFP-N Mars in embryos. Embryos with overexpressed GFP-N Mars show severe mitotic defects during cleavage divisions at the syncytial blastoderm stage. (A) In the overview, the nuclei are not evenly distributed and the dividing spindles also lose synchrony. Microtubules were stained with an antibody against $\beta$-tubulin (red), GFP-N Mars was stained by an antibody against GFP (green) and DNA was stained with DAPI (turquoise). (B) The primary defect is the detachment of centrosomes from the mitotic spindle. (C) Chromosomes were found to be around the spindle pole while the others aligned at the metaphase plate. (D) Mitotic spindles without centrosomes stacked together instead of being collapsed into monopolar spindles as in $\operatorname{mars}^{91}$ mutant embryos. (E) Chromosomes could not be segregated properly which caused the formation of chromosome bridges at anaphase. Also the newly separated centrosome moved away from the spindle structure. Scale bar $=50 \mu \mathrm{m}$ in (A) and $10 \mu \mathrm{m}$ 
in (B), (C), (D), (E).
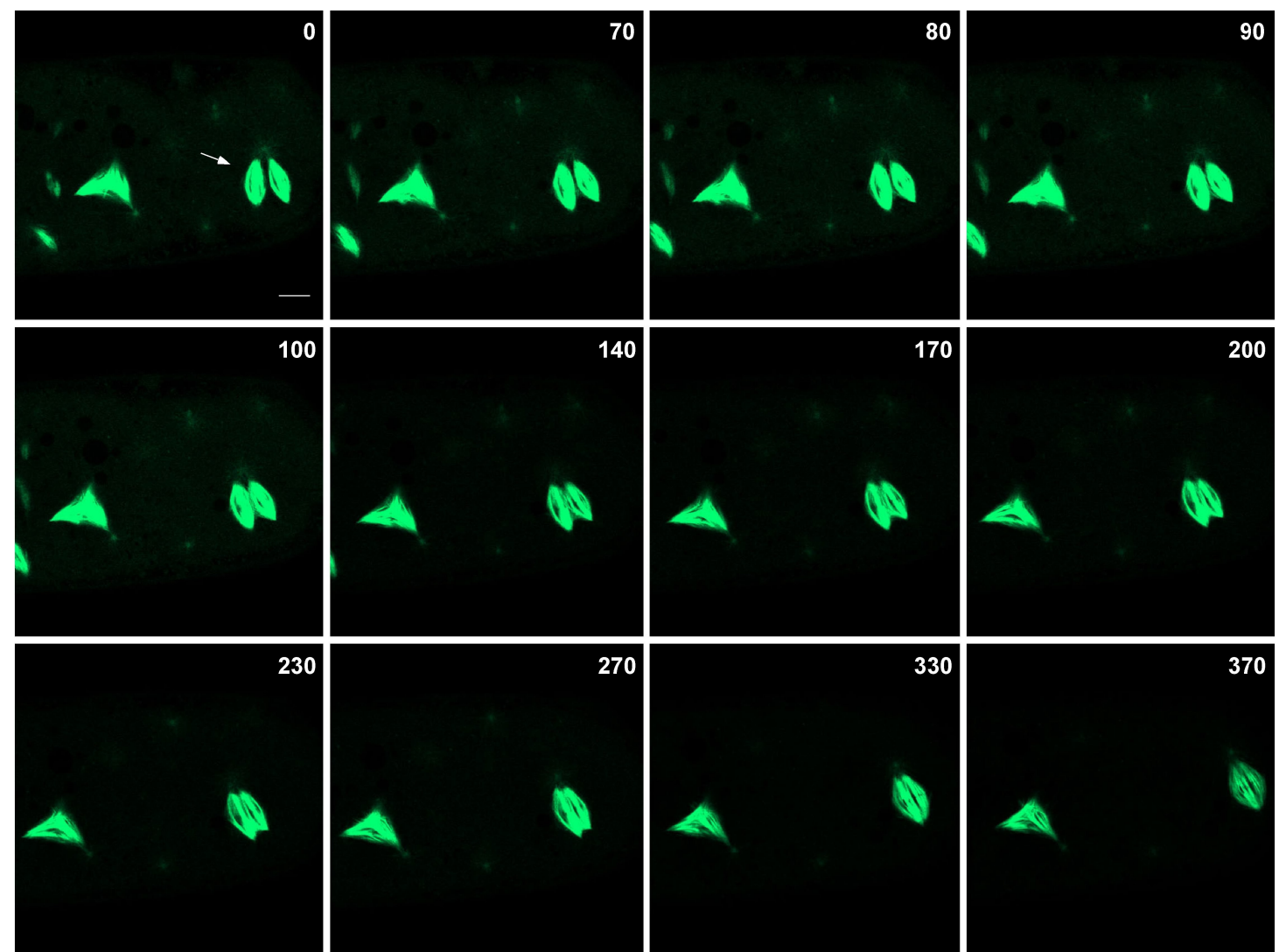

Fig. 22 Spindle fusion in embryos with overexpressed GFP-N Mars. GFP-N Mars was driven by maternal driver mat67-GAL4. The dynamics of GFP-N Mars was recorded by live imaging from embryos. Two mitotic spindles labeled by GFP-N Mars happened to get close to each other. Then the two spindles fused into a relatively large spindle at the end. Scale bar=10 $\mu \mathrm{m}$.

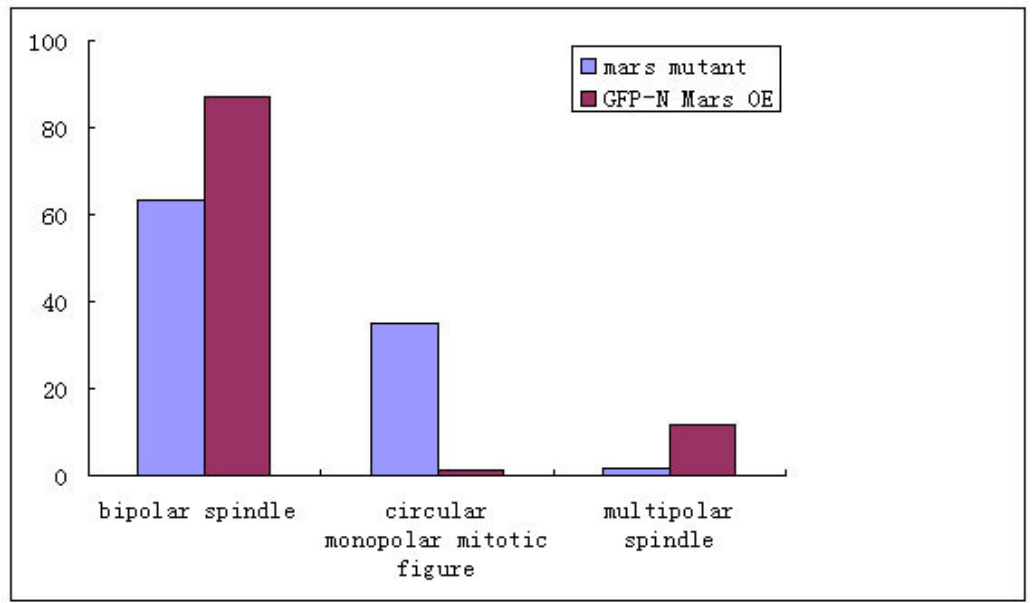

Fig. 23 Comparison of mitotic spindle phenotypes in mars $^{91}$ mutant embryos and in embryos with overexpressed GFP-N Mars. The mitotic spindles were classified into three types, bipolar 
spindle, monopolar spindle and multipolar spindle in this figure. The embryos with overexpression of GFP-N Mars had more bipolar spindles including the ones that lost one or two centrosomes, and more multipolar spindles than mars $^{91}$ mutant embryos. In contrast, mars $^{91}$ mutant embryos showed many more monopolar spindles, which were very rare in the embryos with overexpressed GFP-N Mars. The results indicate that overexpression of GFP-N Mars can stabilize the mitotic spindles without centrosomes and prevent the spindle collapse.

\subsubsection{Localization of GFP-C Mars}

The localization of GFP-C Mars was also examined in embryos (Fig. 24). As shown in Fig. 9 and Fig. 10, the last 521 amino acids contain at least one NLS. Consistent with the previous work, the truncated protein was found in the nucleus during interphase. Unlike the full length Mars or the GFP-N Mars, it only faintly stained the mitotic spindle during metaphase. This faint staining may be caused by the trapped GFP-C Mars within the nuclear envelope, which does not completely break down during metaphase.

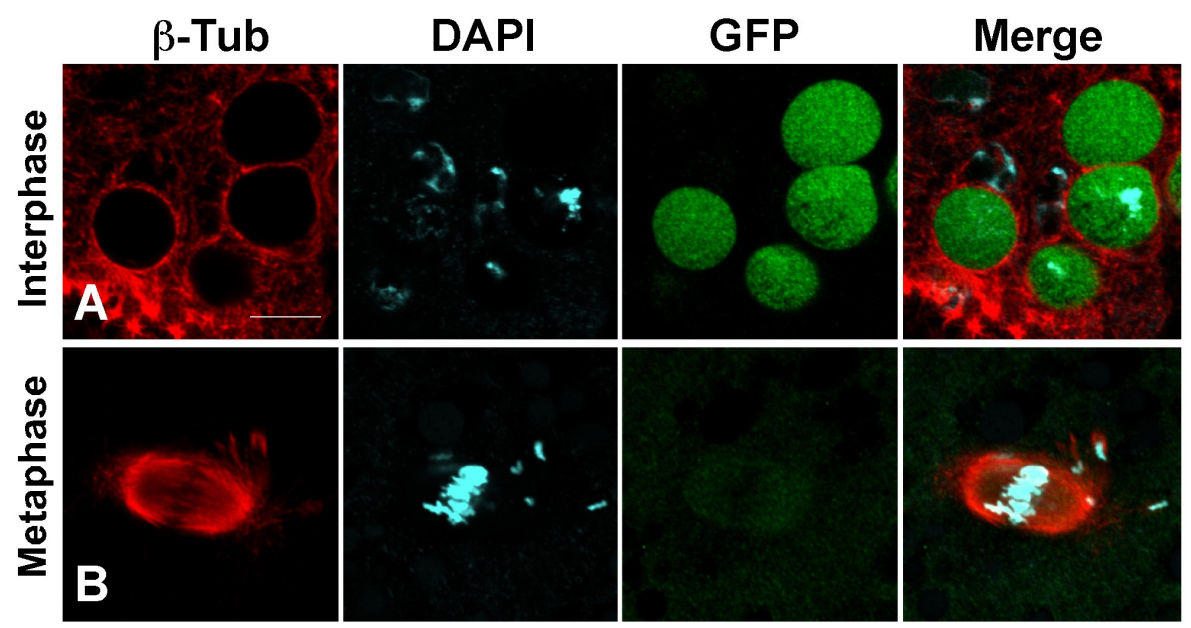

Fig. 24 Localization of GFP-C Mars in embryos. GFP-C Mars was driven by maternal driver mat67-GAL4 in embryos. Fixed embryos were stained by an antibody against $\beta$-tubulin (red), an antibody against GFP (green) and DAPI for DNA (turquoise). (A) At interphase, GFP-C Mars was found in the nucleus. (B) At metaphase, GFP-C Mars only showed very faint staining around the mitotic spindle. This was probably due to the incomplete breakdown of the nuclear envelope.

\subsubsection{Defects caused by overexpression of GFP-C Mars}


The defects caused by overexpression of GFP-C Mars were examined in fixed embryos (Fig. 25). The most significant defect was the existence of some big nuclei as shown by DAPI staining in Fig. 25A. The time lapse showed that this phenotype was caused not only by the improper segregation of chromosomes but also by the fusion of interphase nuclei (Fig. 25E, Fig. 26 arrow heads). Though GFP-C Mars did not show strong staining on the mitotic spindle, overexpression of it caused severe mitotic spindle defects perhaps by interfering with the activity of proteins important for spindle organization. The mitotic spindles were loosely organized and the poles were not focused (Fig. 25C). There were also multipolar spindles with long astral microtubules (Fig. 25D). The defective spindles also affected the proper segregation of chromosomes as shown by the chromosome bridge in Fig. 25E.

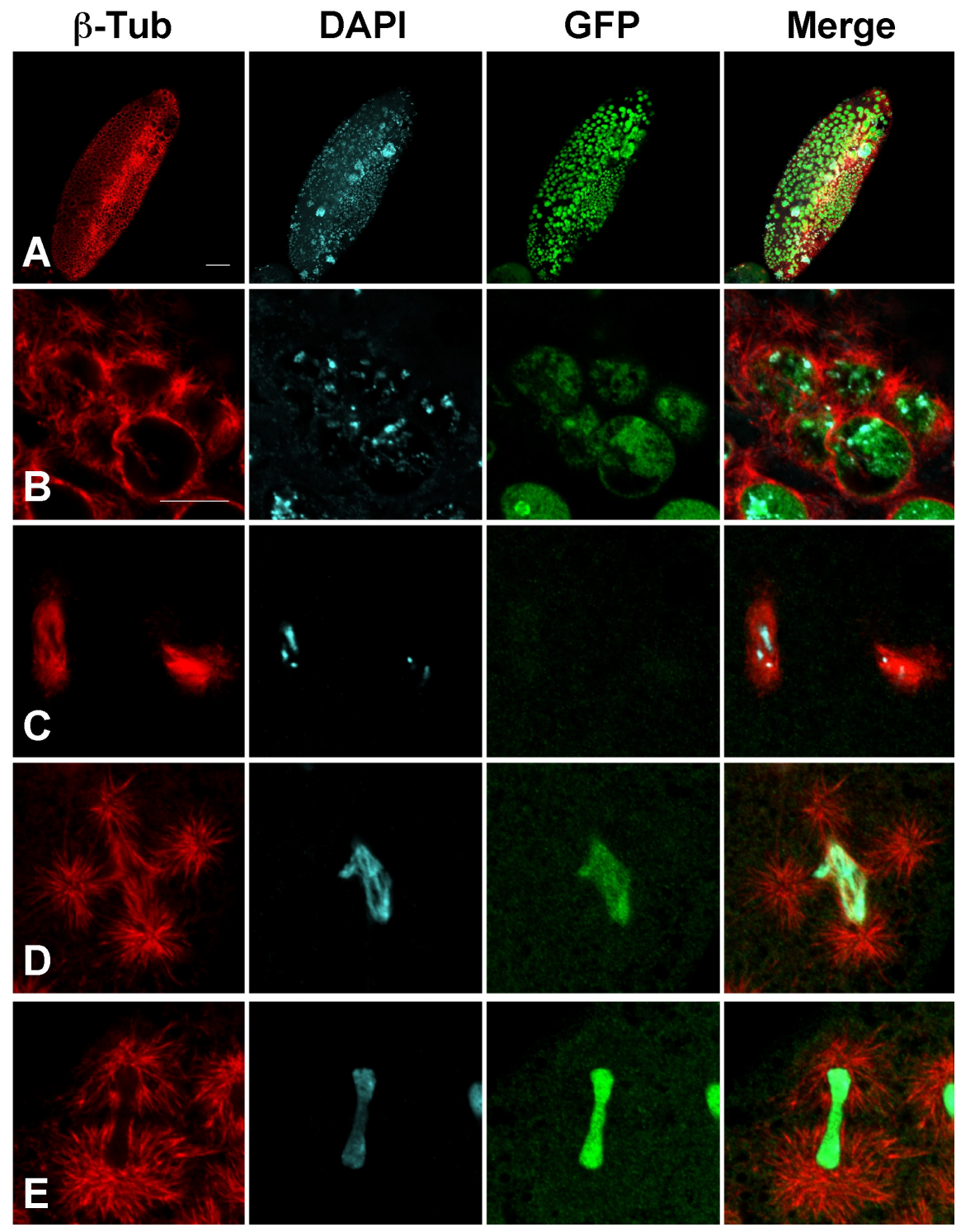


Fig. 25 Defects caused by overexpression of GFP-C Mars in embryos. GFP-C Mars was driven by maternal driver mat67-GAL4. Fixed embryos were stained with an antibody against $\beta$-tubulin (red), an antibody against GFP (green) and DAPI for DNA (turquoise). (A) The overview figure showed one embryo with unevenly spaced nuclei at different sizes. (B) GFP-C Mars is in the nucleus at interphase. However, the sizes of nuclei are very different. Some are much larger than others. (C) Some mitotic spindles are poorly organized and the poles are not focused. (D) Multipolar spindle is also observed in the embryos with robust astral microtubule at the poles. (E) Chromosome bridge indicates the failure of proper chromosome segregation.
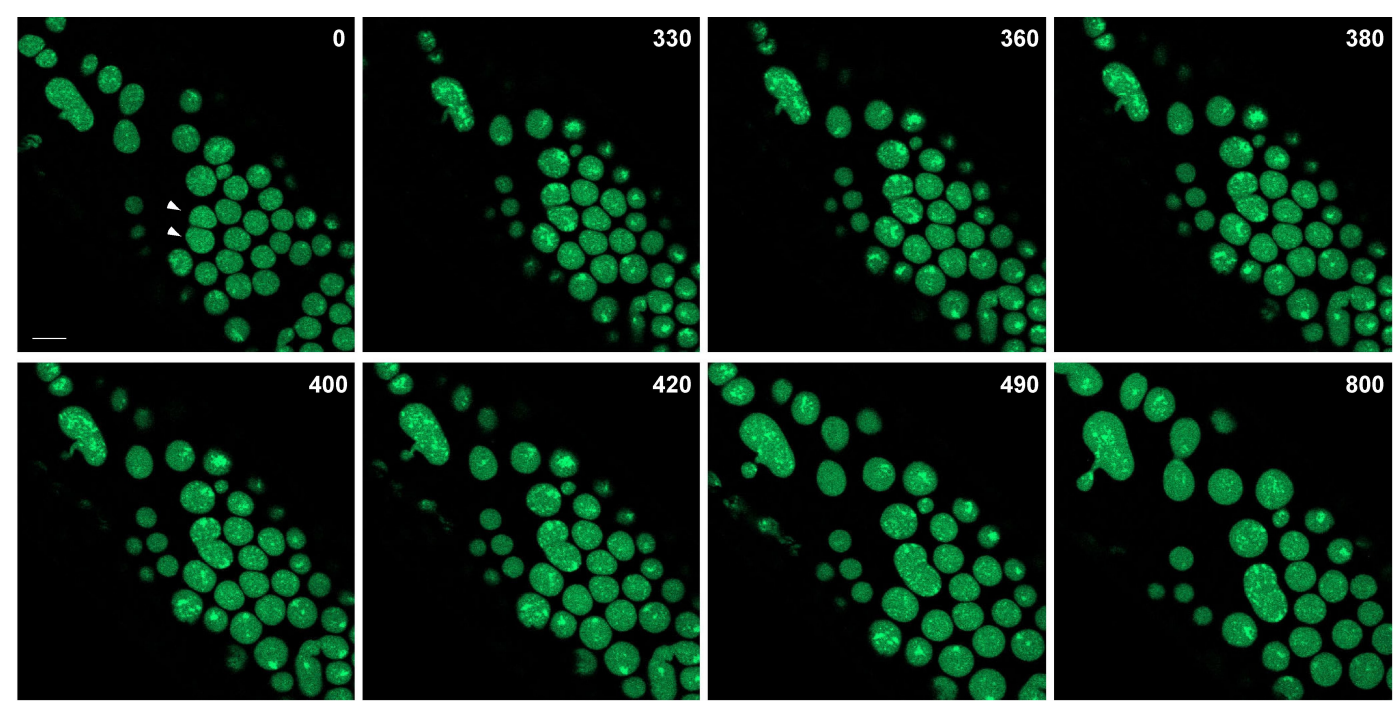

Fig. 26 Nuclear fusion caused by overexpression of GFP-C Mars in embryos. GFP-C Mars was driven in embryos by maternal driver mat67-GAL4. The dynamics of GFP-C Mars was recorded by live imaging from embryos. As indicated by arrows, two nuclei at interphase started to touch and finally fused into a big nucleus which contributes partially to the significant size difference of interphase nuclei.

\subsubsection{Endogenous Mars in the presence of overexpressed GFP-N and C Mars}

Since the overexpression of GFP-N Mars also caused centrosome detachment as in the $\operatorname{mars}^{91}$ mutant, we tested whether the endogenous Mars was affected by staining and Western blot. Using the antibody specific for either the N-terminal or the C-terminal region of Mars, endogenous Mars could be distinguished from the overexpressed GFP-C or N Mars. As shown in figure 27A, the endogenous Mars was significantly reduced in nuclei at interphase and on mitotic spindles at metaphase in 
the embryos with overexpressed GFP-N Mars, compared to wild type embryos. This may be caused by competitive binding to importins or microtubule binding sites on mitotic spindles between GFP-N Mars and endogenous Mars. However, Western blot did not show a significantly reduced signal from the endogenous Mars (data not shown). In the case of GFP-C Mars, there was no obvious difference between wild type embryos and overexpression embryos on the mitotic spindles (Fig. 27B). The antibody directed against the N-terminal region of Mars did not detect Mars in nuclei at interphase (data not shown).

A

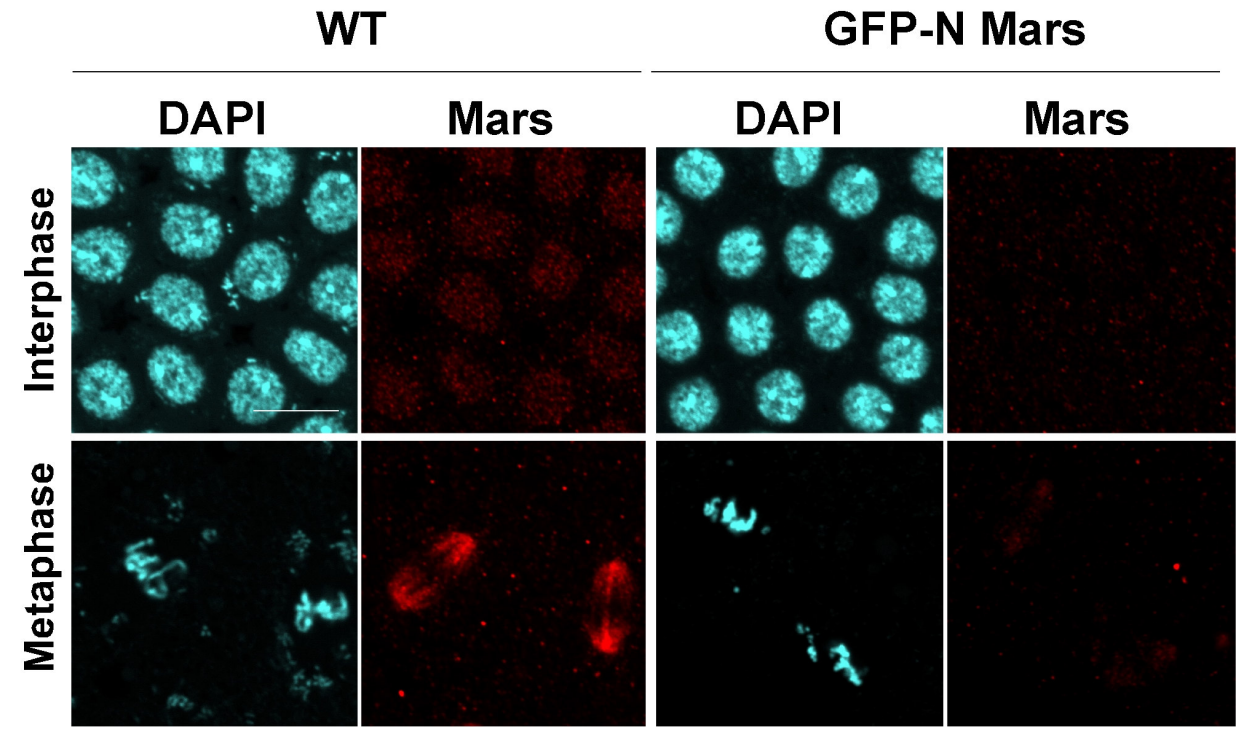

B

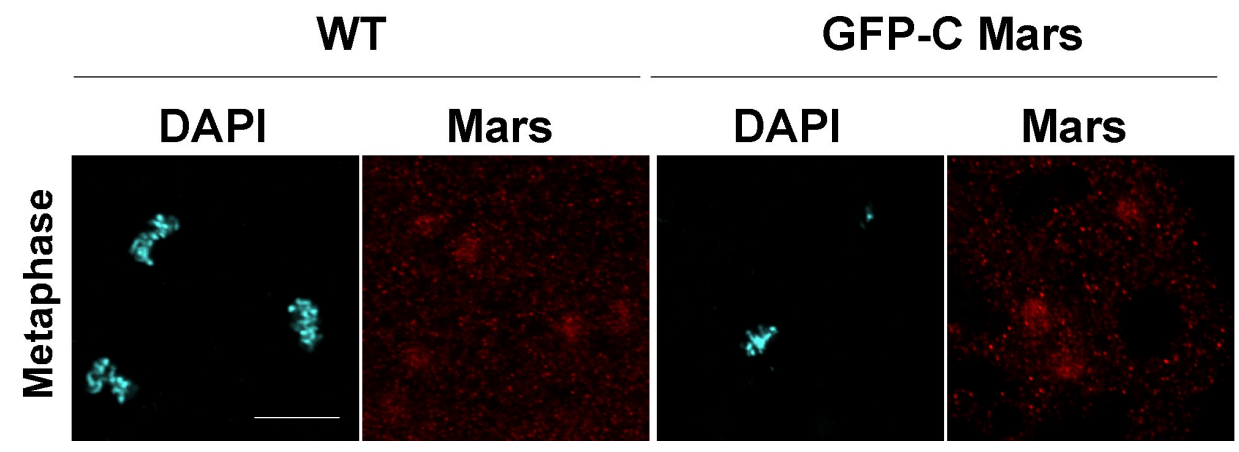

Fig. 27 Endogenous Mars in the presence of overexpressed GFP-N and C Mars in embryos. Fixed embryos were stained with DAPI for DNA (turquoise) and antibodies specific for the C-terminal or the N-terminus of Mars (red). (A) Staining for endogenous Mars was much weaker in nuclei and on mitotic spindles in the embryos with overexpressed GFP-N Mars than in wild 
type embryos under the same conditions. (B) Staining for endogenous Mars was not significantly different on mitotic spindles with overexpressed GFP-C Mars compared to wild type spindles. The antibody against the $\mathrm{N}$-terminus of Mars was not sensitive enough to detect endogenous Mars in the nucleus (data not shown).

\subsection{Regulation of Mars translocation and function}

\subsubsection{Phosphorylation study of Mars}

It was already known that phosphorylation controls the activity of some MAPs as described in the introduction. For Mars, it was also reported to be highly phosphorylated during the cell cycle (Yang and Fan, 2008). But the phosphorylation sites, the kinases involved and the biological significance have not been studied yet. To understand the molecular mechanisms of the translocation and function of Mars, we decided to investigate the phosphorylation of Mars.

In collaboration with the mass spectrometry lab of Dr. Henning Urlaub at the Max-Planck Institute of Biophysical Chemistry in Goettingen, we analyzed the phosphorylation status of GFP-Mars protein in vivo. First, we pulled down GFP-Mars from transgenic embryo lysate by GFP-Trap beads, which has a very high affinity to the GFP antigen. GFP-Mars and other bound proteins were eluted from the beads by boiling in $2 \times$ SDS sample buffer. The samples were digested by trypsin and phospho-peptides were enriched by $\mathrm{TiO}_{2}$. Phosphorylated sites were analyzed by liquid-chromatography tandem mass spectrometry (LC-MS/MS). S16, S49, T51 and S76 were found to be phosphorylated in our sample. Besides the mass spectrometry analysis, we also checked the databases from two large-scale screens for phosphorylation sites of proteins isolated from Drosophila cells and embryos (Zhai et al., 2008; Bodenmiller 2007). PhosphoPep, the database of phosphorylated sites in Drosophila Kc167 cells was generated by Bodenmiller and colleagues. They identified over 10,000 high-confidence phosphorylation sites from 3472 gene products. For Mars, there are 16 sites which were found to be phosphorylated. 11 of them are highly confident and 5 are ambiguous (table 3 ). The second database from 
Drosophila embryos contains 13,720 phosphorylated sites from 2702 proteins (Zhai et al., 2008). Mars was found phosphorylated at 24 sites including 13 sites with high confidence and 11 with ambiguity (table 3). The differences among these two databases and our own data may be due to the stage difference between embryos and cells. It may also be explained by the fact that the reproducibility of phosphorylation site identification is quite low at the moment (Heck A., personal communication).

\begin{tabular}{|c|c|c|}
\hline $\begin{array}{l}\text { Amino } \\
\text { acids }\end{array}$ & Peptides identified & $\begin{array}{l}\text { Phosphate } \\
\text { detected }\end{array}$ \\
\hline $11-17$ & QSLVLSP & 1 \\
\hline $45-56$ & IISVSPTPVKIK & 2 \\
\hline $58-78$ & LAAAQAALTQEDVAPKLESPE & 1 \\
\hline $168-180$ & RCSLYMIANPTGK & 2 \\
\hline $267-280$ & ITTTIPRPTPATVT & 2 \\
\hline $426-450$ & SNNSSGHLLEAFGDTILLSPVAPVK & 4 \\
\hline $483-523$ & $\begin{array}{c}\text { YSVANSPAEDSLILDPQQTTVKEDTGDST } \\
\text { VPEGTKTPPRR }\end{array}$ & 2 \\
\hline $524-539$ & ESNGMPNYLSPFVSVS & 1 \\
\hline $552-567$ & RNSFYLSNEESPLEVR & 1 \\
\hline $743-765$ & TKVEEPTLEDGLPATSSRHSSPR & 2 \\
\hline 775-778 & FSPA & 1 \\
\hline $784-800$ & MSTGEGRQSIAPNALLK & 2 \\
\hline 792-799 & SIAPNALL & 1 \\
\hline $802-819$ & AILAAAEQNAAKTPPPKP & 1 \\
\hline $821-832$ & TSILKTPGTTKR & 5 \\
\hline $836-843$ & GVLFSAKK & 1 \\
\hline
\end{tabular}

Table 3 phosphorylated sites detected in vivo by mass spectrometry. GFP-Mars was captured by GFP Binder from GFP-Mars embryo lysate. The sample was separated by SDS-PAGE and the corresponding bands were treated for mass spectrometry. Mass spectrometry identified four peptides which were phosphorylated in vivo. These four peptides are the first four peptides in the 
table. The remaining 12 peptides were found in two databases for in vivo phosphorylated sites from Drosophila embryos and Kc167 cells. From the 16 peptides, 29 sites are supposed to be phosphorylated in vivo. Among them, 18 sites are very likely to be phosphorylated (blue letter), while the rest are ambiguous (red letter).

We think that the phosphorylation sites with high significance are likely to be phosphorylated in vivo and decided to investigate the following sites: S16, S49, T51, S76, S170, T275, T280, S426, S444, T519, S525, S554, S785, S792, T814, T826, T829 and S840. Using an online program called ELM for predicting functional sites in eukaryotic proteins (http://elm.eu.org), these sites could be divided into three groups according to three potential kinases. Group one including S16, S49, T51, S76, T275, S444, T519, T814 and S840 may be phosphorylated by proline-directed kinases such as GSK3, mitogen-activated protein kinases and cyclin-dependent kinase Cdc2. Group 2 including S170, T275, S525, S554, S785 and S792 fit the phosphorylation consensus of protein kinase A. Protein kinase $\mathrm{C}$ is supposed to phosphorylate the sites in group three which are T280, S426, T829 and S840 (Fig. 28). To understand the biological function of phosphorylation on these sites, we generated non-phosphorylatable and phospho-mimetic constructs of these sites by mutating S/T into $\mathrm{A} / \mathrm{E}$ according to different groups. We also made two mutant plasmids with all the sites mutated into A or E. We plan to generate transgenic flies with these mutant constructs in the near future. The dynamics and functionality of mutated proteins will then be analyzed. Preliminary data from overexpression of GFP-Mars ${ }^{9 \mathrm{~A}}$ and GFP-Mars $^{18 \mathrm{~A}}$ in Drosophila S2r cells showed very high frequency of chromosome bridges during anaphase (data not shown). This indicates that phosphorylation may play critical roles in the functionality of Mars. 

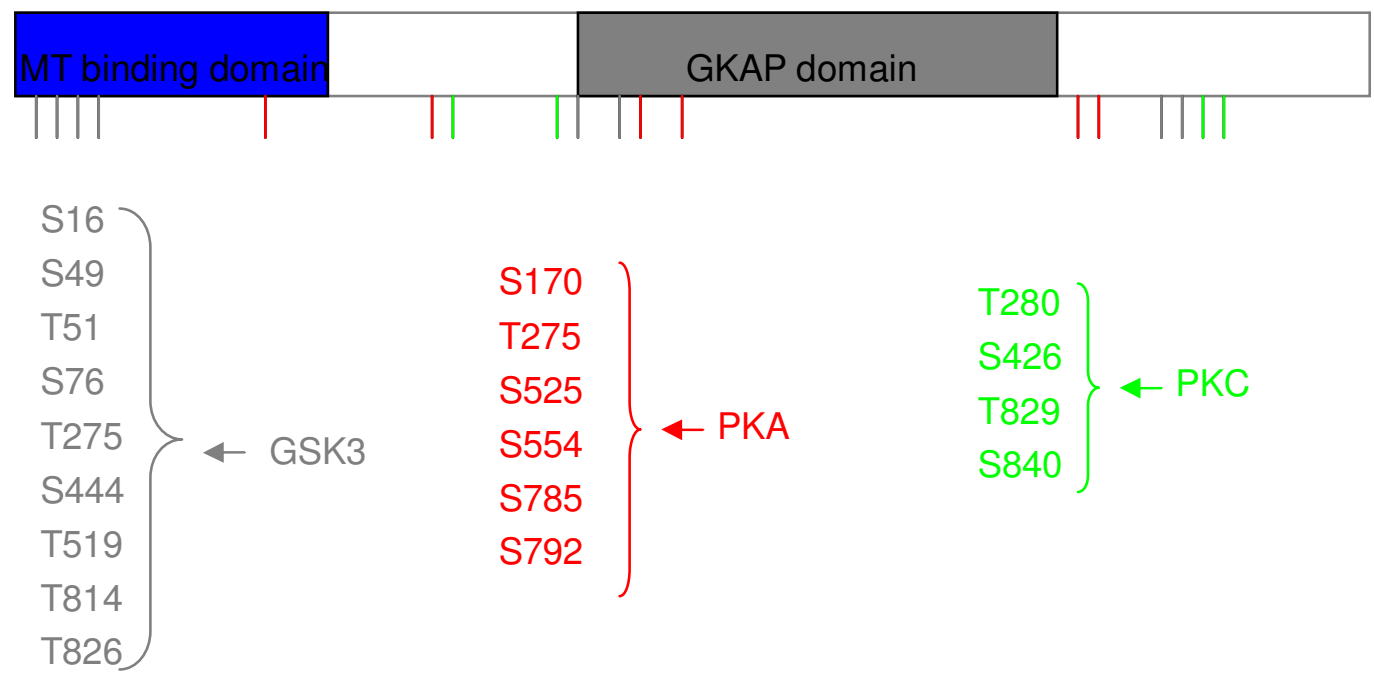

Fig. 28 Phosphorylation sites of Mars and potential kinases for the phosphorylation. 18 Ser or Thr residues of Mars have been found to be phosphorylated in vivo. Those sites could be divided into three groups by the potential kinases such as GSK3, PKA and PKC which may be required for the phosphorylation.

\subsubsection{Mars and Polo kinase}

To find interaction partners of Mars, we searched a Drosophila Interaction Database (www.droidb.org) based on yeast-two-hybrid screening. Mars was found to interact with Polo kinase with high confidence (Fig. 29). To test the interaction between Mars and Polo kinase, we first did in vitro kinase assays. GST-Mars N400 containing the first 400 amino acids and GST-Mars C521 with the last 521 amino acids were purified by glutathione-Sepharose beads (Fig. 30A, arrow heads). Western blot with antibody against GST and C-terminus of Mars was performed to confirm the quality of the purification (Fig. 30B). Kinase assays with commercial Polo kinase were conducted according to standard procedures. Strong signals were detected on the X-ray sensitive film which means that Polo kinase can phosphorylate Mars protein in vitro (Fig. 30C). 19 phosphorylation sites were identified by mass spectrometry (Table 3). Among them, three sites at S493, T511 and T749 fit well to the classic Polo kinase phosphorylation consensus, (.[DE].[ST] [ILFWMVA]..) (http://elm.eu.org). Unfortunately, these three sites were not found to be phosphorylated in vivo (table 2). We can not exclude the possibility that the other sites may be the targets for Polo kinase in vivo since the 
following sites were actually found in vivo: S554, S785, S792, T814, T826 and T829. However, other kinases are proposed to be more likely to phosphorylate these sites (Fig. 28). It is also possible that the two databases did not cover the full length Mars protein and may have missed some phosphorylation sites. Besides the in vitro kinase assays, we also did a genetic interaction assay between mars $^{91}$ mutant flies and polo $^{1}$ mutant flies. We found that introducing one mutant copy of the polo ${ }^{1}$ allele did not affect the viability of homozygous $\operatorname{mars}^{91}$ mutant flies.

\begin{tabular}{|l||l|l|l|l|}
\hline Symbol1 & Symbol2 & Conflence & Found In & Select \\
\hline \hline flw & mars & .371 & Other physical interactions & $\checkmark$ \\
\hline Mer & mars & .392 & Hybrigenics yeast two-hybrid & $\checkmark$ \\
\hline polo & mars & .408 & Hybrigenics yeast two-hybrid & $\checkmark$ \\
\hline \hline Pp1-13C & mars & .301 & Other physical interactions & $\checkmark$ \\
\hline Pp1-57B & mars & .211 & Other phys|cal interactions & $\checkmark$ \\
\hline Ppla-96A & mars & .21 & Other physical interactions & $\checkmark$ \\
\hline
\end{tabular}

Fig. 29 Interaction between Mars and Polo kinase by Y2H screening. Mars and Polo were found to interact in the Drosophila Interaction Database. Protein phosphatase 1 (PP1), Mer and flw have also been found to interact with Mars.
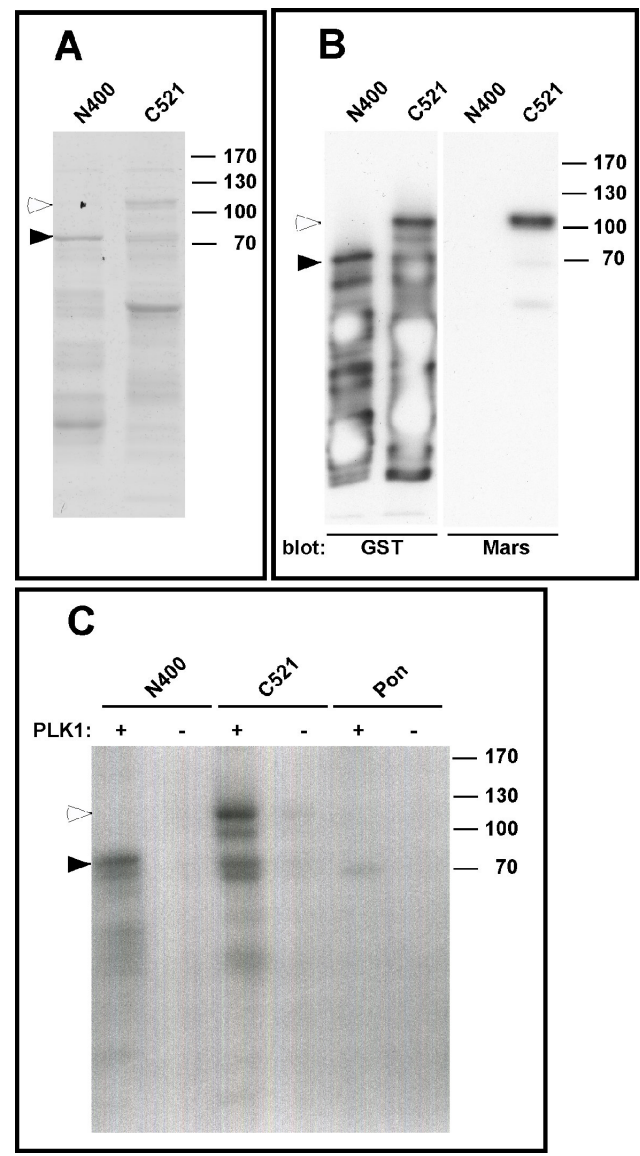
Fig. 30 in vitro kinase assay of GST-Mars by Polo kinase. In vitro kinase assay shows that Mars can be phosphorylated by Polo kinase. (A) Truncated GST-N400 and GST-C521 were purified by glutathione-Sepharose beads (arrow heads). There are some degraded or unspecific proteins as shown by Coomassie blue staining. (B) The purified proteins were confirmed by Western blotting with both GST antibody and Mars antibody. The GST antibody gave quite high background which was probably due to the degradation of GST fusion proteins during purification. However, the top bands in both lanes were distinguishable and fit the predicted sizes (arrow heads). The Mars antibody against C-terminal end detected one band at the right size in the GST-C521 sample as expected. (C) in vitro kinase assay with Polo kinase did phosphorylate both N400 and C521 Mars as shown by the strong signals at the expected positions (arrow heads). Truncated Pon protein was used as positive control. However the purification of Pon protein did not work well and the in vitro assay only gave one faint band around $70 \mathrm{kD}$.

\begin{tabular}{|c|c|c|}
\hline Amino acids & Peptides identified & $\begin{array}{c}\text { phosphates } \\
\text { detected }\end{array}$ \\
\hline $45-54$ & IISVSPTPVK & 1 \\
$142-154$ & SQTFRVPDNLASA & 1 \\
$282-288$ & AKTPGIR & 1 \\
$351-360$ & FKDTAGATSK & 1 \\
$375-385$ & SQYTRLQKNVR & 1 \\
$483-504$ & YSVANSPAEDSLILDPQQTTVK & 1 \\
$505-518$ & EDTGDSTLVPEGTK & 1 \\
$553-567$ & NSFYLSNEESPLVER & 1 \\
$605-622$ & LQETGGIDMINVTIGQTR & 1 \\
$743-760$ & TKVEEPTLEDGLPATSSR & 2 \\
$774-783$ & SFSPARTVLR & 2 \\
$780-790$ & TVLRMSTGEGR & 1 \\
$791-800$ & QSSIAPNALLK & 1 \\
$801-820$ & SAILAAAEQNAAKTPPPKPR & 1 \\
$821-831$ & TSILKTPGTTK & 1 \\
\hline
\end{tabular}




\begin{tabular}{|c|c|c|}
\hline $893-908$ & DSNQENEATPRTYTLR & 1 \\
$911-921$ & RVNLRPSSEFM & 1 \\
\hline
\end{tabular}

Table 3 in vitro phosphorylated sites on Mars by Polo kinase. GST-N400 and C521 Mars proteins were incubated with Polo kinase at $30^{\circ} \mathrm{C}$ for $20 \mathrm{~min}$. The reaction mixture was separated by SDS-PAGE. The corresponding bands were cut and treated as required for mass spectrometry. Mass spectrometry identified 19 sites which were phosphorylated by Polo kinase as shown in the table. Three of the peptides included sequences fitting well with the classic Polo phosphorylation consensus (blue letters).

\subsubsection{Mars and Ran-GTP}

The Ran-GTP pathway has been well studied in human cell culture systems and Xenopus embryos and was found to be very important for the assembly of mitotic spindles by releasing the inhibition of spindle assembly factors by importins (Clark and Zhang, 2008, Walczak and Heald, 2008). For example, NuMA, NuSAP, TPX2 and HURP are all regulated by this pathway in human cell culture or Xenopus embryos (Joukov et al., 2006, Ribbeck et al., 2006, Gruss et al., 2001, Koffa et al., 2006, Sillje et al., 2006). Is Mars also regulated by Ran-GTP pathway in the Drosophila cell system? Since there are no available Ran GTPase (CG1404) mutant flies, we decided to work on Drosophila S2r cells for this question. We generated Ran mutant T24N and L43E constructs which mimic GDP and GTP bound Ran, respectively, and expressed these constructs in S2r cells. As predicted, Ran T24N showed strong signals binding to the condensed chromosomes at the mitotic plate while Ran L43E did not show specific localization (Fig. 31 and data not shown). However, in the first case, mitotic spindles were still properly assembled (Fig. 31A). Mars also showed specific staining on mitotic spindles in the presence of RanT24N, which is unlike the reported cases in human cells or Xenopus embryos (Fig. 31B). As a further test, we transfected S2r cells with importin $\beta$. Again, the assembly of mitotic spindles was not affected and Mars showed normal localization on the mitotic spindles (data not shown). These data show that the Ran-GTP pathway may not play an essential role in regulating spindle assembly in Drosophila cells. 

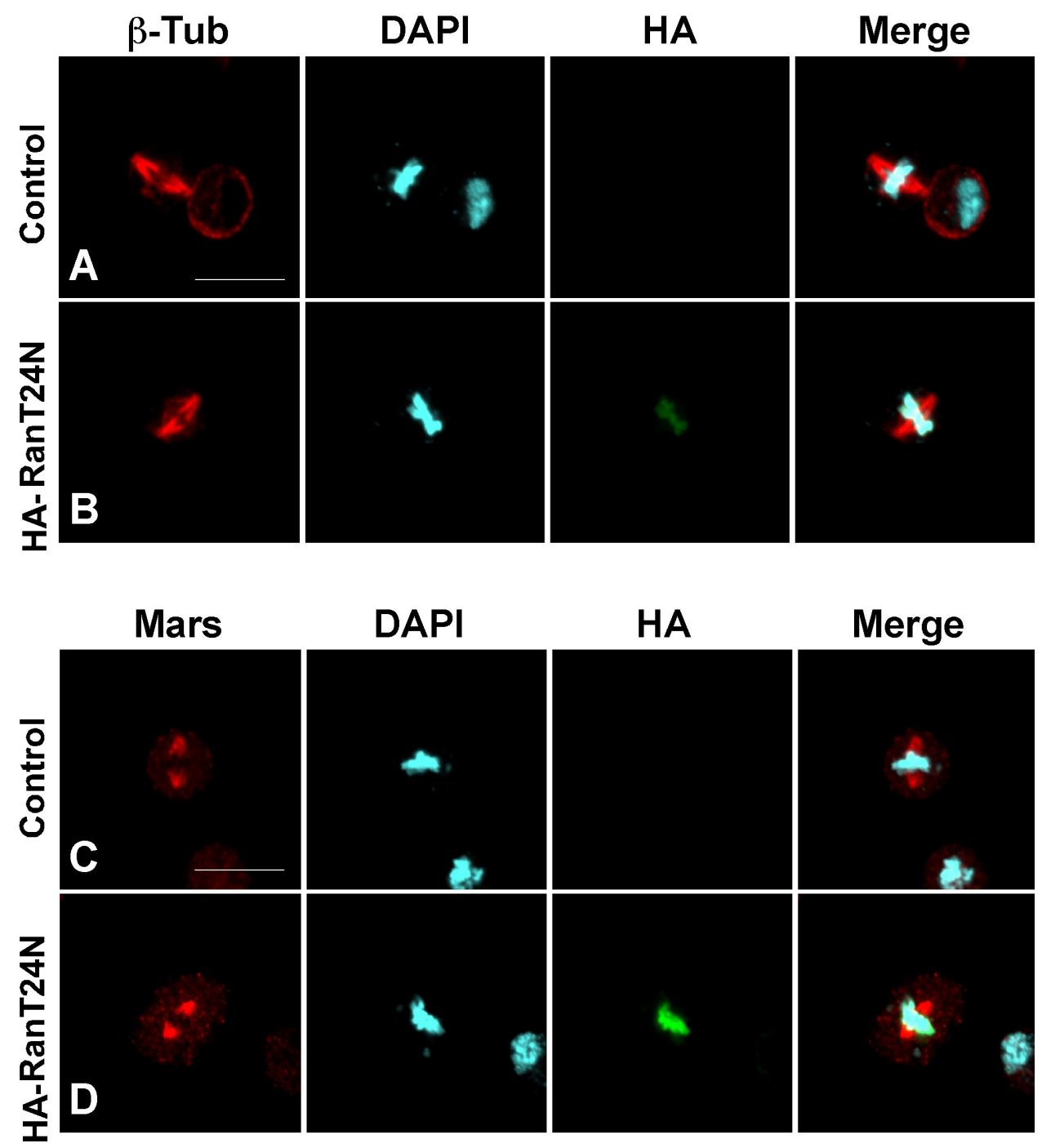

Fig. 31 No effect of RanT24N on the mitotic spindle and spindle localization of Mars. S2r cells were transfected with Ran-GTP mutant RanT24N and stained with an antibody against $\beta$-tubulin (red in A and B), an antibody against Mars (red in C and D), an antibody against HA (green) and DAPI for DNA. (A) Untransfected cells at metaphase show bipolar mitotic spindle. (B) Bipolar spindle is intact with the expression of RanT24N which is detected on congressed chromosomes. (C) Untransfected cells show spindle-shaped Mars staining around the chromosomes. (D) Mars was detected on mitotic spindle in the presence of RanT24N. Scale bar $=10 \mu \mathrm{m}$.

\subsection{Identification of potential interaction partners of Mars}

To further understand the molecular mechanism of Mars' function, we tried several methods to look for its potential interaction partners. For example, 
immunoprecipitation of GFP-Mars by GFP-Trap, immunoprecipitation of endogenous Mars by Mars-antibody-coupled sepharose beads and GS-tag tandem affinity purification have been tried to find proteins which interact with Mars in vivo. At the moment, only the sample from GFP-Trap purification is analyzed and presented in the thesis. GFP-Mars from transgenic embryos was pulled down by GFP-Trap beads. The bound proteins were eluted from the beads by the peptides with higher affinity to GFP-Trap beads (Fig. 32A). The eluted sample was separated by SDS-PAGE and digested by trypsin. After mass spectrometry analysis, around 1000 peptides belonging to more than 950 proteins were identified from the sample. The identified protein with the highest score is Mars which means the success of the pull-down experiment. The second highest score is from the protein importin $\beta$ (Ketel, CG2637). This is consistent with our finding that Mars was detected in the nucleus at interphase. Co-immunoprecipitation experiments also confirmed the interaction between Mars and importin $\beta$ (Fig. 32B). However, it is very difficult to determine the interaction with the other proteins from so many candidates. We expect more mass spectrometry data from the other purifications which may have less background than the first experiment. A more specific mass spectrometry method, SILAC (stable isotope labeling with amino acids) will also be considered for later research.

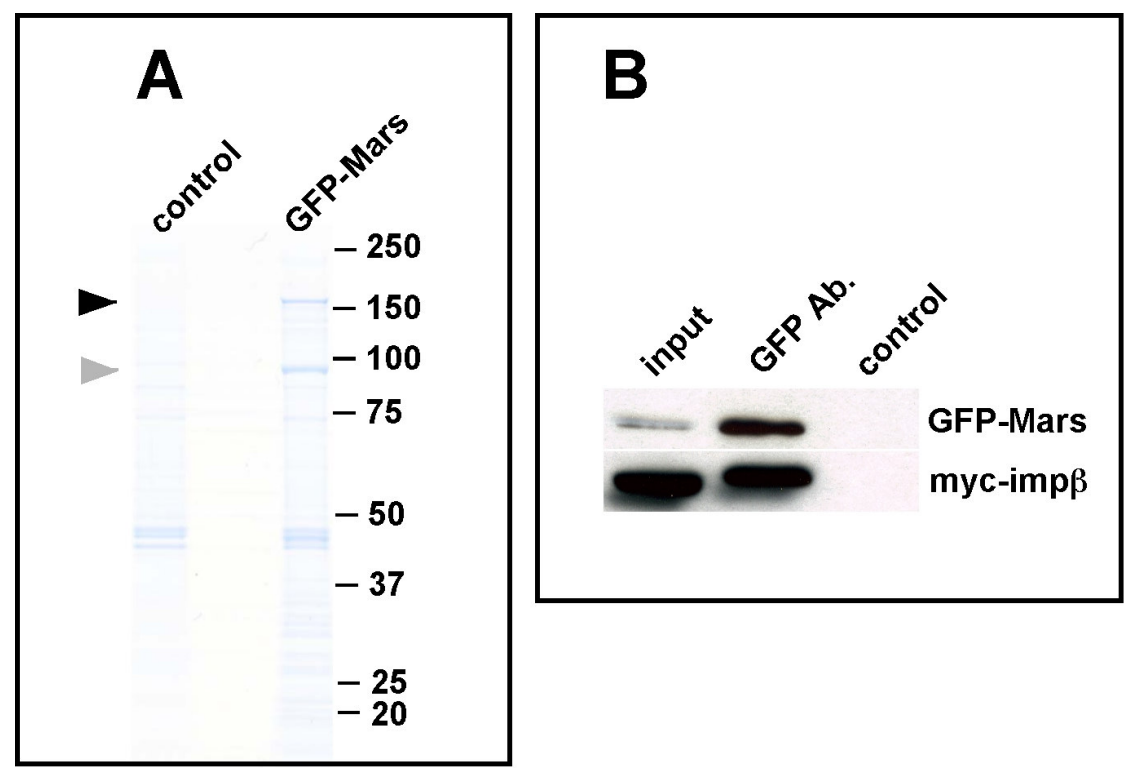

Fig. 32 Protein purification for mass spectrometry to search for interaction partners of Mars. (A) GFP-Mars was purified by GFP Binder from GFP-Mars transgenic embryo lysate and 
separated by SDS-PAGE. Coomassie blue staining found one specific band around $100 \mathrm{kD}$ (gray arrow head) besides the GFP-Mars band (black arrow head). The band was identified by mass spectrometry to be importin $\beta$. (B) Co-immunoprecipitation was conducted in S2r cells transfected with GFP-Mars and myc-imp $\beta$. GFP-Mars was pulled down by GFP antibody. Importin $\beta$ was also detected in the sample indicating an interaction between Mars and importin $\beta$.

However, some physiological binding partners may be among the proteins found in our first mass spectrometry experiment. Recently a genome-wide screening for genes essential for mitotic spindle assembly in Drosophila S2 cells identified around 200 genes which contribute to spindle assembly (Goshima et al., 2007). Another study about microtubule associated proteins from early Drosophila embryos was done by MT cosedimentation, combined with 2D PAGE and mass spectrometry (Hughes et al., 2008). Over 250 proteins were found to associate with microtubules in early embryos. Since Mars is a microtubule associated protein which plays important roles in mitotic spindle assembly, we did a BLAST search with the proteins identified in our mass spectrometry results against these two databases to find some potential interaction partners which also binds to microtubules and are important for mitotic spindle assembly. 68 proteins overlapped between our data with the products of genes essential for mitotic spindle assembly and 156 proteins were found in our mass spectrometry experiment and among the microtubule binding proteins (data not shown). 26 proteins found in all three studies are listed below (table 4).

\begin{tabular}{|c|c|c|c|}
\hline Deletion Phenotype & Gene & MS Score & MS Ranking \\
\hline Dim gamma-tubulin (spindle) & Dgt4, cg4865 & 24 & 959 \\
& Dgt5, cg8828 & 48 & 591 \\
\hline \multirow{5}{*}{ Tubulin: } & & \\
& alpha-Tub84B, cg1913 & 371 & 68 \\
& alpha-Tub67C, cg8308 & 453 & 49 \\
& Tubulin chaperon: & & \\
& Tcp1, cg5374 & 586 & 32 \\
& cg5525 & 304 & 86 \\
\hline
\end{tabular}




\begin{tabular}{|c|c|c|c|}
\hline & $\begin{array}{c}\text { cg7033 } \\
\text { Tcp-1-zeta, cg8231 } \\
\text { cg8258 } \\
\text { Tcp-1-eta, cg8351 } \\
\text { Cct5, cg8439 } \\
\text { Tcp-1-gamma, cg8977 }\end{array}$ & $\begin{array}{l}677 \\
507 \\
821 \\
690 \\
661 \\
710\end{array}$ & $\begin{array}{l}24 \\
41 \\
14 \\
23 \\
28 \\
21\end{array}$ \\
\hline Monastral bipolar & $\begin{array}{c}\text { Proteasome: } \\
\text { Pros29, cg9327 }\end{array}$ & 121 & 272 \\
\hline Pole detachment & Dhc64C, cg7507 & 27 & 886 \\
\hline Long spindle & Klp10A, cg1453 & 24 & 953 \\
\hline Short spindle & $\begin{array}{c}\text { Msps, cg5000 } \\
\text { Ribosome/translation factor: } \\
\text { Ef2b, cg2238 } \\
\text { Eif-4E, cg4035 } \\
\text { Eef-2, CG4153 } \\
\text { Eif-4A, CG9075 } \\
\text { Eif-2, cg9946 } \\
\text { sta, cg14792 }\end{array}$ & $\begin{array}{l}220 \\
531 \\
69 \\
78 \\
451 \\
123 \\
144\end{array}$ & $\begin{array}{l}138 \\
38 \\
430 \\
394 \\
50 \\
268 \\
222\end{array}$ \\
\hline Chromosome misalignment & $\begin{array}{l}\text { Klp3A, cg8590 } \\
\text { RpA-70, cg9633 } \\
\text { Hel25E, cg7269 }\end{array}$ & $\begin{array}{l}41 \\
227 \\
61\end{array}$ & $\begin{array}{l}661 \\
135 \\
482\end{array}$ \\
\hline aromosome condensation defect & SMC2, $\operatorname{cg} 10212$ & 65 & 454 \\
\hline
\end{tabular}

Table 4 Common genes identified in mass spectrometry of GFP Binder elute, genes essential for mitotic spindle assembly and genes whose protein products bind to microtubule. Mass spectrometry identified around 1000 peptides belonging to more than 950 proteins from the GFP-Mars sample. 26 proteins were also found in another two large scale screenings. One is the screening for the genes essential for mitotic spindle assembly in S2 cells (Goshima et al., 2007). Another is the identification of proteins binding to microtubules in Drosophila embryos (Hughes et al., 2008). Since Mars protein is a microtubule associated protein and important for the 
maintenance of the integrity of the mitotic spindle, some of the proteins coded by the genes in the table may interact with Mars in vivo. 


\section{Chapter 4. Discussion}

\subsection{Mars is required for the attachment of centrosomes to the nuclear envelope and to the mitotic spindle}

In most cell types, centrosomes are tightly linked to the nuclear envelope in interphase and localize to the spindle poles in mitosis (Kellogg et al., 1988; Gonzalez et al., 1998). The attachment of the centrosome to the nuclear envelope and to the mitotic spindle is generally thought to result from the interaction of microtubules nucleated at the centrosome with microtubule-associated proteins located either at the nuclear envelope or at the minus ends of spindle microtubuli (Robinson et al., 1999; Malone et al., 2003; Kwon and Scholey, 2004; Maiato et al., 2004). In mars mutant embryos at the syncytial blastoderm stage, centrosomes frequently detached from nuclei and from mitotic spindles, pointing to a function of Mars in linking centrosomal microtubules to the nuclear envelope and to spindle microtubules. Like attached centrosomes in wild type, the free centrosomes in mars mutant embryos showed immunoreactivity for $\gamma$-tubulin, Cnn, Aurora A and D-TACC. The free centrosomes retained their capacity to nucleate microtubules and continued to duplicate and separate, resulting in numerous microtubule asters detached from nuclei. Similar observations have been reported for other situations that result in the formation of free centrosomes (Raff and Glover, 1988; Gonzalez et al., 1990; Yasuda et al., 1991; Debec et al., 1996). Most likely as a secondary consequence of the centrosome detachment, different types of mitotic defects accumulated in mars mutant embryos, including monopolar spindles with circular condensed chromosomes, multipolar spindles and short anastral spindles that were probably organized by the nucleation of microtubules around chromosomes. Thus, the function of Mars is apparently not strictly required for the normal assembly and microtubule nucleating activity of centrosomes, but rather for the interaction of the centrosomal microtubules with the nuclear envelope and the spindle microtubules.

A very similar phenotype has been described for Dhc64C mutant embryos (Robinson 
et al., 1999). In these mutants, centrosomes also detached from the nuclear envelope and from mitotic spindles. The authors proposed that dynein associated with the nuclear envelope might be required for attachment of centrosomal microtubules. During mitosis, dynein at the centrosome could be necessary to link spindle microtubules to astral microtubules (Maiato et al., 2004). We have shown that the spindle pole localization of Mars was unaffected in the hypomorphic allelic combination of Dhc64C mutants that we used. This could either mean that dynein is indeed not required for localization of Mars to the minus ends of microtubules or that the levels of dynein still produced from the hypomorphic Dhc64C alleles are sufficient for proper localization of Mars. Nonetheless, the intriguing similarity of the mars and Dhc64C mutant phenotypes suggests the existence of a functional link between these two proteins.

\subsection{Is Mars generally required for proper spindle formation in}

\section{Drosophila?}

One surprising finding of our work is the fact that homozygous mars $^{91}$ mutant flies are viable and even fertile, despite of the dramatic mitotic defects in more than $90 \%$ of mutant embryos. This could be most easily explained if $\operatorname{mars}^{91}$ was a hypomorphic and not an amorphic or null allele. For several reasons we think that this is very unlikely: 1) The phenotype of heterozygous $\operatorname{mars}^{91} / D f(2 R) C X 1$ embryos is indistinguishable from the phenotype of $\operatorname{mars}^{91}$ homozygous mutant embryos, which is a classical genetic criterion for its classification as an amorphic mutation. 2) The mars $^{91}$ deletion removes the ATG start codon of the gene. Although apparently an N-terminally truncated form of Mars can be translated in this allele starting from an ATG downstream of the 3' breakpoint of the deletion, this truncated form lacks the $\mathrm{N}$-terminal region of Mars required for spindle localization and thus is presumably nonfunctional. Consistent with this, we did not detect any localized staining for Mars in the mars $^{91}$ homozygous mutant embryos. A second recently published null allele of mars causes phenotypes essentially identical to the ones we report here, but these 
embryos never develop beyond the fifth nuclear division cycle (Tan et al., 2008). Whether this apparent discrepancy in the lethality of the two alleles is caused by some minor residual function still preserved in the $\operatorname{mars}^{91}$ allele or by some differences in the genetic background of both alleles remains to be shown.

Based on these results we think that Mars is specifically required for spindle organization during the rapid cleavage divisions in the early Drosophila embryo but becomes dispensable later in embryonic, larval and adult development. The same finding was made for centrosomes, which, quite surprisingly, are not essential for mitosis at later developmental stages (Megraw et al., 1999; Vaizel-Ohayon and Schejter, 1999; Gergely et al., 2000; Stevens et al., 2007). Consistent with this interpretation, we and others (Goshima et al., 2007) did not observe any dramatic increase of mitotic spindle defects after knock-down of Mars by RNAi in S2r cells compared to controls. However, a recent study quantified defects in mitotic spindle formation after RNAi-mediated knock-down of Mars in S2r cells and found a statistically significant increase in spindles with abnormal kinetochore microtubules (Yang and Fan, 2008). Thus, while Mars does not appear to be essential for proper spindle formation after the rapid cleavage divisions in embryos, it may contribute to the efficient formation of kinetochore microtubules at later developmental stages.

\subsection{Is Mars a functional homolog of HURP?}

Homology searches using the BLAST algorithm revealed that the closest vertebrate relative of Mars is the spindle associated protein HURP (Yang et al., 2005). However, by our analysis of Mars localization and mutant phenotype, it appears that those two proteins may have at least partially different functions in spindle organization. HURP was identified as a component of a Ran-dependent complex in Xenopus egg extract which also contains Eg5, TPX2, XMAP215 and Aurora A (Koffa et al., 2006). Upon depletion of HURP, HeLa cells showed a delayed transition from prophase to anaphase with frequent misalignment of chromosomes at the mitotic plate (Koffa et al., 2006; Sillje et al., 2006; Wong and Fang, 2006). These data indicate that HURP 
stabilizes K-fibers and is required for the efficient capture of kinetochores by spindle microtubules. Whether Mars has a similar function in chromosome alignment at the mitotic plate is difficult to answer due to the severe mitotic defects resulting from centrosome detachment. While we frequently observed misaligned chromosomes in mars mutant embryos, these defects may be secondary consequences of the disorganized spindle poles.

The subcellular localization of HURP is under control of the Ran-GTP gradient originating from the chromosomes. Ran-GTP negatively regulates the binding of HURP to the nuclear import receptor importin $\beta$ which in turn prevents its interaction with microtubules (Sillje et al., 2006). In mitosis, HURP is associated with the spindle and is enriched in the part of the spindle that is close to the chromosomes (Koffa et al., 2006; Sillje et al., 2006; Wong and Fang, 2006). During interphase, HURP levels are strongly reduced and the protein is mainly found in the cytosol, with low amounts detectable in the nucleus (Sillje et al., 2006). By contrast, Mars associates with spindle poles and kinetochore fibers, is not enriched in proximity to the chromosomes at mitosis and is localized in the nucleus at interphase. Our results suggest that the subcellular localization of Mars to the spindle poles may be independent from Aurora A, in contrast to HURP, where phosphorylation of its C-terminal region by Aurora A is required for the association with microtubules (Wong et al., 2008). Again, we cannot exclude the possibility that the low levels of Aurora A activity present in embryos homozygous for the hypomorphic aurA ${ }^{287}$ allele (Giet et al., 2002) are sufficient for proper localization of Mars. Despite of these differences, the microtubule binding activity of both HURP and Mars resides in the N-terminal region of both proteins (Wong et al., 2008).

\subsection{Mars may be functionally related to vertebrate TPX2 and NuMa}

The subcellular localization and loss-of-function phenotype of Mars shows striking similarities to the vertebrate Ran-GTP regulated proteins TPX2 and NuMA. Both proteins are required to ensure normal spindle morphology and spindle pole integrity. 
Upon knock-down of TPX2, mitotic cells form multipolar spindles in HeLa cells (Garrett et al., 2002). In Xenopus egg extract, the depletion of TPX2 causes less compact spindles and a variety of spindle pole defects (Wittmann et al., 2000). The regulation of TPX2 activity occurs via its binding to importin $\alpha$, which is mutually exclusive with the binding to microtubules and is regulated by Ran-GTP (Gruss et al., 2001). Very interestingly, TPX2 was found in a complex together with Aurora A, Eg5, XMAP215 and HURP (Koffa et al., 2006). TPX2 is required for targeting Aurora A to the spindle (Kufer et al., 2002; Ozlu et al., 2005) and HURP is a phosphorylation target of Aurora A (Yu et al., 2005; Wong et al., 2008), revealing a functional interaction between TPX2 and HURP.

The second vertebrate protein that resembles Mars with respect to its subcellular localization and loss-of-function phenotype is NuMa. This protein interacts with the dynein-dynactin complex and is required for the focussing of spindle poles and for the tight attachment of centrosomes to the spindle (Merdes et al., 1996; Merdes et al., 2000). In a recent study of NuMA function in development, NuMA mutant mice showed phenotype very similar to those of mars mutant embryos in Drosophila (Silk, et al., 2009). NuMA was demonstrated to be essential for early embryogenesis and cellular proliferation. Without the normal function of NuMA, the mitotic spindle could still form properly. However, once the tension within the spindle was generated, the physical tethering between centrosomes and the spindle was lost. Though the spindle morphology was largely disrupted, duplicated chromosomes could still be segregated similar to what we observed in mars mutant embryos. Centrosome separation was also deregulated.

Because the phenotype of mars mutants is very similar to the phenotype of cytoplasmic dynein heavy chain mutants (Robinson et al., 1999) and no function in spindle pole focussing and centrosome attachment has been described for Mud, a potential NuMa homolog in Drosophila (Bowman et al., 2006; Izumi et al., 2006; Siller et al., 2006), we speculate that Mars may be a Drosophila counterpart to NuMa and TPX2 with respect to its function in spindle organization. Unlike NuMA or TPX2 
which both are under the regulation of Ran-GTP, we found Mars may not depend on this pathway to conduct its function. Overexpression of the GDP bound Ran mutant RanT24N did neither affect the assembly of the mitotic spindle, nor the spindle localization of Mars. This indicates that in insect cells, the Ran-GTP pathway may not be required for the assembly of mitotic spindles, in contrast to human cell culture systems or Xenopus embryos. Consistent with our results, Ran was also not identified in two large scale screens for genes essential for mitotic spindle assembly (Goshima et al., 2007, Somma et al., 2008).

Due to its mutant phenotype and its subcellular localization (Gonzalez et al., 1990; Saunders et al., 1997; do Carmo Avides and Glover, 1999; Wakefield et al., 2001), the Asp protein of Drosophila has been discussed as a potential functional equivalent to NuMa and TPX2 (Manning and Compton, 2008). In asp mutants, spindle poles are disorganized and centrosomes frequently detach from the mitotic spindle, leading to the formation of free centrosomes (Gonzalez et al., 1990; do Carmo Avides and Glover, 1999; Wakefield et al., 2001; Morales-Mulia and Scholey, 2005). The subcellular localization of Asp overlaps with Mars at spindle poles, but in contrast to Mars, Asp is also localized to centrosomes in mitosis and is enriched at the side of the centrosome facing the spindle microtubules (Saunders et al., 1997; do Carmo Avides and Glover, 1999; Wakefield et al., 2001). Thus, Mars and Asp may have related and possibly redundant functions in spindle pole focussing and attachment of centrosomes to the spindle. Our genetic interaction studies strongly support this interpretation. We never obtained flies doubly mutant for mars and asp, but one intact copy of either mars or asp is sufficient for development to adulthood.

\subsection{Molecular mechanism of the function of Mars}

From our studies, Mars was found to be required for the tethering of centrosomes to the nuclear envelope and to the mitotic spindle. It may also have a role in maintaining the stability of mitotic spindles, since the spindles that lost one centrosome tended to collapse into monopolar spindles in mutant embryos, while overexpression of GFP-N 
Mars prevented the spindle from collapsing. What is the molecular mechanism behind these functions? One possibility is that Mars works as a physical linker between centrosomes and mitotic spindles. We do not favor this possibility, because Mars is not localized on centrosomes throughout mitosis. Also, the physical linker hypothesis can not explain the spindle collapse, because detachment of centrosomes does not necessarily result in spindle collapse (Goshima et al., 2007, Robinson et al., 1999). However, we can not exclude the possibility that Mars may regulate the activity of other proteins required for the connection at the spindle poles and stabilize the mitotic spindles at the same time. Another possibility is that Mars mainly stabilizes microtubules of the spindles, especially the kinetochore microtubules. In mars mutant embryos, the spindles become unstable when the kinetochore fibers are under tension to separate sister chromatids. Centrosomes tend to lose connections with the spindle because of the weak structure of kinetochore fibers. Concomitantly, spindles are also not able to maintain their morphology. We prefer this possibility because centrosomes only detach from the spindles after the formation of bipolar spindles, but not before. Does Mars stabilize the spindle microtubules directly or indirectly via other proteins? At the moment, there is no strong evidence to distinguish these two possibilities. But from the charge analysis of Mars protein, it seems that Mars is able to bind directly to microtubules through its three continuous positively charged regions within the $\mathrm{N}$-terminal region. Overexpression of GFP-N Mars itself is sufficient to stabilize the defective spindles without centrosomes. So it appears likely that Mars directly binds to and stabilizes the spindle microtubules. We plan to perform some in vivo and in vitro experiments in the near future to investigate the direct stabilization of microtubules by Mars.

Nearly at the same time as we published our data, two additional reports on the function of Mars on spindle organization were published (Tan et al., 2008; Yang and Fan, 2008). Fully consistent with our results, both studies show that Mars localizes to spindle microtubules, is enriched at the minus ends of microtubules and is absent from centrosomes and astral microtubules. In one study, null mutants for mars were 
generated, which showed detachment of centrosomes from the spindle during nuclear divisions at the very early stage (Tan et al., 2008), the same phenotype as we report here. The study furthermore showed that Mars binds to protein phosphatase 1 (PP1), D-TACC and Msps. The binding with PP1 is required for dephosphorylation of D-TACC on the spindle. This study proposes that Mars is mainly required to promote dephosphorylation of D-TACC by PP1. However, the role of D-TACC in mitosis is still elusive. TACC3, the Xenopus homolog of D-TACC, does not stabilize microtubules (Albee and Wiese, 2008). TACC3 is also not required for the microtubule plus end-stabilizing activity of XMAP215, the Xenopus homolog of Drosophila protein Msps. Another fact they ignored is that Mars and D-TACC do not completely colocalize on the spindle in the whole process of mitosis. D-TACC is mainly concentrated on centrosomes from interphase onwards. A low level of D-TACC was also found on the mitotic spindle, especially at the spindle poles at metaphase. The D-TACC enriched at spindle poles was slightly separated from D-TACC enriched at centrosomes (Gergely et al., 2000). In contrast, Mars was not found on centrosomes at any stage of mitosis. Moreover, D-TACC localizes to the central spindle during anaphase and telophase while Mars is absent from the central spindle. However, we can not really exclude the possibility that Mars and D-TACC interact on the mitotic spindle at metaphase since their localization partially overlaps. Very surprisingly, we could not reproduce some of the genetic experiments published by Tan et al. For example, we tested the lethality of the embryos with a single copy of

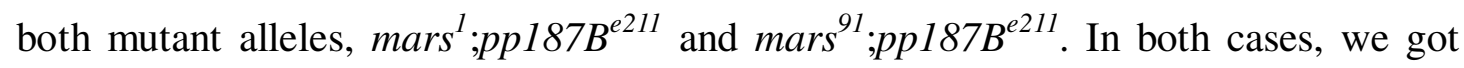
more than $90 \%$ of embryo hatching rates, which is much more than the reported $33 \%$. We also tested the level of phosphorylated D-TACC in our mutant embryos by an antibody that specifically recognizes D-TACC phosphorylated at Ser 863 (Barros et al., 2005). Unfortunately, in both wild type and $\operatorname{mars}^{91}$ mutant embryos, we detected strong signals on the mitotic spindles with similar levels. Does this apparent discrepancy come from the genetic background difference or is it due to technical issues? Our future work on the direct role of Mars on stabilization of microtubules may provide an answer on this. 
The second report (Yang and Fan, 2008) found Mars mainly on kinetochore microtubules during mitosis in Drosophila S2 cells. Depletion of Mars from S2 cells by RNA interference caused severe defects including poorly organized kinetochore microtubules, diminished $\gamma$-tubulin on mitotic spindles and increased number of cells with uncongressed chromosomes (Yang and Fan, 2008). Though most of their data are quite consistent with Tan and our results, there are still some disagreements. For example, they overexpressed Flag-Ran in the third instar eye discs and found enhanced Mars staining in mitotic cells. They propose that Mars is regulated by Ran-GTP. However, from our data, we found that overexpression of the GDP bound version of RanT24N did not affect the localization and the intensity of Mars on the mitotic spindles (Fig. 31A). Also the assembly and maintenance of mitotic spindles were not affected by the overexpression of RanT24N (Fig. 31B). In small cells like insect cells, Ran-GTP does not seem to be as important as in big cells like Xenopus embryos or human cells in the assembly of the mitotic spindles. The fact that Ran was not identified in two large screens of genes required for mitotic spindle assembly also supports this idea (Goshima et al., 2007, Somma et al., 2008). Another finding from them is the diminished $\gamma$-tubulin on the mitotic spindles when Mars was depleted in S2 cells. But in mars mutant embryos, $\gamma$-tubulin was still detectable on the mitotic spindles at an amount that was undistinguishable from the wild type embryos (Fig. 13D). We can not exclude the possibility that this discrepancy may come from the difference between cell culture and embryos. However, from the developmental view, $\gamma$-tubulin is not affected by mars dysfunction.

At the moment, some basic features about Mars are well documented such as the translocation and its main function in the attachment of centrosomes to the mitotic spindle. But the molecular mechanisms behind are still elusive. How is Mars excluded from the central spindle at anaphase? Does Mars have functions in the nucleus? Does Mars stabilize the microtubules directly or via other proteins? In the near future, some experiments such as in vitro MT stabilization assay by purified Mars protein and phosphorylation studies on Mars will be conducted, which may shed some light on 
these unanswered questions. 


\section{Summary}

The formation of the mitotic spindle is controlled by the microtubule organizing activity of the centrosomes and by the effects of chromatin-associated Ran-GTP on the activities of spindle assembly factors. In this study we show that Mars, a Drosophila protein with sequence similarity to vertebrate hepatoma upregulated protein (HURP), is required for the maintenance of integrity of mitotic spindles. More than $90 \%$ of embryos derived from mars mutant females do not develop properly due to severe mitotic defects during the rapid nuclear divisions in early embryogenesis. Centrosomes frequently detach from spindles and from the nuclear envelope and nucleate astral microtubules in ectopic positions. The mitotic spindles with detached centrosomes collapse into rosette-like monopolar spindle. Consistent with its function in spindle organization, Mars localizes to nuclei at interphase and associates with the mitotic spindle at metaphase, in particular with the kinetochore fibers during anaphase. The analysis of truncated versions of Mars indicates that the N-terminal region, in particular the first 210 amino acids, are necessary for spindle localization. The C-terminal region of Mars may be required for the exclusion of the protein from the central spindle during anaphase and telophase. We also found that Mars is hyperphosphorylated during the cell cycle. Phosphorylation may play important roles in the translocation and function of Mars. We propose that Mars is important for proper spindle organization and linking the centrosomes to the spindle during the rapid mitotic cycles in early embryogenesis. 


\section{References}

Barros, T. P., Kinoshita, K., Hyman, A. A. and Raff, J. W. (2005). Aurora A activates D-TACC-Msps complexes exclusively at centrosomes to stabilize centrosomal microtubules. J Cell Biol 170, 1039-46.

Beall, E. L., Lewis, P. W., Bell, M., Rocha, M., Jones, D. L. and Botchan, M. R. (2007). Discovery of tMAC: a Drosophila testis-specific meiotic arrest complex paralogous to Myb-Muv B. Genes Dev 21, 904-19.

Bennett, D. and Alphey, L. (2004). Cloning and expression of mars, a novel member of the guanylate kinase associated protein family in Drosophila. Gene Expr Patterns 4, 529-35.

Bodenmiller, B., Malmstrom, J., Gerrits, B., Campbell, D., Lam, H., Schmidt, A., Rinner, O., Mueller, L. N., Shannon, P. T., Pedrioli, P. G., Panse, C., Lee, H. K., Schlapbach, R. and Aebersold, R. (2007). PhosphoPep-a phosphoproteome resource for systems biology research in Drosophila Kc167 cells. Mol Syst Biol 3, 139.

Bowman, S. K., Neumuller, R. A., Novatchkova, M., Du, Q. and Knoblich, J. A. (2006). The Drosophila NuMA Homolog Mud regulates spindle orientation in asymmetric cell division. Dev Cell 10, 731-42.

Cavey, M. and Lecuit, T. (2008). Imaging cellular and molecular dynamics in live embryos using fluorescent proteins. In Drosophila: Methods and Protocols, vol. 420 (ed. C. Dahmann), pp. 219-238. Totowa, NJ: Humana Press.

Ciferri, C., Pasqualato, S., Screpanti, E., Varetti, G., Santaguida, S., Dosreis, G., Maiolica, A., Polka, J., Deluca, J. and Dewulf, P. (2008). Implications for kinetochore-microtubule attachment from the structure of an engineered Ndc80 complex. Cell 133: 427-39.

Clarke, P. R. and Zhang, C. (2008). Spatial and temporal coordination of mitosis by Ran GTPase. Nat Rev Mol Cell Biol. 
Cravchik, A., Reddy, D. and Matus, A. (1994). Identification of a novel microtubule-binding domain in microtubule-associated protein 1A (MAP1A). J Cell Sci 107, 661-72.

Debec, A., Kalpin, R. F., Daily, D. R., McCallum, P. D., Rothwell, W. F. and Sullivan, W. (1996). Live analysis of free centrosomes in normal and aphidicolin-treated Drosophila embryos. J Cell Biol 134, 103-15.

do Carmo Avides, M. and Glover, D. M. (1999). Abnormal spindle protein, Asp, and the integrity of mitotic centrosomal microtubule organizing centers. Science $\mathbf{2 8 3}$, $1733-5$

Donaldson, M. M., Tavares, A. A., Ohkura, H., Deak, P. and Glover, D. M. (2001). Metaphase arrest with centromere separation in polo mutants of Drosophila. $J$ Cell Biol 153, 663-76.

Garrett, S., Auer, K., Compton, D. A. and Kapoor, T. M. (2002). hTPX2 is required for normal spindle morphology and centrosome integrity during vertebrate cell division. Curr Biol 12, 2055-9.

Gergely, F., Kidd, D., Jeffers, K., Wakefield, J. G. and Raff, J. W. (2000). D-TACC: a novel centrosomal protein required for normal spindle function in the early Drosophila embryo. Embo J 19, 241-52.

Giet, R., McLean, D., Descamps, S., Lee, M. J., Raff, J. W., Prigent, C. and Glover, D. M. (2002). Drosophila Aurora A kinase is required to localize D-TACC to centrosomes and to regulate astral microtubules. J Cell Biol 156, 437-51.

Glover, D. M., Leibowitz, M. H., McLean, D. A. and Parry, H. (1995). Mutations in aurora prevent centrosome separation leading to the formation of monopolar spindles. Cell 81, 95-105.

Gonzalez, C., Saunders, R. D., Casal, J., Molina, I., Carmena, M., Ripoll, P. and Glover, D. M. (1990). Mutations at the asp locus of Drosophila lead to multiple free centrosomes in syncytial embryos, but restrict centrosome duplication in larval 
neuroblasts. J Cell Sci 96 (Pt 4), 605-16.

Gonzalez, C., Tavosanis, G. and Mollinari, C. (1998). Centrosomes and microtubule organisation during Drosophila development. J Cell Sci 111, 2697-706.

Goshima, G., Wollman, R., Goodwin, S. S., Zhang, N., Scholey, J. M., Vale, R. D. and Stuurman, N. (2007). Genes required for mitotic spindle assembly in Drosophila S2 cells. Science 316, 417-21.

Goshima, G., Mayer, M., Zhang, N., Stuurman, N. and Vale, R. D. (2008). Augmin: a protein complex required for centrosome-independent microtubule generation within the spindle. J Cell Biol 181, 421-9.

Gruss, O. J., Carazo-Salas, R. E., Schatz, C. A., Guarguaglini, G., Kast, J., Wilm, M., Le Bot, N., Vernos, I., Karsenti, E. and Mattaj, I. W. (2001). Ran induces spindle assembly by reversing the inhibitory effect of importin alpha on TPX2 activity. Cell 104, 83-93.

Gruss, O. J. and Vernos, I. (2004). The mechanism of spindle assembly: functions of Ran and its target TPX2. J Cell Biol 166, 949-55.

Hill, T. L. (1985). Theoretical problems related to the attachment of microtubules to kinetochores. Proc Natl Acad Sci U S A 82, 4404-8.

Holy, T. E. and Leibler, S. (1994). Dynamic instability of microtubules as an efficient way to search in space. Proc Natl Acad Sci U S A 91, 5682-5.

Hong, K. U., Kim, H. J., Kim, H. S., Seong, Y. S., Hong, K. M., Bae, C., D. and Park, J. (2009). Cdk1/Cyclin B1-mediated phosphorylation of tumor-associated microtubule-associated protein/cytoskeleton-associated protein 2 in mitosis. $\mathrm{J}$ Biol Chem 284, 16501-12.

Hughes, J. R., Meireles, A. M., Fisher, K. H., Garcia, A., Antrobus, P. R., Wainman, A., Zitzmann, N., Deane, C., Ohkura, H. and Wakefield, J. G. (2008). A microtubule interactome: complexes with roles in cell cycle and mitosis. PLoS Biol 6, 785-95. 
Izumi, Y., Ohta, N., Hisata, K., Raabe, T. and Matsuzaki, F. (2006). Drosophila Pins-binding protein Mud regulates spindle-polarity coupling and centrosome organization. Nat Cell Biol 8, 586-93.

Joukov, V., Groen, A. C., Prokhorova, T., Gerson, R., White, E., Rodriguez, A., Walter, J. C., and Livingston, D. M. (2006). The BRCA1/BARD1 heterodimer modulates ran-dependent mitotic spindle assembly. Cell 127, 539-52.

Kellogg, D. R., Mitchison, T. J. and Alberts, B. M. (1988). Behaviour of microtubules and actin filaments in living Drosophila embryos. Development 103, 675-86.

Khodjakov, A., Cole, R. W., Oakley, B. R. and Rieder, C. L. (2000). Centrosome-independent mitotic spindle formation in vertebrates. Curr Biol 10, 59-67.

Kirschner, M. and Mitchison, T. (1986). Beyond self-assembly: from microtubules to morphogenesis. Cell 45, 329-42.

Knowlton, A. L., Lan, W. and Stukenberg, P. T. (2006). Aurora B is enriched at merotelic attachment sites, where it regulates MCAK. Curr Biol 16, 1705-10.

Knowlton, A. L., Vorozhko, V. V., Lan, W., Gorbsky, G. J. and Stukenberg, P. T. (2009). ICIS and Aurora B coregulate the microtubule depolymerase Kif2a. Curr Biol 19: 758-63.

Koffa, M. D., Casanova, C. M., Santarella, R., Kocher, T., Wilm, M. and Mattaj, I. W. (2006). HURP is part of a Ran-dependent complex involved in spindle formation. Curr Biol 16, 743-54.

Kufer, T. A., Sillje, H. H., Korner, R., Gruss, O. J., Meraldi, P. and Nigg, E. A. (2002). Human TPX2 is required for targeting Aurora-A kinase to the spindle. J Cell Biol 158, 617-23.

Kwon, M. and Scholey, J. M. (2004). Spindle mechanics and dynamics during mitosis in Drosophila. Trends Cell Biol 14, 194-205. 
Lantz, V. A. and Miller, K. G. (1998). A class VI unconventional myosin is associated with a homologue of a microtubule-binding protein, cytoplasmic linker protein-170, in neurons and at the posterior pole of Drosophila embryos. J Cell Biol 140, 897-910.

Lu, B., Ackerman, L., Jan, L. Y. and Jan, Y. N. (1999). Modes of protein movement that lead to the asymmetric localization of partner of Numb during Drosophila neuroblast division. Mol Cell 4, 883-91.

Maiato, H., Rieder, C. L. and Khodjakov, A. (2004). Kinetochore-driven formation of kinetochore fibers contributes to spindle assembly during animal mitosis. J Cell Biol 167, 831-40.

Maiato, H., Sampaio, P. and Sunkel, C. E. (2004). Microtubule-associated proteins and their essential roles during mitosis. Int Rev Cytol 241, 53-153.

Malone, C. J., Misner, L., Le Bot, N., Tsai, M. C., Campbell, J. M., Ahringer, J. and White, J. G. (2003). The C. elegans hook protein, ZYG-12, mediates the essential attachment between the centrosome and nucleus. Cell 115, 825-36.

Manning, A. L. and Compton, D. A. (2008). Structural and regulatory roles of nonmotor spindle proteins. Curr Opin Cell Biol 20, 101-6.

McCartney, B. M., Dierick, H. A., Kirkpatrick, C., Moline, M. M., Baas, A., Peifer, M. and Bejsovec, A. (1999). Drosophila APC2 is a cytoskeletally-associated protein that regulates wingless signaling in the embryonic epidermis. J Cell Biol 146, 1303-18.

Megraw, T. L., Li, K., Kao, L. R. and Kaufman, T. C. (1999). The centrosomin protein is required for centrosome assembly and function during cleavage in Drosophila. Development 126, 2829-39.

Mennella, V., Tan, D. Y., Buster, D. W., Asenjo, A. B., Rath, U., Ma, A., Sosa, H. J. and Sharp, D. J. (2009). Motor domain phosphorylation and regulation of the Drosophila kinesin 13, KLP10A. J Cell Biol 186, 481-90. 
Merdes, A., Heald, R., Samejima, K., Earnshaw, W. C. and Cleveland, D. W. (2000). Formation of spindle poles by dynein/dynactin-dependent transport of NuMA. J Cell Biol 149, 851-62.

Merdes, A., Ramyar, K., Vechio, J. D. and Cleveland, D. W. (1996). A complex of NuMA and cytoplasmic dynein is essential for mitotic spindle assembly. Cell 87, 447-58.

Morales-Mulia, S. and Scholey, J. M. (2005). Spindle pole organization in Drosophila S2 cells by dynein, abnormal spindle protein (Asp), and KLP10A. Mol Biol Cell 16, 3176-86.

Müller, H. A. J. (2008). Immunolabeling of embryos. In Drosophila: Methods and Protocols, vol. 420 (ed. C. Dahmann), pp. 207-218. Totowa, NJ: Humana Press.

Nasmyth, K. (2002). Segregating sister genomes: the molecular biology of chromosome separation. Science 297, 559-65.

O'Connell, C. B. and Khodjakov, A. L. (2007). Cooperative mechanisms of mitotic spindle formation. $J$ Cell Sci 120, 1717-22.

Ozlu, N., Srayko, M., Kinoshita, K., Habermann, B., O'Toole E, T., Muller-Reichert, T., Schmalz, N., Desai, A. and Hyman, A. A. (2005). An essential function of the C. elegans ortholog of TPX2 is to localize activated aurora A kinase to mitotic spindles. Dev Cell 9, 237-48.

Raff, J. W. and Glover, D. M. (1988). Nuclear and cytoplasmic mitotic cycles continue in Drosophila embryos in which DNA synthesis is inhibited with aphidicolin. J Cell Biol 107, 2009-19.

Reinders, J., Sickmann, A. (2005). State-of-the-art in phosphoproteomics. Proteomics 5, 4052-4061.

Ribbeck, K., Groen, A. C., Santarella, R., Bohnsack, M. T., Raemaekers, T., Koecher T., Gentzel, M., Goerlich, D., Wilm, M., Carmeliet, G., Mitchison, T. J., Ellenberg, J., Hoenger A. and Mattaj, I. W. (2006). NuSAP, a mitotic RanGTP 
target that stabilizes and cross-links microtubules. Mol Biol Cell 17, 2646-60.

Robertson, H. M., Preston, C. R., Phillis, R. W., Johnson-Schlitz, D. M., Benz, W. K. and Engels, W. R. (1988). A stable genomic source of P element transposase in Drosophila melanogaster. Genetics 118, 461-70.

Robinson, J. T., Wojcik, E. J., Sanders, M. A., McGrail, M. and Hays, T. S. (1999). Cytoplasmic dynein is required for the nuclear attachment and migration of centrosomes during mitosis in Drosophila. J Cell Biol 146, 597-608.

Rogers, S. L., Rogers, G. C., Sharp, D. J. and Vale, R. D. (2002). Drosophila EB1 is important for proper assembly, dynamics, and positioning of the mitotic spindle. J Cell Biol 158, 873-84.

Rogers, G. C., Rogers, S. L., Schwimmer, T. A., Ems-McClung, S. C., Walczak, C. E., Vale, R. D., Scholey, J. M. and Sharp, D. J. (2004). Two mitotic kinesins co-operate to drive sister chromatid separation during anaphase. Nature 427, 364-70.

Saunders, R. D., Avides, M. C., Howard, T., Gonzalez, C. and Glover, D. M. (1997). The Drosophila gene abnormal spindle encodes a novel microtubule-associated protein that associates with the polar regions of the mitotic spindle. J Cell Biol 137, 881-90.

Silk, A. D., Holland, A. J. and Cleveland, D. W. (2009). Requirements for NuMA in maintenance and establishment of mammalian spindle poles. J Cell Biol 184, 677-90.

Siller, K. H., Cabernard, C. and Doe, C. Q. (2006). The NuMA-related Mud protein binds Pins and regulates spindle orientation in Drosophila neuroblasts. Nat Cell Biol 8, 594-600.

Sillje, H. H., Nagel, S., Korner, R. and Nigg, E. A. (2006). HURP is a Ran-importin beta-regulated protein that stabilizes kinetochore microtubules in the vicinity of chromosomes. Curr Biol 16, 731-42. 
Sisson, J. C., Ho, K. S., Suyama, K. and Scott, M. P. (1997). Costal2, a novel kinesin-related protein in the Hedgehog signaling pathway. Cell 90, 235-45.

Somma, M. P., Ceprani, F., Bucciarelli, E., Naim, V., De Arcangelis, V., Piergentili, R., Palena, A., Ciapponi, L., Giansanti, M. G., Pellacani, C., Petrucci, R., Cenci, G., Verni, F., Fasulo, B., Goldberg, M. L., DiCunto, F. and Gatti, M. (2008). Identification of Drosophila mitotic genes by combining co-expression analysis and RNA interference. PLoS Genet 18, e1000126.

Spradling, A. C., Stern, D., Beaton, A., Rhem, E. J., Laverty, T., Mozden, N., Misra, S. and Rubin, G. M. (1999). The Berkeley Drosophila Genome Project gene disruption project: Single P-element insertions mutating 25\% of vital Drosophila genes. Genetics 153, 135-77.

Stevens, N. R., Raposo, A. A., Basto, R., St Johnston, D. and Raff, J. W. (2007). From stem cell to embryo without centrioles. Curr Biol 17, 1498-503.

Sunkel, C. E. and Glover, D. M. (1988). polo, a mitotic mutant of Drosophila displaying abnormal spindle poles. J Cell Sci 89 (Pt 1), 25-38.

Tan, S., Lyulcheva, E., Dean, J. and Bennett, D. (2008). Mars promotes D-TACC dephosphorylation on mitotic spindles to ensure spindle stability. J Cell Biol 182, 27-33.

Thingholm, T. E., Jensen O. N. and Larsen, M. R. (2009). Analytical strategies for phosphoproteomics. Proteomics 9, 1451-1468.

Tsou, A. P., Yang, C. W., Huang, C. Y., Yu, R. C., Lee, Y. C., Chang, C. W., Chen, B. R., Chung, Y. F., Fann, M. J., Chi, C. W. et al. (2003). Identification of a novel cell cycle regulated gene, HURP, overexpressed in human hepatocellular carcinoma. Oncogene 22, 298-307.

Vaizel-Ohayon, D. and Schejter, E. D. (1999). Mutations in centrosomin reveal requirements for centrosomal function during early Drosophila embryogenesis. Curr Biol 9, 889-98. 
Wakefield, J. G., Bonaccorsi, S. and Gatti, M. (2001). The drosophila protein asp is involved in microtubule organization during spindle formation and cytokinesis. J Cell Biol 153, 637-48.

Walczak, C. E. and Heald R. (2008). Mechanisms of mitotic spindle assembly and function. Int Rev Cytol 265, 111-158.

Weaver, B. A. and Cleveland, D. W. (2005). Decoding the links between mitosis, cancer, and chemotherapy: The mitotic checkpoint, adaptation, and cell death. Cancer Cell 8, 7-12.

Wiese, C., Wilde, A., Moore, M. S., Adam, S. A., Merdes, A. and Zheng, Y. (2001). Role of importin-beta in coupling Ran to downstream targets in microtubule assembly. Science 291, 653-6.

Wilde, A. and Zheng, Y. (1999). Stimulation of microtubule aster formation and spindle assembly by the small GTPase Ran. Science 284, 1359-62.

Wittmann, T., Wilm, M., Karsenti, E. and Vernos, I. (2000). TPX2, A novel Xenopus MAP involved in spindle pole organization. J Cell Biol 149, 1405-18.

Wodarz, A. (2008). Extraction and immunoblotting of proteins from embryos. In Drosophila: Methods and Protocols, vol. 420 (ed. C. Dahmann), pp. 335-345. Totowa, NJ: Humana Press.

Wong, J. and Fang, G. (2006). HURP controls spindle dynamics to promote proper interkinetochore tension and efficient kinetochore capture. J Cell Biol 173, 879-91.

Wong, J., Lerrigo, R., Jang, C. Y. and Fang, G. (2008). Aurora A Regulates the Activity of HURP by Controlling the Accessibility of Its Microtubule-binding Domain. Mol Biol Cell 19, 2083-91.

Yang, C. P., Chen, M. S., Liaw, G. J., Chen, S. F., Chou, G. and Fan, S. S. (2005). Using Drosophila eye as a model system to characterize the function of mars gene in cell-cycle regulation. Exp Cell Res 307, 183-93. 
Yang, C. P. and Fan, S. S. (2008). Drosophila mars is required for organizing kinetochore microtubules during mitosis. Exp Cell Res.

Yasuda, G. K., Baker, J. and Schubiger, G. (1991). Independent roles of centrosomes and DNA in organizing the Drosophila cytoskeleton. Development 111, 379-91.

Yu, C. T., Hsu, J. M., Lee, Y. C., Tsou, A. P., Chou, C. K. and Huang, C. Y. (2005). Phosphorylation and stabilization of HURP by Aurora-A: implication of HURP as a transforming target of Aurora-A. Mol Cell Biol 25, 5789-800.

Yu, J. X., Guan, Z. and Nash, H. A. (2006). The mushroom body defect gene product is an essential component of the meiosis II spindle apparatus in Drosophila oocytes. Genetics 173, 243-53.

Zhai, B., Villen, J., Beausoleil, S. A., Mintseris, J. and Gygi, S. P. (2008). Phosphoproteome analysis of Drosophila melanogaster embryos. J Proteome Res 7, $1675-82$.

Zhang, X., Lan, W., Ems-McClung, S. C., Stukenberg, P. T. and Walczak, C. E. (2007). Aurora B phosphorylates multiple sites on mitotic centromere-associated kinesin to spatially and temporally regulate its function. Mol Biol Cell 18, 3264-76. 


\section{Acknowledgement}

First, I would like to thank my supervisor Prof. Andreas Wodarz very much for his continuous support and inspiring supervisions. From him, I have learned not only the latest knowledge, but also the sincere attitude towards science. I would also like to thank Prof. Ernst Wimmer and Prof. Joerg Grosshans for their long-term concerns as members of my thesis committee. I am grateful to L. Alphey, D. Bennett, A. Carpenter, J. Crang, R. Giet, D. Glover, L. Goldstein, C. Gonzalez, T. Hays, H. Patrick, T. Raabe, J. Raff, B. Raynaud-Messina, S. Rogers, E. Schejter, A. Spradling and C. Sunkel ,Y. Bellaïche for the plasmids and flies. I thank the Bloomington Drosophila stock center at the University of Indiana for sending numerous fly stocks and the Developmental Studies Hybridoma Bank at the University of Iowa for sending monoclonal antibodies.

I am also lucky to become friends with all the lab members with whom I have lots of happy memories, Mona Honemann-Capito, Karen Fricke, Soya Kim, Carmen Koch, Tobias Morawe, Nils Halbsgut, Karen Linnemannstoens, AnKathrin Foerster, Hamze Beati, Ieva Gailite. I am also happy to become friends with the following Chinese students in Goettingen, Zhang Qingwei, Zhang Yanjie, Zhang Xin, Zhang Zhensheng, Zhang Lu, Zhang Xiaoqin, Li Yujie, Li Jianfeng, Ma Changle, Qiu Yue, Ding Haixia, Ding Xiangdong, Yang Fan, Lei Jun, Chen Tianhui, Guo Wei, Xing Yuyun, Yin Dongjiao, Wang Xinmin, Yao Lijun, Guo Qinchuan.

At the end, I have to express my great gratitude to my wife Ms Wang Ying and my parents for their long-term unconditional support for my research and my life. 